\title{
Rapid Assessment of Delay-of-Reinforcement Effects on Key Pecking Maintained by Fixed-Ratio Schedules
}

David P. Jarmolowicz

Follow this and additional works at: https://researchrepository.wvu.edu/etd

\section{Recommended Citation}

Jarmolowicz, David P., "Rapid Assessment of Delay-of-Reinforcement Effects on Key Pecking Maintained by Fixed-Ratio Schedules" (2011). Graduate Theses, Dissertations, and Problem Reports. 4735.

https://researchrepository.wvu.edu/etd/4735

This Dissertation is protected by copyright and/or related rights. It has been brought to you by the The Research Repository @ WVU with permission from the rights-holder(s). You are free to use this Dissertation in any way that is permitted by the copyright and related rights legislation that applies to your use. For other uses you must obtain permission from the rights-holder(s) directly, unless additional rights are indicated by a Creative Commons license in the record and/ or on the work itself. This Dissertation has been accepted for inclusion in WVU Graduate Theses, Dissertations, and Problem Reports collection by an authorized administrator of The Research Repository @ WVU.

For more information, please contact researchrepository@mail.wvu.edu. 
Rapid Assessment of Delay-of-Reinforcement Effects on Key Pecking Maintained by Fixed-Ratio Schedules

David P. Jarmolowicz

Dissertation submitted to the

Eberly College of Arts \& Sciences

At West Virginia University

in partial fulfillment of the requirements

for the degree

Doctor of Philosophy

In

Psychology

\author{
Kennon A. Lattal, Ph.D., Chair \\ Karen G. Anderson, Ph.D \\ Michael Perone, Ph.D. \\ Sherry Shuman, Ed.D \\ JoNell Strough, Ph.D.
}

2011

Keywords: delay of reinforcement, fixed ratio, rapid assessment, signals, pigeon 


\begin{abstract}
Rapid Assessment of Delay-of-Reinforcement Effects on Key Pecking Maintained by
\end{abstract}

Fixed-Ratio Schedules

David P. Jarmolowicz

Previous research on delay of reinforcement has focused primarily on variable-interval schedules. A fair amount is known about effects of delay duration, signaled versus unsignaled delays, and interval length in the context of these schedules. Less is known about these effects on other schedules of reinforcement. For example, little is known about the effects of delay duration, signals versus unsignaled delays, or the way that delays interact with ratio requirement when behavior is maintained by fixed-ratio schedules. Furthermore, the steady-state designs (wherein stable responding is obtained at each delay duration) used to investigate delay-ofreinforcement effects are often time consuming. The present experiments used delay-ofreinforcement procedures to rapidly examine effects of delay duration and signals on responding under different fixed-ratio requirements. Experiments 1-3 used a procedure wherein the delay of reinforcement increased each session until the pigeon paused for $300 \mathrm{~s}$ to examine effects of delay duration (Experiments 1-3), signaled versus unsignaled delays (Experiments 1-3), the influence of decreased rates of reinforcement (Experiment 2) and the role of interval versus ratio baseline schedules (Experiment 3). Experiment 4 examined the interaction between signaled versus unsignaled delays of different durations and fixed-ratio requirement using a procedure wherein the fixed-ratio requirement increased each session until the pigeon paused for $300 \mathrm{~s}$. These procedures yielded negative relations between delay duration and response rate that were consistent with previous findings using steady-state designs with variable-interval baselines, and were consistent across schedule type (Experiment 3 ) and fixed-ratio requirement (Experiment 4). These findings suggest generality in this negative relation across experimental design, schedule type, and schedule parameters. A similar decrease in response rates was not obtained when the rate of immediate reinforcement was similarly decreased (Experiment 2), suggesting that these findings cannot be wholly accounted for by changes in rates of reinforcement. Response rates were similar with signaled and unsignaled delays during Experiments 1-3, which rapidly changed delay durations, but not during Experiment 4, which held delays constant across a range of fixed-ratio requirements. This finding suggests that the higher response rates often seen with signaled (relative to unsignaled) delays may require several sessions to be established. 


\section{Acknowledgements}

I would like to thank my family for accepting my absence and my wife for accepting my presence while these studies were conducted. The process has been long, and I appreciate your understanding. I especially thank my wife, Allison Tetreault, for her constant support, unwavering belief in me and my work, and for always pushing me to be a better scientist (and person).

I would like to thank the members of my committee, Andy Lattal, Mike Perone, Karen Anderson, JoNell Strough, and Sherry Shuman for their patience and flexibility during the process and their helpful comments on the document. Each has treated me with more respect than a junior colleague could ever ask for. I have learned much from them, both within and outside the context of this project.

I am not sure that I could ever sufficiently thank my academic mentor, Andy Lattal. Without Andy, this dissertation would not exist. I thank Andy for his patience and subtle guidance throughout the ups and downs of the last four years. But most of all, I thank Andy for showing me how to be a scientist and providing me with an environment that facilitated my exploration of interesting questions. His enthusiasm for our work has always made me proud. Someday I hope to be half as good of a mentor (and scientist) as Andy Lattal.

I thank the Lattal Lab. These experiments were time intensive, yet my lab mates were always very supportive and flexible. I thank Roger, Alicia, Carlos and Toshi for their help with this project and for their ongoing enthusiasm for the science of behavior. I am proud to have had my work shaped by theirs.

Lastly, I would like to thank Karen Anderson, Sherry Shuman, and Vennessa Walker for their careful proofreading of this document. 


\section{Table of Contents}

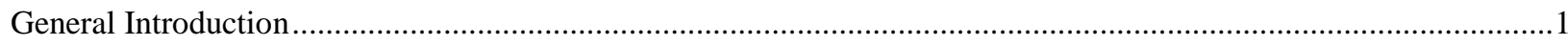

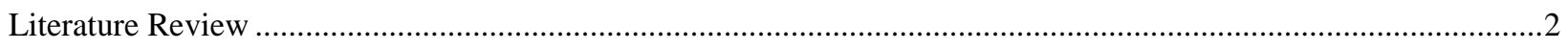

Delay of Reinforcement and Variable-Interval Schedule Performance ............................................................2

Delay of Reinforcement and Variable-Interval Schedule Performance ............................................................2

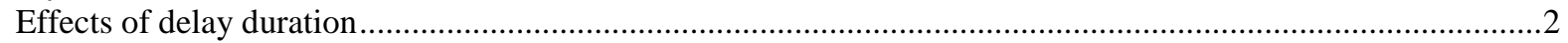

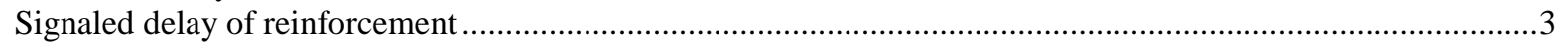

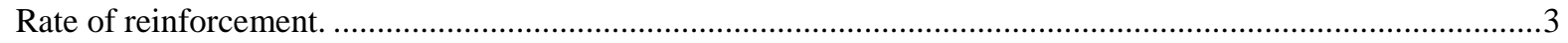

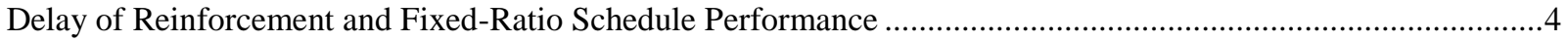

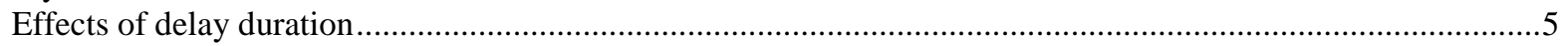

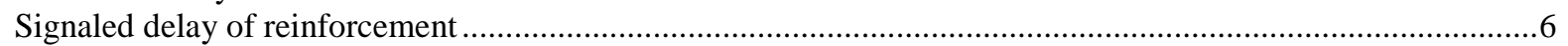

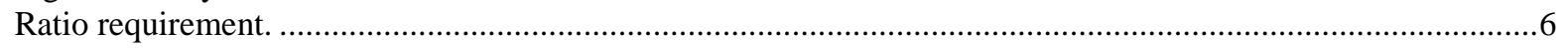

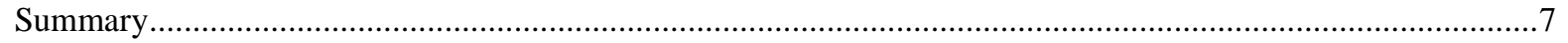

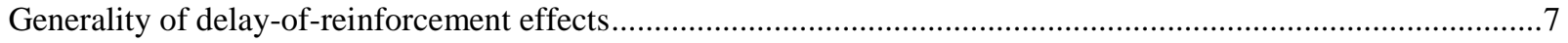

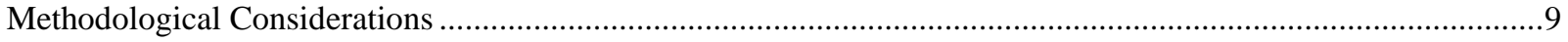

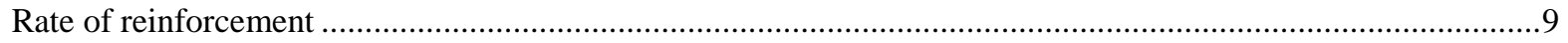

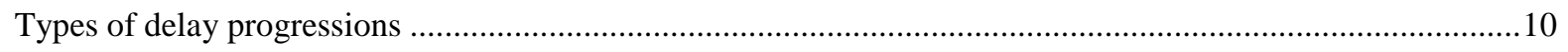

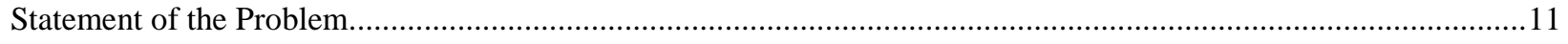

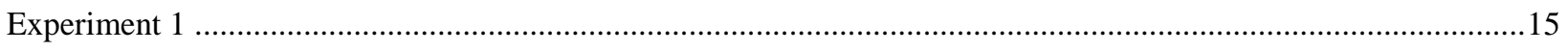

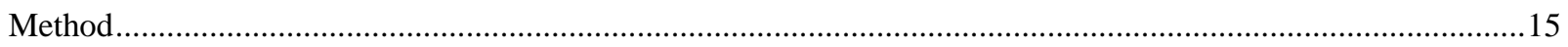

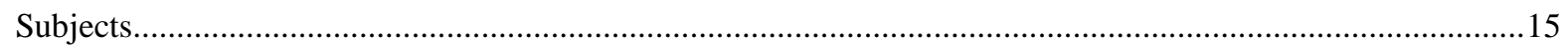

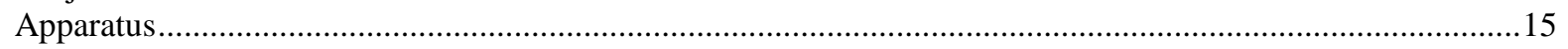

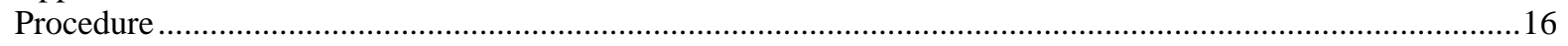

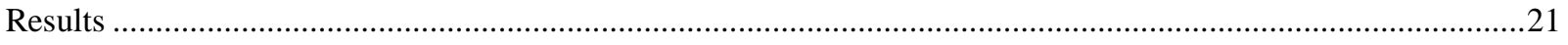

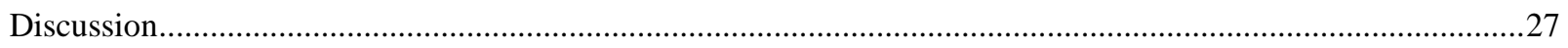

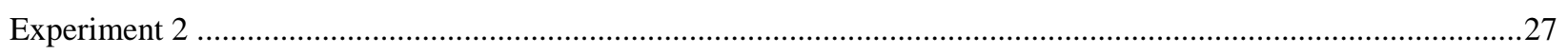

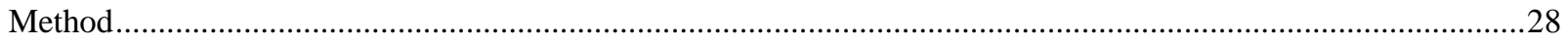

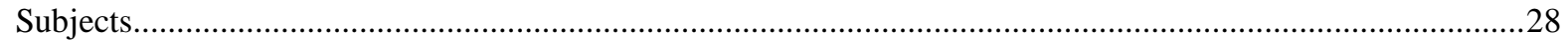

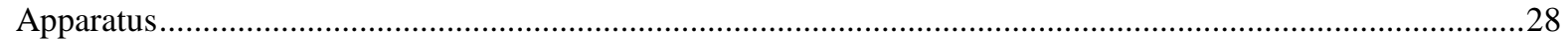

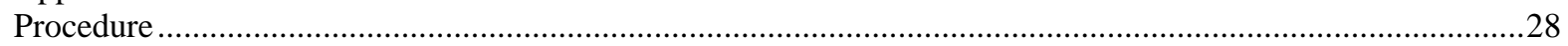

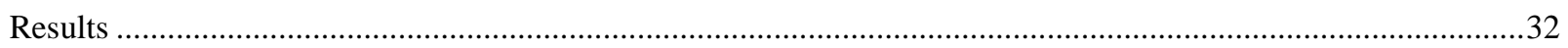

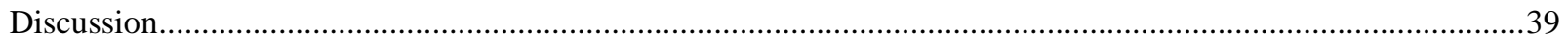

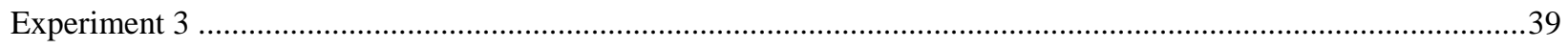

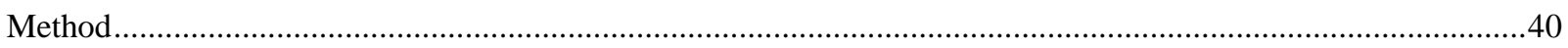

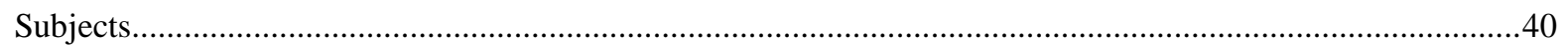

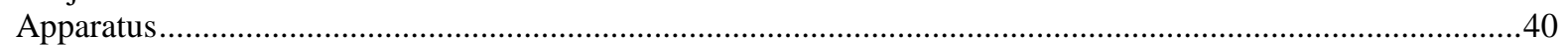

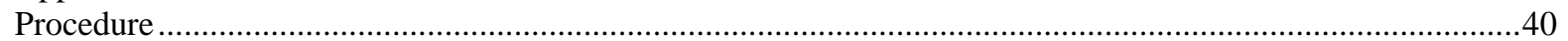

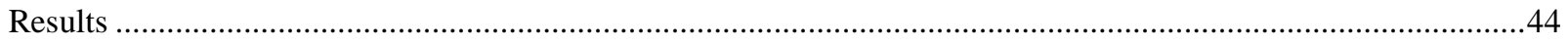

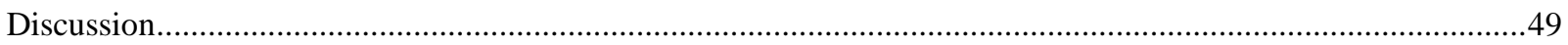

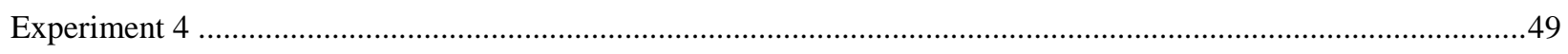

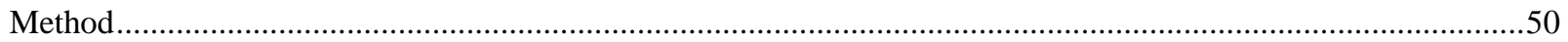

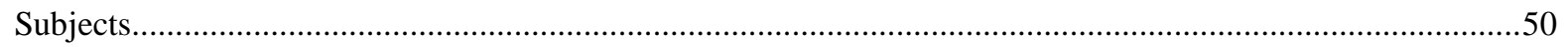

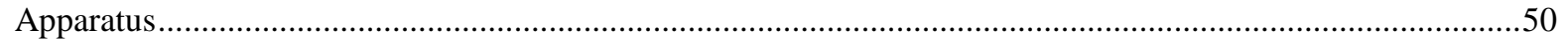




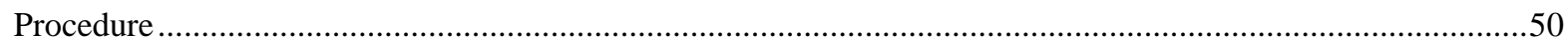

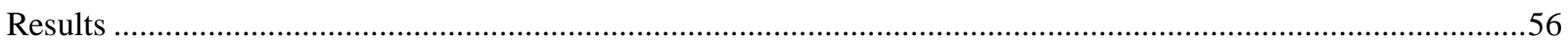

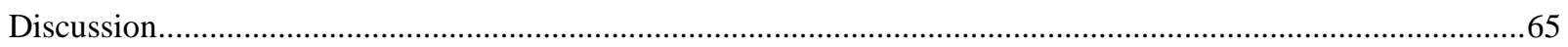

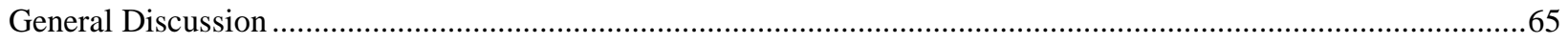

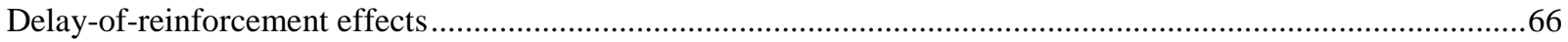

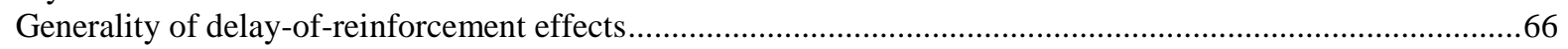

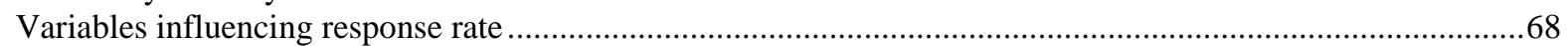

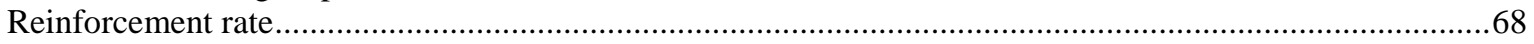

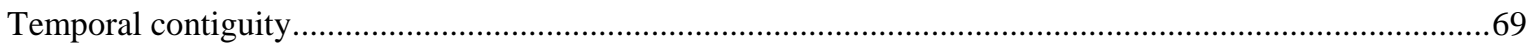

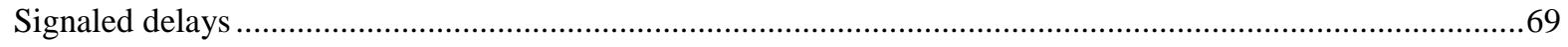

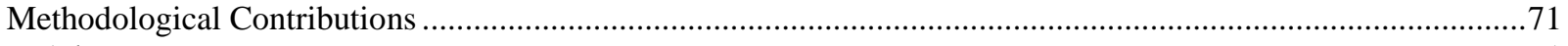

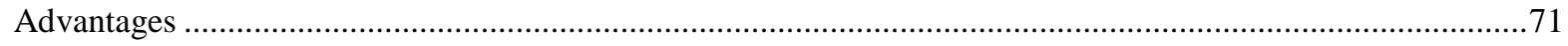

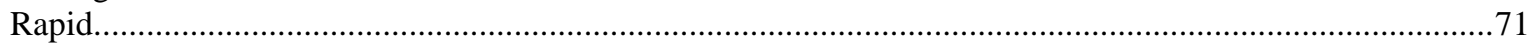

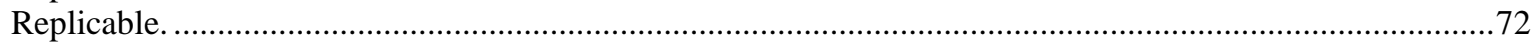

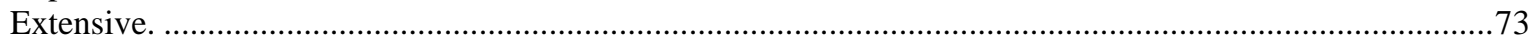

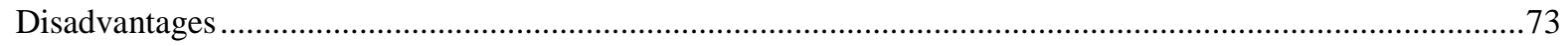

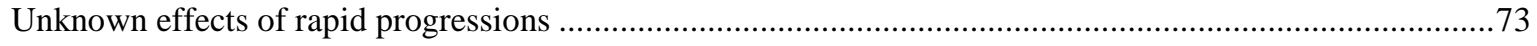

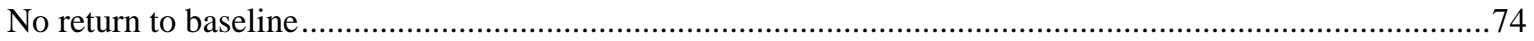

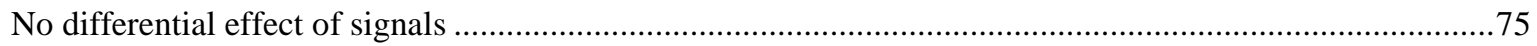

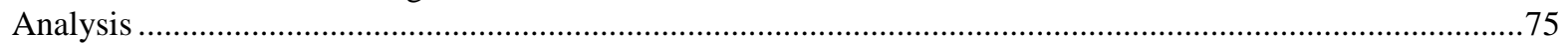

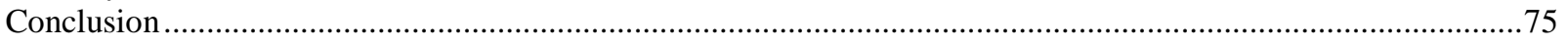

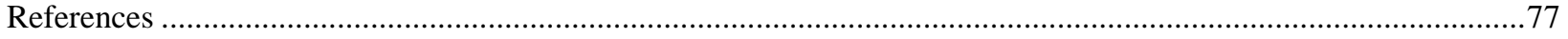

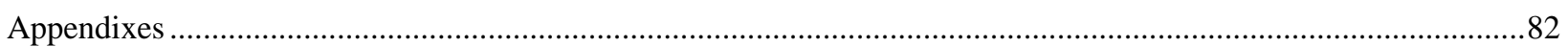




\section{List of Tables}

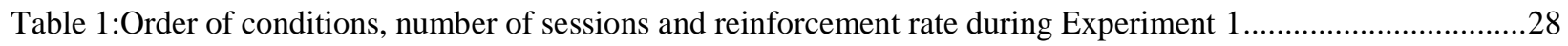

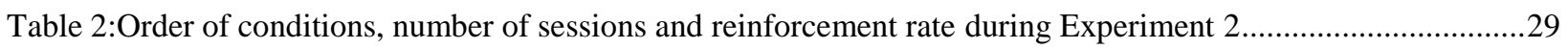

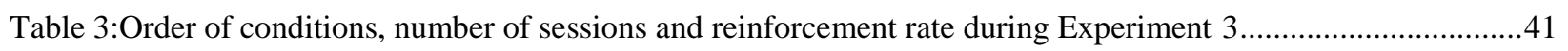

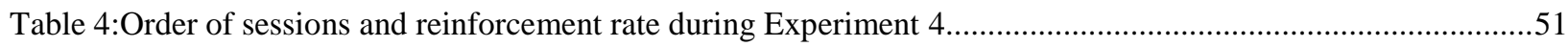

Table 5:Fitted parameters for hyperbolic function at each ratio during Experiment 4 ......................................49 


\section{List of Figures}

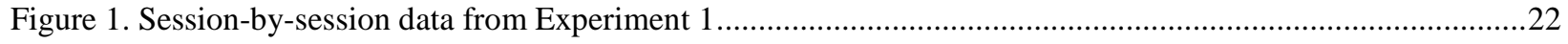

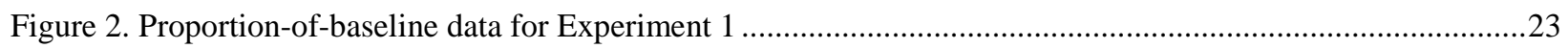

Figure 3. Relation between obtained and programmed delays during Experiment 1 . ...........................................25

Figure 4. Hyperbolic-discounting data from Experiment 1 ..................................................................................2

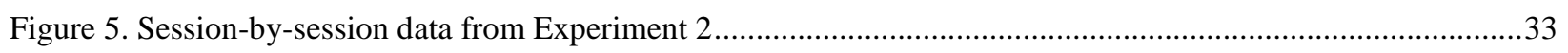

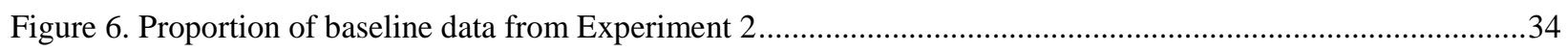

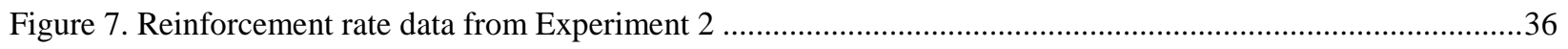

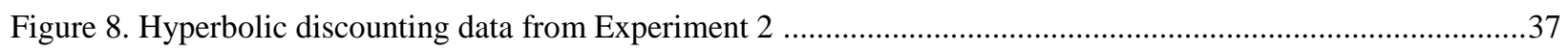

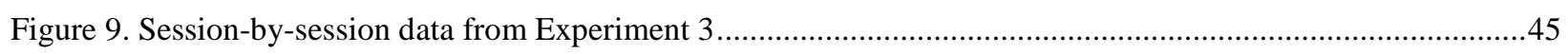

Figure 10. Proportion-of-baseline data from Experiment 3 …........................................................................... 46

Figure 11. Hyperbolic-discounting data from Experiment 3 ..............................................................................4

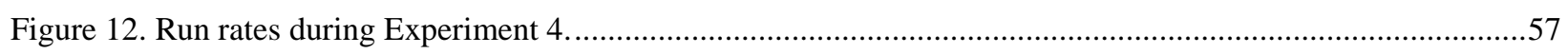

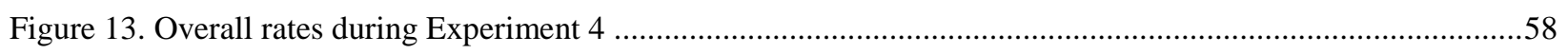

Figure 14. Post-reinforcement pauses during Experiment 4 ..............................................................................59

Figure 15. Proportion of baseline run rates from Experiment 4 . .....................................................................63

Figure 16. Proportion of baseline post-reinforcement pauses during Experiment 4...............................................64

Appendix A: Run rate data from Experiment 4 excluding incomplete sessions .......................................................82

Appendix B: Overall rate data from Experiment 4 excluding incomplete sessions .................................................83

Appendix C: Post-reinforcement pause data from Experiment 4 excluding incomplete sessions ..............................84 


\section{General Introduction}

“Along with rate, quality, and magnitude, delay has been considered a primary determinant of the effectiveness of a reinforcer" (Lattal, 2010, p.129). Thus, understanding reinforcement may require a comprehensive understanding of delay of reinforcement across a range of conditions. The empirical database on delay-of-reinforcement effects, however, is incomplete. For example, studies of effects of delay of reinforcement on responding maintained by variable-interval (VI) schedules are relatively numerous (e.g., Sizemore \& Lattal, 1978; Richards, 1981; Reilly \& Lattal, 2004; Shahan \& Lattal, 2005; Williams, 1976). In the context of this schedule, a good deal is known about how parameters such as delay duration (e.g., Sizemore \& Lattal; Richards; Reilly \& Lattal; Shahan \& Lattal; Williams), the presence or absence of signals (e.g., blackouts; Reilly \& Lattal; Richards), and reinforcement rate (i.e., reinforcers per minute; Shahan \& Lattal) interact. By contrast, data on effects of these variables on fixed-ratio (FR) schedules are minimal.

The relatively extensive literature describing delay-of-reinforcement effects on VI schedules may not completely predict delay-of-reinforcement effects on FR schedules because of the different contingencies arranged by the two. On ratio schedules, reinforcement rate depends on the response rate, whereas on interval schedules rate of reinforcement is largely, but not exclusively, experimenter controlled. Furthermore, these schedules may interact differentially with other variables such as signals. These between-schedule differences may affect the way that these schedules interact with schedule manipulations such as delay of reinforcement. The current research was designed to examine in some detail the effects of delays of reinforcement on FRmaintained responding using a procedure that allows relatively rapid assessment of such effects. 


\section{Literature Review}

Four points are important in constructing the rationale for the current series of experiments. First, effects of delay parameters on responding maintained by VI schedules will be reviewed. Second, these effects will be contrasted with the modest literature base regarding effects of these variables on FR schedule performance. Third, the generality of delay-ofreinforcement effects will be considered. And fourth, methodological issues relevant to the study of effects of reinforcement delays on FR schedules will be examined. The latter are important because, along with the other variables already mentioned, the procedures used also contribute to the behavioral effects of delays of reinforcement.

\section{Delay of Reinforcement and Variable-Interval Schedule Performance}

Variable-interval schedules are useful in evaluating the effects of reinforcement parameters because they allow a range of response rates while holding reinforcement rates nearly constant.

Effects of delay duration. Response rates generally decrease as delays to reinforcement increase. For example, Sizemore and Lattal (1978) compared overall response rates on schedules with unsignaled delay of reinforcement (i.e., tandem VI fixed-time [FT] schedules) to overall response rates (i.e., responses per minute during all times aside from during reinforcer delivery) on VI schedules matched to provide similar rates of reinforcement (e.g., VI 70 s compared to tandem VI 60 s FT 10 s). Delay durations of 0.5 s, 1 s, 2 s, 4 s, and $10 \mathrm{~s}$ were examined. Overall response rates were primarily a decreasing function of delay duration (see also, Ferster, 1953; Reilly \& Lattal, 2004; Richards, 1981; Williams, 1976; Shahan \& Lattal, 2005). 
Sizemore and Lattal's (1978) findings are consistent with those of Pierce, Hanford, and Zimmerman (1972), who examined delay-of-reinforcement effects across a range of signaleddelay arrangements. After establishing stable responding on a VI 60-s schedule, Pierce et al. compared conditions during which cue-light signaled delays either lasted for a fixed period of time, reset following each response, or were accompanied by a retraction of the response lever. A negative relation between overall response rate and delay duration was obtained in all conditions.

Signaled delay of reinforcement. On VI schedules, signaled and unsignaled delays of reinforcement often generate different delay-of-reinforcement gradients. For example, Richards (1981) attempted to replicate Sizemore and Lattal's (1978) findings with both signaled and unsignaled delays. Richards examined signaled and unsignaled $0.5-\mathrm{s}, 1-\mathrm{s}, 2.5-\mathrm{s}, 5-\mathrm{s}$, and 10-s delays. Although overall response rates were higher with brief unsignaled than brief signaled delays, the delay-of-reinforcement gradients were steeper in the unsignaled-delay condition (i.e., the gradients were not uniform across delay type). Consistent with the increase in overall response rate seen with brief (i.e., 0.5-s) unsignaled, but not signaled, delays reported in other studies (e.g., Lattal \& Ziegler, 1982) these findings highlight the differential effects of signaled versus unsignaled delays.

Rate of reinforcement. Delay of reinforcement generally has been studied across a restricted range of VI lengths. Most studies have examined effects of delays of reinforcement on responding maintained by VI 60-s schedules (e.g., Arbuckle \& Lattal,1988; Ferster, 1953, Experiments 3, 4, and 5; Hall et al., 1987, Experiment 1; Lattal \& Ziegler, 1982; Pierce et al., 1972; Richards, 1981; Sizemore and Lattal, 1978). Studies that have examined delay-ofreinforcement effects on other VI schedules such as VI 120 s (e.g., Ferster, Experiments 1 and 2; Williams, 1976) and VI 50 s (e.g., Lattal, 1984), however, have yielded similar results. 
When delay-of-reinforcement effects on VI schedules arranging different reinforcement rates have been compared, similar results have been obtained across a range of reinforcement rates. For example, Shahan and Lattal (2005, Experiment 1) examined effects of 3-s unsignaled delays of reinforcement on responding maintained by VI 15-s, VI 90-s, VI 360-s, and VI 540-s schedules. After stable rates of baseline responding were established with immediate reinforcement on a multiple VI 15-s, VI 90-s, VI 540-s schedule for two subjects (multiple VI 15-s VI 90-s VI 360-s for a third subject), a 3-s delay was introduced in each component. With rates of reinforcement in each component equated to the baseline reinforcement rates, absolute response rates were lower in the 3-s delay condition at each of the VI lengths evaluated; however, this decrease in overall response rate was proportionally equal across VI lengths.

\section{Delay of Reinforcement and Fixed-Ratio Schedule Performance}

Fixed-ratio schedules differ from VI schedules in multiple ways. On interval schedules, reinforcers are delivered for the first response after a specified period of time, irrespective of the number of responses that are made. Low to moderate response rates are thus likely to develop. By contrast, the reinforcer is delivered after a specified number of responses on ratio schedules, irrespective of the time that it takes to complete the response requirement. Not only are high response rates typically generated, decreases in response rate result in decreases in rate of reinforcement.

Structural differences between fixed and variable schedules may also impact responding. The probability of reinforcement for the first response (ratio schedules) or for responding immediately after reinforcement (interval schedules) is low on fixed schedules. As a result, a period of little or no responding typically occurs after reinforcement delivery followed by a period of rapid (ratio schedules) or positively accelerated (interval schedules) responding 
(Ferster \& Skinner, 1957). By contrast, variable schedules keep the probability of reinforcement for each response (ratio schedules) or at any time (interval schedules) relatively constant. As a result, steady rates of responding occur.

These structural differences make the study of delay of reinforcement on FR schedules interesting for two reasons. First, because FR schedules differ from VI schedules in being both a fixed and a ratio schedule the potential for differential interaction with delays is maximized. Second, the unique pattern of responding generated by FR schedules (Ferster \& Skinner, 1957), wherein periods of non-responding (i.e., post-reinforcement pause [PRP]) alternate with periods of responding (i.e., runs) facilitates the study of the impact of delays on these two separate characteristics of responding.

Effects of delay duration. Previous studies have failed to demonstrate a relation between run rate and delay duration on FR schedules. For example, Morgan (1972) reinforced subjects' responding on an FR-9 schedule after, in different conditions, 12-s, 3-s, or 0.75-s delays signaled by dimming the houselight. Each delay was in effect for six sessions. There was a positive relation between PRP (i.e., the time between the end of the reinforcement period and the first response) and delay duration, but no relation was found between running time (i.e., time from the end of the PRP until the ratio requirement is satisfied) and delay. Similarly, Meunier and Ryman (1974) conducted a study during which the completion of an FR-45 schedule resulted in a 30-s intertrial interval during which the response lever was retracted from the chamber. Across a series of phases, responding was evaluated when reinforcers were delivered immediately (i.e., a 0-s delay) and 5 and $10 \mathrm{~s}$ after the response lever was retracted (i.e., 5 and 10-s delays). As with Morgan's study, a positive relation between delay duration and PRP was obtained, but no systematic relation between run rate (i.e., responses per minute during the time between the end 
of the PRP and the response that satisfies the ratio requirement) and delay duration was reported. These studies, however, evaluated effects of two or three delay durations. It is possible that delays may had impacted run rates had more delays been evaluated.

Signaled delay of reinforcement. Both Morgan (1972) and Meunier and Ryman (1974) studied signaled delays of reinforcement; therefore they do not provide information on effects of signaled versus unsignaled delays. Signals interact with other schedule parameters, resulting in advantages and disadvantages to their use. For example, because subjects do not typically respond during blackouts, blackout-signaled delays allow the experimenter to precisely control temporal contiguity (i.e., the time between the response and reinforcer delivery). Such signals, however, may have conditioned-reinforcing or overshadowing effects (e.g., Pearce \& Hall, 1978), complicating the interpretation of the findings. The failure to demonstrate a systematic relation between response rate and delay duration therefore may have been an artifact of these signals.

Ratio requirement. Topping, Johnson, and McGlynn (1973) extended Morgan’s (1972) and Meunier and Ryman's (1974) findings by examining effects of signaled delays of reinforcement on responding maintained by a range of FR schedules. First, baseline run rates were established for three groups of subjects on FR-10, FR-75, or FR-150 schedules. Across a series of phases, 10-s, 30-s, 60-s, 90-s, and 180-s blackout-signaled delays were evaluated. Consistent with Meunier and Ryman's (1974), and Morgan's (1972) findings, a positive relation between delay duration and PRP was observed, but there was no relation between run rate and delay duration. Furthermore, consistent with previous findings (e.g., Felton \& Lyon, 1966; Ferster \& Skinner, 1957; Powell, 1968), a positive relation between PRP and FR requirement 
was observed. This study, however, compared ratio requirements across relatively small groups, and no statistical evaluation of the data was provided, limiting the conclusions that can be made.

Summary. There currently are little data on how delay of reinforcement affects FR performance. Previous parametric analyses have been restricted to only a few delay durations and comparisons between signaled and unsignaled delays have not been made. A review of the

literature shows no within-subject comparisons of the effects of delays on responding maintained at different FR requirements. Furthermore, unlike studies examining delays of reinforcement imposed on VI baselines, studies using FR baselines have not reported a negative relation between response rate and delay duration.

Generality of delay-of-reinforcement effects

Although empirical findings are often consistent across schedules, the consistency of delay-of-reinforcement effects across schedules is not fully known. As noted above, there are multiple ways that FR and VI schedules are structurally dissimilar. These structural differences may impact the way that these dissimilar schedules interact with delays of reinforcement. Because of these structural dissimilarities, data showing delay-of-reinforcement effects on behavior maintained by FR schedules may provide a conservative test of the generality previous findings established with VI baselines.

Delays of reinforcement may interact differently with interval and ratio schedules. For example, Lattal, Reilly, and Kohn (1998) found that responding on interval schedules was more persistent than on ratio schedules. In their first experiment, subjects responded on either progressive-ratio $(\mathrm{PR})$ schedules (i.e., schedules wherein the ratio requirement increases for successive reinforcers) or on yoked-interval (YI) schedules; the latter set up a reinforcer for the second subject in the pair every time a reinforcer was earned on the PR schedule. In their second 
experiment, subjects responded on a sequence of PR and YI schedules that alternated daily. In both experiments, responding was more persistent on the YI schedules (i.e., responding on YI schedule continued past the breakpoint on the PR schedule). Because responding is more persistent on interval than on ratio schedules, delay-of-reinforcement gradients may be steeper on FR schedules than has been previously seen on VI schedules (e.g., Sizemore \& Lattal, 1978).

As noted above, overall rates of responding on VI schedules often decrease less with signaled rather than unsignaled delays of reinforcement (e.g., Lattal \& Ziegler, 1982; Reilly \& Lattal, 2004; Richards, 1981). Studies of delayed reinforcement on FR schedules, however, have focused on signaled delays of reinforcement (Meunier \& Ryman, 1974; Morgan, 1972; Topping et al., 1973). From these studies, no systematic relation between run rate and delay duration has been reported. Findings from studies examining the effects of signaled reinforcement on variable-ratio (VR) schedules suggest that this may be due to the way that responding on ratio schedules interacts with signals.

For example, Reed and Hall (1988) found that although signals presented at the time of immediate reinforcement on tandem VR VI schedules decreased overall response rates, the same signals increased overall response rates on tandem VI VR schedules. These findings were then extended to brief (i.e., 0.5-s) signaled delays of reinforcement on either VI 60-s or VR-30 schedules (Reed, Schachtman, \& Hall, 1988). Consistent with Reed and Hall's findings with immediate reinforcement, and with previous findings on VI schedules (e.g., Lattal \& Ziegler, 1982; Richards, 1982), overall response rates decreased on the VI schedule whereas a slight increase in overall response rate was observed on the VR schedule. Hence, when reinforcement is either immediate or briefly delayed, the effects of signaled reinforcement may depend on the baseline schedule. 
As noted above, the relative decrease in overall rate of responding does not interact with VI length (Shahan \& Lattal, 2005). The parametric relation between schedule value (i.e., ratio requirement) and response rate on FR schedules, however, may be different than the parametric relation between schedule value (i.e., interval length) and response rate on interval schedules. For example, Zeiler (1999) exposed two subjects to an ascending series of FI lengths (from $1 \mathrm{~s}$ to 100,000 s), two subjects to an ascending series of FR requirements (from 1 to 10,000), and two subjects to an ascending series of random-interval lengths (from $300 \mathrm{~s}$ to 10,000 s). Response rates decreased as interval length increased, but there was no relation between response rate and ratio requirement. Because FR and interval schedules differ in these interactions, Shahan and Lattal's findings using VI schedules may not generalize to FR requirements.

\section{Methodological Considerations}

The study of delay-of-reinforcement effects raises not only questions of the generality and scope of such effects, but also methodological questions about both the nature of delay of reinforcement and the ways in which delay-of-reinforcement effects are investigated.

Rate of reinforcement. When a delay of reinforcement is introduced, the rate of reinforcement also typically decreases. This confounding of two variables complicates interpretation of the findings. If reinforcement rate is not controlled, it is difficult to parse out effects on response rate controlled by the delay of reinforcement and those resulting from changes in reinforcement rates.

This confound has been addressed in different ways. Sizemore and Lattal (1978) compared their delay conditions (e.g., tandem VI 60-s FT 10-s schedules) to baseline conditions that were adjusted to provide equal interreinforcer intervals (IRI; e.g., VI 70 s). Other studies have isolated effects of the delay of reinforcement by comparing delay conditions to conditions 
during which the rate of immediate reinforcement similarly decreases. For example, Reilly and Lattal (2004) compared delayed reinforcement (e.g., tandem VI progressive-time schedules) to an immediate-reinforcement condition that was matched for rate of reinforcement (e.g., tandem VI progressive interval schedules). In both cases, response rates were lower with delayed reinforcement, suggesting that the decreased response rates were primarily controlled by delays of reinforcement.

Types of delay progressions. There are different ways to assess the relation between delay duration and response rate. Delay durations can be changed across conditions, within session, or across sessions. Although each procedure may yield consistent relations between delay duration and response rates, there are advantages and disadvantages to each.

To date, most studies on effects of delay of reinforcement have used across-condition designs wherein each delay duration remains in effect for several sessions, and is preceded and followed by an immediate-reinforcement baseline. This is one type of what are referred to as steady-state designs. These steady-state designs often provide reliable results that demonstrate relations between variables in a static environment (Sidman, 1960). Use of steady-state designs, however, requires considerable time to generate delay-of-reinforcement gradients. This time commitment may limit the delay parameters explored in a single study or may preclude exploration of the interactive effects of delay duration and other independent variables (e.g., reinforcer magnitude, drugs, etc.).

Reilly and Lattal (2004) developed a within-session delay-of-reinforcement procedure that decreased the time required to generate delay-of-reinforcement gradients. They used a progressive-delay procedure in which a progressively increasing delay was initiated after the response that completed either a VI or a FI schedule. The FT duration started at $2 \mathrm{~s}$ and increased 
by $2 \mathrm{~s}$ after each reinforcer. By comparing this procedure to a control condition wherein the IRI in an immediate reinforcement condition increased by the same amount following each reinforcer (Experiment 1), this procedure generated consistent delay-of-reinforcement gradients that could not be accounted for by the progressively decreasing rate of reinforcement alone. Replication of these effects, with both signaled and unsignaled delays (Experiment 2) showed that, like studies which increased delays across conditions (e.g., Richards, 1981), this procedure generated steeper delay-of-reinforcement gradients for unsignaled relative to signaled delays of reinforcement. Although this procedure produced orderly delay-of-reinforcement gradients, unless the data are aggregated across several sessions, the within-session progression provides a relatively small sample of responding at each delay duration.

An alternative to increasing delay durations within sessions is to increase delay duration across sessions. This procedure would quickly establish delay-of-reinforcement gradients across relatively few sessions. Unlike the within-session procedure developed by Reilly and Lattal (2004), however, this procedure would provide a sufficient sample of behavior at each delay duration without aggregating data across sessions. Effects of such an across-session delay-ofreinforcement procedure, however, are unexamined.

\section{Statement of the Problem}

Response rates are an orderly decreasing function of the delay duration between the reinforcer and the response that produces it (e.g., Sizemore \& Lattal, 1978; Richards, 1981; Reilly \& Lattal, 2005). Studies of such delays of reinforcement in the operant tradition generally include immediate reinforcement baseline conditions conducted before and after each delay condition. This alternating of conditions allows each delay condition to be compared to an immediately preceding baseline condition. Additionally, these baseline and delay conditions are 
generally conducted until responding is stable. This increases the likelihood that the data obtained show the rates of responding that can be maintained in that condition, rather than the rates that can be expected as behavior transitions from condition to condition (Sidman, 1960). As components of what are typically referred to as steady state designs, these design features yield data that are both directly and systematically replicable and contribute to unambiguous interpretation of the findings. These steady state designs, however, take a large number of sessions to generate delay-of-reinforcement gradients. For example, it took Shahan and Lattal (2005) between 433 and 601 sessions to generate delay gradients in their second experiment.

By contrast, Reilly and Lattal (2004) developed an operant procedure that generated delay-of-reinforcement gradients within a single session. This procedure introduced a delay-ofreinforcement that increased after each reinforcer. These delay-of-reinforcement gradients, which were extensively replicated across sessions, were qualitatively similar to those generated using steady-state designs (e.g., Sizemore \& Lattal, 1978; Richards, 1981; Reilly \& Lattal, 2005; Shahan \& Lattal, 2005; Williams, 1976) in relatively few sessions (e.g., between 21 and 36 sessions in Experiment 2).

Delay-of-reinforcement parameters impact responding. As noted above, as delay durations increase, response rates typically decrease. For example, Sizemore and Lattal (1978) exposed their subjects' responding to $0.5-\mathrm{s}, 1-\mathrm{s}, 2-\mathrm{s}, 4-\mathrm{s}$, and 10-s unsignaled delays. Rates of responding decreased as delay duration increased. This decrease in response rate, however, is typically greater for signaled relative to unsignaled delays (e.g., Reilly and Lattal, 2004; Richards, 1981) For example, Richards compared response rates during 0.5-s, 1-s, 2.5-s, 5-s, and 10-s signaled versus unsignaled delays. Although the unsignaled delay-of-reinforcement 
gradients were similar to those generated by Sizemore and Lattal, the signaled delay-ofreinforcement gradients were much shallower.

A number of studies have examined ways that delays interact with other reinforcement parameters. For example, Shahan and Lattal (2005) examined effects of a 3-s unsignaled delay on behavior maintained by a multiple VI 15-s VI 90-s VI 540-s. Response rates decreased in all three multiple schedule components, yet the relative decreases from baseline rates of responding was consistent across components. Hence, delays of reinforcement appear to similarly impact responding across a wide range of reinforcement rates. Similarly, delays of reinforcement also decrease response rates on VI (Richards, 1981; Reilly \& Lattal, 2004; Shahan \& Lattal, 2005; Sizemore \& Lattal, 1978; Williams, 1976), FI (e.g., Dews, 1969; Reilly \& Lattal, 2004), PR (Jarmolowicz \& Lattal, in press) and DRL (Gonzalez \& Newlin, 1976; Richards) schedules. Structural features of FR schedules may make the study of delayed reinforcement interesting on these schedules. First, reinforcers are delivered after a specified number of responses on ratio schedules, irrespective of the time that it takes to complete the response requirement. Not only are high response rates typically generated, decreases in response rate result in decreases in rate of reinforcement. Second, the probability of reinforcement for the first response is low on fixed schedules. As a result, a period of no responding (i.e., PRP) typically occurs after reinforcement delivery followed by a period of rapid responding (i.e., runs; Ferster \& Skinner, 1957). Although independent variables can impact responding during either of these periods, PRPs show more systematic relations with variables such as reinforcer magnitude (e.g., Perone \& Courtney, 1992), ratio requirement (e.g., Felton \& Lyon, 1966; Powell, 1968), and punishment (e.g., Azrin, 1959). 
Few studies have examined effects of delayed reinforcement on behavior reinforced on FR schedules. Morgan (1972) reinforced subjects' responding on an FR-9 schedule after, in different conditions, 12-s, 3-s, or 0.75-s delays signaled by dimming the houselight. Each delay was in effect for six sessions. There was a positive relation between PRP and delay duration, but no relation was found between running time and delay. Similarly, Meunier and Ryman (1974) conducted a study during which the completion of an FR-45 schedule resulted in a 30-s intertrial interval during which the response lever was retracted from the chamber. Across a series of phases, responding was evaluated when reinforcers were delivered immediately (i.e., a 0 -s delay) and 5 and $10 \mathrm{~s}$ after the response lever was retracted (i.e., 5 and 10-s delays). As with Morgan's study, a positive relation between delay duration and PRP was obtained, but no systematic relation between run rate and delay duration was reported. Topping et al. (1973) examined effects of signaled delays of reinforcement on responding maintained by a range of FR schedules. First, baseline run rates were established for three groups of subjects on FR-10, FR75, or FR-150 schedules. Across a series of phases, 10-s, 30-s, 60-s, 90-s, and 180-s blackoutsignaled delays were evaluated. Consistent with Meunier and Ryman's (1974), and Morgan's (1972) findings, a positive relation between delay duration and PRP was observed, but there was no relation between run rate and delay duration.

The purpose of the current research is twofold. First, although delays of reinforcement have been examined on many schedules, most studies of delayed reinforcement have used VI baselines (Richards, 1981; Reilly \& Lattal, 2004; Shahan \& Lattal, 2005; Sizemore \& Lattal, 1978; Williams, 1976). Hence although data on effects of parameters such as delay duration (Sizemore \& Lattal; Richards; Reilly \& Lattal; Shahan \& Lattal; Williams), signals (Richards; Reilly \& Lattal), and rate of reinforcement (Shahan \& Lattal) are available on VI schedules, the 
analysis of responding on other schedules has been less extensive. Because of the unique structure of FR schedules, these parameters may impact response rate and/or PRP. Second, because a parametric analysis of these parameters are of interest, the current research used a modification of Reilly and Lattal's (2004) procedure wherein delay durations increased across, rather than within sessions to rapidly assess effects of these parameters.

\section{Experiment 1}

This experiment examined effects of signaled and unsignaled delays across a range of delay durations on responding maintained by an FR 50 schedule. In line with the observations in the statement of the problem about methods for obtaining delay of reinforcement gradients, the delay duration was increased daily to examine the effects of a range of both types of delays.

Method

\section{Subjects}

Three White Carneau pigeons were maintained at $80 \%(+/-2 \%)$ of their free-feeding weights. Water and health grit were available continuously in the home cage, where a 12-hr light: 12-hr dark cycle was maintained. Each pigeon had a history of responding on schedules of reinforcement.

\section{Apparatus}

Three sound-attenuating operant conditioning chambers (31-cm wide, 30-cm long, and 38-cm high) containing a brushed aluminum work panel were used. Three response keys were affixed to the panel. Each of the side keys $(2 \mathrm{~cm}$ diameter) was $5 \mathrm{~cm}$ from the side wall of the chamber, $10 \mathrm{~cm}$ from the center key ( $2 \mathrm{~cm}$ diameter), center to center, and $25 \mathrm{~cm}$ from the floor. All three keys could be transilluminated white. A rectangular aperture $(6 \mathrm{~cm}$ wide by $6.5 \mathrm{~cm}$ high) was located on the midline of the panel, $8 \mathrm{~cm}$ from the floor. The aperture provided access 
to mixed grain when a hopper was raised. A 28-V DC clear bulb illuminated the aperture and all other lights were dark during presentations of the hopper for reinforcer deliveries. A ventilation fan, located behind an aperture in the lower right corner of the rear wall, and white noise delivered through a speaker, located in the lower left corner of the work panel, masked extraneous noise. Programming and data recording were controlled by a computer in an adjacent room using MED-PC $®$ software and hardware (MED Associates, Inc. \& Tatham, 1991).

\section{Procedure}

Because the pigeons had histories of responding on FR schedules, the pigeons were exposed immediately to an FR-50 schedule. Sessions occurred 6-7 days a week at approximately the same time each day and ended after either 60 (40 for Pigeon 536) reinforcers were delivered or when 300 s lapsed without a key peck, whichever came first. During the experiment, blocks of baseline and test sessions alternated. The order of conditions for Experiment 1 is shown in Table 1. During baseline sessions, completion of an FR-50 schedule resulted in the immediate delivery of 3-s (2.5-s for Pigeon 536) access to grain. Each baseline condition lasted for at least 13 days and until both run rates and PRPs were stable (13-32 sessions, see Table 1). Stability required that over the last six sessions, the mean of the run rates during the first and last three sessions of that period did not deviate from the grand mean of the last six sessions by more than $6 \%$, without any visual evidence of systematic trends in either the run rate or PRP data. During what will be called progressive-fixed-delay (PFD) conditions the pigeons were exposed to a progressively increasing sequence of either blackout-signaled (i.e., no lights were on in the chamber; a chained FR 50 FT x schedule) or unsignaled (i.e., the response that completed the FR requirement initiated the delay but resulted in no stimulus change; a tandem FR 50 FT x schedule) nonresetting delays. This sequence consisted of 1-s, 5-s, 10-s, 20-s, 40-s, 80-s, 160-s, 320-s, and 
640-s delays, with each delay presented in successive sessions. Delay durations increased long this progression until a test session was terminated due to a pause of $300 \mathrm{~s}$. At that point baseline was reinstated. The alternating delay testing and baseline immediate reinforcement sessions continued through three exposures of both the signaled and unsignaled delay conditions. 
Table 1

Order of conditions, number of sessions and reinforcement rate during Experiment 1

\begin{tabular}{|c|c|c|c|c|}
\hline Pigeon & Condition & Schedule & $\mathrm{N}$ & $\begin{array}{l}\text { Reinforcers per minute } \\
\text { (last } 6 \text { sessions) }\end{array}$ \\
\hline \multirow[t]{38}{*}{974} & Baseline & FR 50 & 15 & $2.99(3.67)$ \\
\hline & \multirow{7}{*}{$\begin{array}{l}\text { Unsignaled progressive- } \\
\text { fixed delay }\end{array}$} & Tandem FR 50 FT $1 \mathrm{~s}$ & 1 & 2.93 \\
\hline & & Tandem FR 50 FT $5 \mathrm{~s}$ & 1 & 2.22 \\
\hline & & Tandem FR 50 FT $10 \mathrm{~s}$ & 1 & 1.55 \\
\hline & & Tandem FR 50 FT $20 \mathrm{~s}$ & 1 & 0.93 \\
\hline & & Tandem FR 50 FT $40 \mathrm{~s}$ & 1 & 0.54 \\
\hline & & Tandem FR 50 FT $80 \mathrm{~s}$ & 1 & 0.37 \\
\hline & & Tandem FR 50 FT $160 \mathrm{~s}$ & 1 & 0.15 \\
\hline & Baseline & FR 50 & 14 & $3.18(3.26)$ \\
\hline & \multirow{5}{*}{$\begin{array}{l}\text { Unsignaled progressive- } \\
\text { fixed delay }\end{array}$} & Tandem FR 50 FT $1 \mathrm{~s}$ & 1 & 3.05 \\
\hline & & Tandem FR 50 FT $5 \mathrm{~s}$ & 1 & 2.17 \\
\hline & & Tandem FR 50 FT $10 \mathrm{~s}$ & 1 & 1.68 \\
\hline & & Tandem FR 50 FT $20 \mathrm{~s}$ & 1 & 0.86 \\
\hline & & Tandem FR 50 FT $40 \mathrm{~s}$ & 1 & 0.42 \\
\hline & Baseline & FR 50 & 14 & $3.65(3.69)$ \\
\hline & \multirow{4}{*}{$\begin{array}{l}\text { Unsignaled progressive- } \\
\text { fixed delay }\end{array}$} & Tandem FR 50 FT $1 \mathrm{~s}$ & 1 & 3.65 \\
\hline & & Tandem FR 50 FT $5 \mathrm{~s}$ & 1 & 2.40 \\
\hline & & Tandem FR 50 FT $10 \mathrm{~s}$ & 1 & 1.06 \\
\hline & & Tandem FR 50 FT $20 \mathrm{~s}$ & 1 & 0.42 \\
\hline & Baseline & FR 50 & 24 & $3.42(3.55)$ \\
\hline & \multirow{6}{*}{$\begin{array}{l}\text { Signaled progressive-fixed } \\
\text { delay }\end{array}$} & Chained FR 50 FT $1 \mathrm{~s}$ & 1 & 2.50 \\
\hline & & Chained FR 50 FT $5 \mathrm{~s}$ & 1 & 2.18 \\
\hline & & Chained FR 50 FT $10 \mathrm{~s}$ & 1 & 1.37 \\
\hline & & Chained FR 50 FT $20 \mathrm{~s}$ & 1 & 1.21 \\
\hline & & Chained FR 50 FT $40 \mathrm{~s}$ & 1 & 0.51 \\
\hline & & Chained FR 50 FT $80 \mathrm{~s}$ & 1 & 0.24 \\
\hline & Baseline & FR 50 & 24 & $3.28(2.92)$ \\
\hline & \multirow{4}{*}{$\begin{array}{l}\text { Signaled progressive-fixed } \\
\text { delay }\end{array}$} & Chained FR 50 FT $1 \mathrm{~s}$ & 1 & 2.18 \\
\hline & & Chained FR 50 FT $5 \mathrm{~s}$ & 1 & 1.14 \\
\hline & & Chained FR 50 FT $10 \mathrm{~s}$ & 1 & 1.18 \\
\hline & & Chained FR 50 FT $20 \mathrm{~s}$ & 1 & 0.54 \\
\hline & Baseline & FR 50 & 19 & $3.22(3.36)$ \\
\hline & \multirow{6}{*}{$\begin{array}{l}\text { Signaled progressive-fixed } \\
\text { delay }\end{array}$} & Chained FR 50 FT $1 \mathrm{~s}$ & 1 & 2.82 \\
\hline & & Chained FR 50 FT $5 \mathrm{~s}$ & 1 & 1.85 \\
\hline & & Chained FR 50 FT $10 \mathrm{~s}$ & 1 & 1.68 \\
\hline & & Chained FR 50 FT $20 \mathrm{~s}$ & 1 & 0.86 \\
\hline & & Chained FR $50 \mathrm{FT} 40 \mathrm{~s}$ & 1 & 0.55 \\
\hline & & Chained FR 50 FT $80 \mathrm{~s}$ & 1 & 0.36 \\
\hline \multirow[t]{2}{*}{964} & Baseline & FR 50 & 32 & $1.96(2.47)$ \\
\hline & Unsignaled progressive- & Tandem FR 50 FT $1 \mathrm{~s}$ & 1 & 2.62 \\
\hline
\end{tabular}




\begin{tabular}{|c|c|c|c|}
\hline fixed delay & $\begin{array}{l}\text { Tandem FR } 50 \text { FT } 5 \mathrm{~s} \\
\text { Tandem FR 50 FT } 10 \mathrm{~s} \\
\text { Tandem FR 50 FT } 20 \mathrm{~s} \\
\text { Tandem FR 50 FT } 40 \mathrm{~s} \\
\text { Tandem FR 50 FT } 80 \mathrm{~s}\end{array}$ & $\begin{array}{l}1 \\
1 \\
1 \\
1 \\
1\end{array}$ & $\begin{array}{l}1.95 \\
1.33 \\
1.06 \\
0.67 \\
0.34\end{array}$ \\
\hline Baseline & FR 50 & 13 & $2.77(2.68)$ \\
\hline $\begin{array}{l}\text { Unsignaled progressive- } \\
\text { fixed delay }\end{array}$ & $\begin{array}{l}\text { Tandem FR 50 FT } 1 \mathrm{~s} \\
\text { Tandem FR 50 FT } 5 \mathrm{~s} \\
\text { Tandem FR 50 FT } 10 \mathrm{~s} \\
\text { Tandem FR 50 FT } 20 \mathrm{~s} \\
\text { Tandem FR 50 FT } 40 \mathrm{~s} \\
\text { Tandem FR 50 FT } 80 \mathrm{~s} \\
\text { Tandem FR 50 FT } 160 \mathrm{~s} \\
\text { Tandem FR 50 FT } 320 \mathrm{~s}\end{array}$ & $\begin{array}{l}1 \\
1 \\
1 \\
1 \\
1 \\
1 \\
1 \\
1\end{array}$ & $\begin{array}{l}2.56 \\
2.14 \\
1.73 \\
1.13 \\
0.66 \\
0.43 \\
0.22 \\
0.12\end{array}$ \\
\hline Baseline & FR 50 & 13 & $2.97(2.92)$ \\
\hline $\begin{array}{l}\text { Unsignaled progressive- } \\
\text { fixed delay }\end{array}$ & $\begin{array}{l}\text { Tandem FR } 50 \text { FT } 1 \mathrm{~s} \\
\text { Tandem FR } 50 \text { FT } 5 \mathrm{~s} \\
\text { Tandem FR } 50 \text { FT } 10 \mathrm{~s} \\
\text { Tandem FR } 50 \text { FT } 20 \mathrm{~s} \\
\text { Tandem FR } 50 \text { FT } 40 \mathrm{~s} \\
\text { Tandem FR } 50 \text { FT } 80 \mathrm{~s} \\
\text { Tandem FR } 50 \text { FT } 160 \mathrm{~s}\end{array}$ & $\begin{array}{l}1 \\
1 \\
1 \\
1 \\
1 \\
1 \\
1\end{array}$ & $\begin{array}{l}2.40 \\
2.34 \\
1.78 \\
1.14 \\
0.61 \\
0.38 \\
0.15\end{array}$ \\
\hline Baseline & FR 50 & 13 & $2.73(2.66)$ \\
\hline $\begin{array}{l}\text { Signaled progressive-fixed } \\
\text { delay }\end{array}$ & $\begin{array}{l}\text { Chained FR } 50 \text { FT } 1 \mathrm{~s} \\
\text { Chained FR 50 FT } 5 \mathrm{~s} \\
\text { Chained FR 50 FT } 10 \mathrm{~s} \\
\text { Chained FR 50 FT } 20 \mathrm{~s} \\
\text { Chained FR 50 FT } 40 \mathrm{~s} \\
\text { Chained FR 50 FT } 80 \mathrm{~s}\end{array}$ & $\begin{array}{l}1 \\
1 \\
1 \\
1 \\
1 \\
1\end{array}$ & $\begin{array}{l}1.60 \\
1.58 \\
1.41 \\
0.98 \\
0.56 \\
0.32\end{array}$ \\
\hline Baseline & FR 50 & 13 & $2.64(2.63)$ \\
\hline $\begin{array}{l}\text { Signaled progressive-fixed } \\
\text { delay }\end{array}$ & $\begin{array}{l}\text { Chained FR } 50 \text { FT } 1 \mathrm{~s} \\
\text { Chained FR 50 FT } 5 \mathrm{~s} \\
\text { Chained FR 50 FT } 10 \mathrm{~s} \\
\text { Chained FR 50 FT } 20 \mathrm{~s} \\
\text { Chained FR 50 FT } 40 \mathrm{~s} \\
\text { Chained FR 50 FT } 80 \mathrm{~s} \\
\text { Chained FR 50 FT160 s }\end{array}$ & $\begin{array}{l}1 \\
1 \\
1 \\
1 \\
1 \\
1 \\
1\end{array}$ & $\begin{array}{l}2.48 \\
1.49 \\
1.59 \\
1.19 \\
0.71 \\
0.46 \\
0.23\end{array}$ \\
\hline Baseline & FR 50 & 18 & $2.68(2.95)$ \\
\hline $\begin{array}{l}\text { Signaled progressive-fixed } \\
\text { delay }\end{array}$ & $\begin{array}{l}\text { Chained FR } 50 \text { FT } 1 \mathrm{~s} \\
\text { Chained FR 50 FT } 5 \mathrm{~s} \\
\text { Chained FR 50 FT } 10 \mathrm{~s} \\
\text { Chained FR 50 FT } 20 \mathrm{~s} \\
\text { Chained FR 50 FT } 40 \mathrm{~s} \\
\text { Chained FR 50 FT } 80 \mathrm{~s} \\
\text { Chained FR 50 FT } 160 \mathrm{~s}\end{array}$ & $\begin{array}{l}1 \\
1 \\
1 \\
1 \\
1 \\
1 \\
1\end{array}$ & $\begin{array}{l}2.57 \\
1.86 \\
1.30 \\
1.07 \\
0.59 \\
0.43 \\
0.19\end{array}$ \\
\hline Baseline & FR 50 & 19 & $2.41(3.12)$ \\
\hline $\begin{array}{l}\text { Signaled progressive-fixed } \\
\text { delay }\end{array}$ & $\begin{array}{l}\text { Chained FR } 50 \text { FT } 1 \mathrm{~s} \\
\text { Chained FR } 50 \text { FT } 5 \mathrm{~s}\end{array}$ & $\begin{array}{l}1 \\
1\end{array}$ & $\begin{array}{l}2.67 \\
1.79\end{array}$ \\
\hline
\end{tabular}




\begin{tabular}{|c|c|c|c|}
\hline & $\begin{array}{l}\text { Chained FR 50 FT } 10 \mathrm{~s} \\
\text { Chained FR 50 FT } 20 \mathrm{~s} \\
\text { Chained FR 50 FT } 40 \mathrm{~s} \\
\text { Chained FR 50 FT } 80 \mathrm{~s} \\
\text { Chained FR 50 FT } 160 \mathrm{~s}\end{array}$ & $\begin{array}{l}1 \\
1 \\
1 \\
1 \\
1\end{array}$ & $\begin{array}{l}1.50 \\
1.00 \\
0.70 \\
0.38 \\
0.23\end{array}$ \\
\hline Baseline & FR 50 & 13 & $4.25(3.82)$ \\
\hline $\begin{array}{l}\text { Signaled progressive-fixed } \\
\text { delay }\end{array}$ & $\begin{array}{l}\text { Chained FR 50 FT } 1 \mathrm{~s} \\
\text { Chained FR 50 FT } 5 \mathrm{~s} \\
\text { Chained FR 50 FT } 10 \mathrm{~s} \\
\text { Chained FR 50 FT } 20 \mathrm{~s} \\
\text { Chained FR 50 FT } 40 \mathrm{~s} \\
\text { Chained FR 50 FT } 80 \mathrm{~s}\end{array}$ & $\begin{array}{l}1 \\
1 \\
1 \\
1 \\
1 \\
1\end{array}$ & $\begin{array}{l}3.74 \\
2.41 \\
1.69 \\
0.34 \\
0.79 \\
0.39\end{array}$ \\
\hline Baseline & FR 50 & 15 & $4.12(3.88)$ \\
\hline $\begin{array}{l}\text { Signaled progressive-fixed } \\
\text { delay }\end{array}$ & $\begin{array}{l}\text { Chained FR } 50 \text { FT } 1 \mathrm{~s} \\
\text { Chained FR 50 FT } 5 \mathrm{~s} \\
\text { Chained FR 50 FT } 10 \mathrm{~s} \\
\text { Chained FR 50 FT } 20 \mathrm{~s}\end{array}$ & $\begin{array}{l}1 \\
1 \\
1 \\
1\end{array}$ & $\begin{array}{l}3.38 \\
2.64 \\
1.52 \\
0.52\end{array}$ \\
\hline Baseline & FR 50 & 26 & $3.77(3.46)$ \\
\hline $\begin{array}{l}\text { Unsignaled progressive- } \\
\text { fixed delay }\end{array}$ & $\begin{array}{l}\text { Tandem FR } 50 \text { FT } 1 \mathrm{~s} \\
\text { Tandem FR 50 FT } 5 \mathrm{~s} \\
\text { Tandem FR 50 FT } 10 \mathrm{~s} \\
\text { Tandem FR 50 FT } 20 \mathrm{~s}\end{array}$ & $\begin{array}{l}1 \\
1 \\
1 \\
1\end{array}$ & $\begin{array}{l}3.82 \\
1.47 \\
1.65 \\
0.29\end{array}$ \\
\hline Baseline & FR 50 & 24 & $2.75(4.26)$ \\
\hline $\begin{array}{l}\text { Unsignaled progressive- } \\
\text { fixed delay }\end{array}$ & $\begin{array}{l}\text { Tandem FR 50 FT } 1 \mathrm{~s} \\
\text { Tandem FR 50 FT } 5 \mathrm{~s} \\
\text { Tandem FR 50 FT } 10 \mathrm{~s} \\
\text { Tandem FR 50 FT } 20 \mathrm{~s} \\
\text { Tandem FR 50 FT } 40 \mathrm{~s}\end{array}$ & $\begin{array}{l}1 \\
1 \\
1 \\
1 \\
1\end{array}$ & $\begin{array}{l}3.59 \\
2.01 \\
1.00 \\
0.50 \\
0.28\end{array}$ \\
\hline Baseline & FR 50 & 16 & $3.57(3.62)$ \\
\hline $\begin{array}{l}\text { Unsignaled progressive- } \\
\text { fixed delay }\end{array}$ & $\begin{array}{l}\text { Tandem FR 50 FT } 1 \mathrm{~s} \\
\text { Tandem FR 50 FT } 5 \mathrm{~s} \\
\text { Tandem FR 50 FT } 10 \mathrm{~s}\end{array}$ & $\begin{array}{l}1 \\
1 \\
1\end{array}$ & $\begin{array}{l}3.26 \\
1.39 \\
0.47\end{array}$ \\
\hline
\end{tabular}

Note. Last six sessions refers to the final six sessions of the baseline condition 


\section{Results}

Figure 1 shows the session-by-session run rates (left columns; responses per minute during the time between the end of the PRP until the ratio was completed) and PRPs (right columns; time from the end of the reinforcement period until the first key peck) during the final session of each baseline phase and during testing sessions for each pigeon. The highest run rates and lowest PRPs occurred during baseline sessions. During both the signaled (labeled S) and unsignaled delays (labeled U), run rate systematically decreased and PRP systematically increased with increasing delays. These decreases in rate and increases in PRP were most pronounced for 536, both here and in Experiments 2-4.

Figure 2 shows the data from Figure 1, plus overall response rate (i.e., responses per minute during all non-reinforcement periods) expressed as a proportion of the preceding baseline. The proportion of baseline run rate was calculated by dividing the run rate at each delay by the mean run rate from the final six sessions of preceding baseline. The calculation was done in the same manner for PRPs and overall response rates. The left column of Figure 2 shows the proportion of the baseline run rate at each delay duration during the signaled and unsignaled delays for all three pigeons. A systematic negative relation between run rate and delay duration was observed for all three pigeons, yet there was no systematic difference in behavior between the signaled and unsignaled delays. The center column of Figure 2 shows the proportion of baseline PRPs at each delay. Although this consistent positive relation between PRP and delay duration was obtained, there were no systematic differences between the signaled and unsignaled delay conditions. To facilitate comparisons with other studies of delay-of-reinforcement effects, the proportion of baseline for overall response rates are shown in the right column. As with the run-rate data, a negative relation between overall response rate and delay duration occurred for 


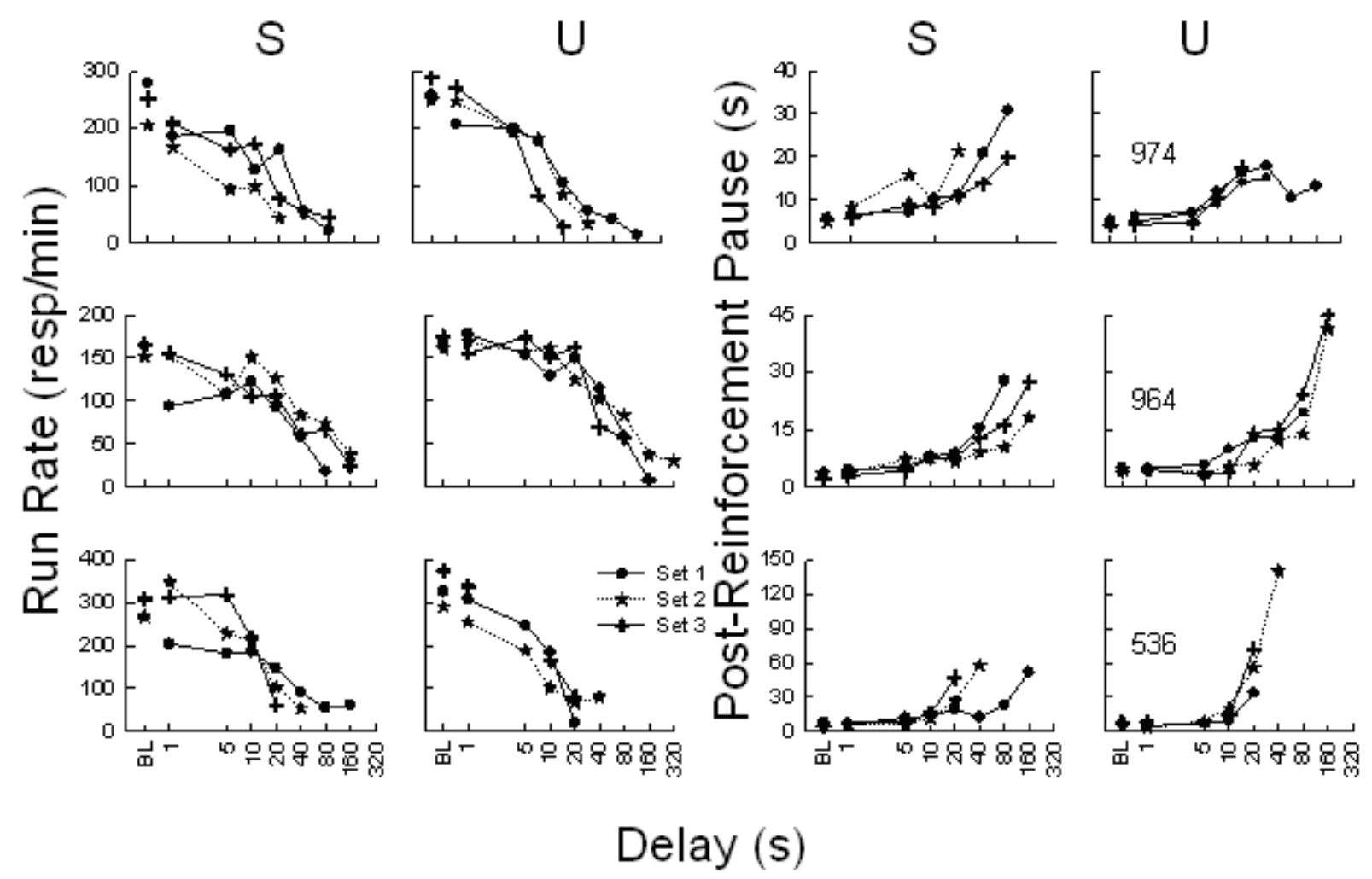

Figure 1. Session-by-session data from Experiment 1. Run rates (left two columns) and PRPs (right two columns) during the final session of each baseline condition and at each delay duration (x-axis) during the signaled (columns labeled S) and unsignaled (columns labeled U) progressive-fixed-delay conditions for 974 (top row) 964 (middle row) and 536 (bottom row). Data from the first (circles) second (stars) and third (crosses) sets of delay are shown separately. 


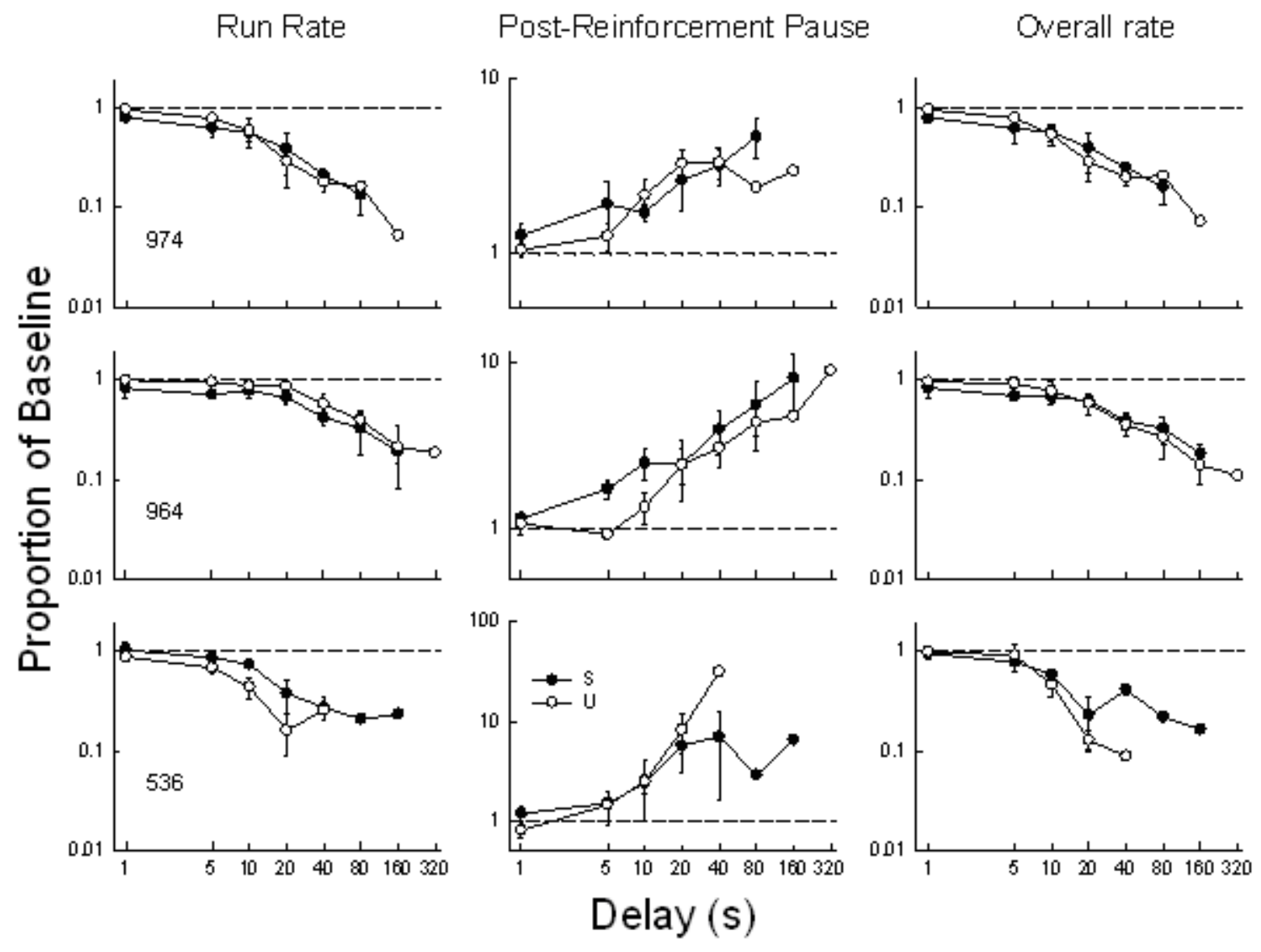

Figure 2. Proportion-of-baseline data for Experiment 1. Proportion of baseline run rates (left column) post-reinforcement pauses (center column) and overall rates (right column) during the signaled (closed circles) and unsignaled (open circles) progressive-fixed-delay conditions for 974 (top row), 964 (middle row) and 536 (bottom row). Error bars show one standard deviation. 
each pigeon in both the signaled and unsignaled-delay conditions, yet no systematic differences were seen between signaled and unsignaled delays.

Obtained delays (i.e., time between the last response and reinforcer delivery) at each programmed delay are shown in Figure 3. Obtained signaled delays approximated the programmed delays. Obtained unsignaled delays were shorter than the programmed delays. Both signaled and unsignaled obtained delays increased with increases in the programmed delays.

Figure 4 shows delay of reinforcement gradients for running rates as a function of whether the delays were signaled (left graphs) and unsignaled (right graphs). Data are shown as a proportion of the baseline run rate plotted against nominal delay values. Non-linear regression lines were fitted to the data based on the following equation adapted from Mazur (1987) by Reilly and Lattal (2004)

$$
B=\frac{B_{1}}{1+k D}
$$

where $\mathrm{B}$ is response rate, $\mathrm{D}$ is the programmed delay, $\mathrm{B}_{1}$ is baseline response rate (set to 1 ) and $k$ is a free parameter that represents the rate decreasing effects of the delay (i.e., discounting rate). These parameters were estimated using a non-linear regression curve fitting routine (Sigma Plot 11) that minimized the sum-of-squares error between the predicted curve and the obtained data. The hyperbolic discounting functions provided an adequate fit to the data in all cases (i.e., $\mathrm{r}^{2}=$ 0.80 or above). As was seen with response rates, discounting rates (i.e., $k$ ) did not systematically differ in the signaled versus unsignaled-delay conditions. 


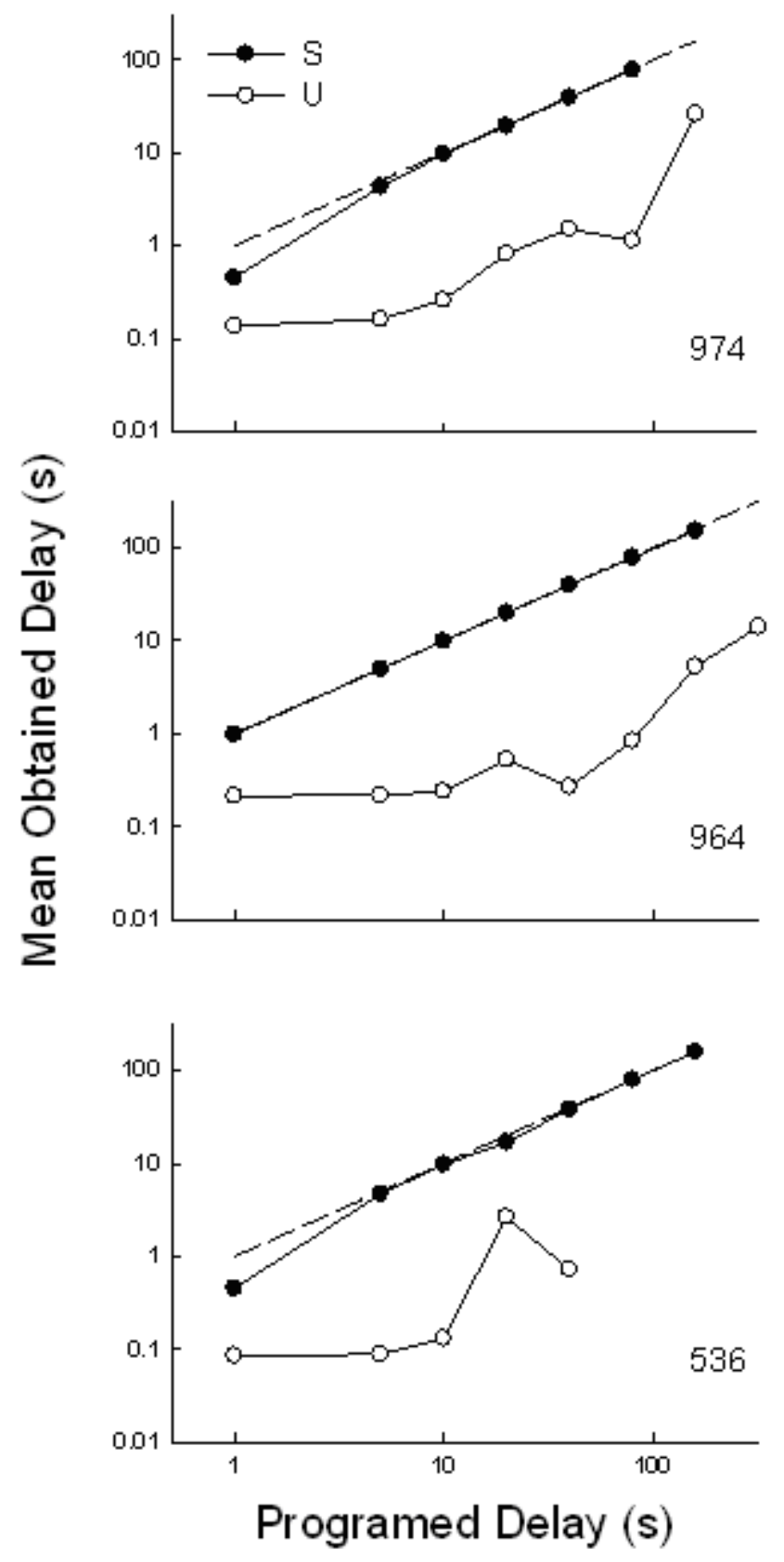

Figure 3. Relation between obtained and programmed delays during Experiment 1. Obtained delays at each programmed delay during the signaled (closed circles) and unsignaled (open circles) progressive-fixed-delay conditions of Experiment 1 for 974 (top graph), 964 (middle graph) and 536 (bottom graph). The dashed lines show the data that would be obtained if obtained and programmed delays were equal. 


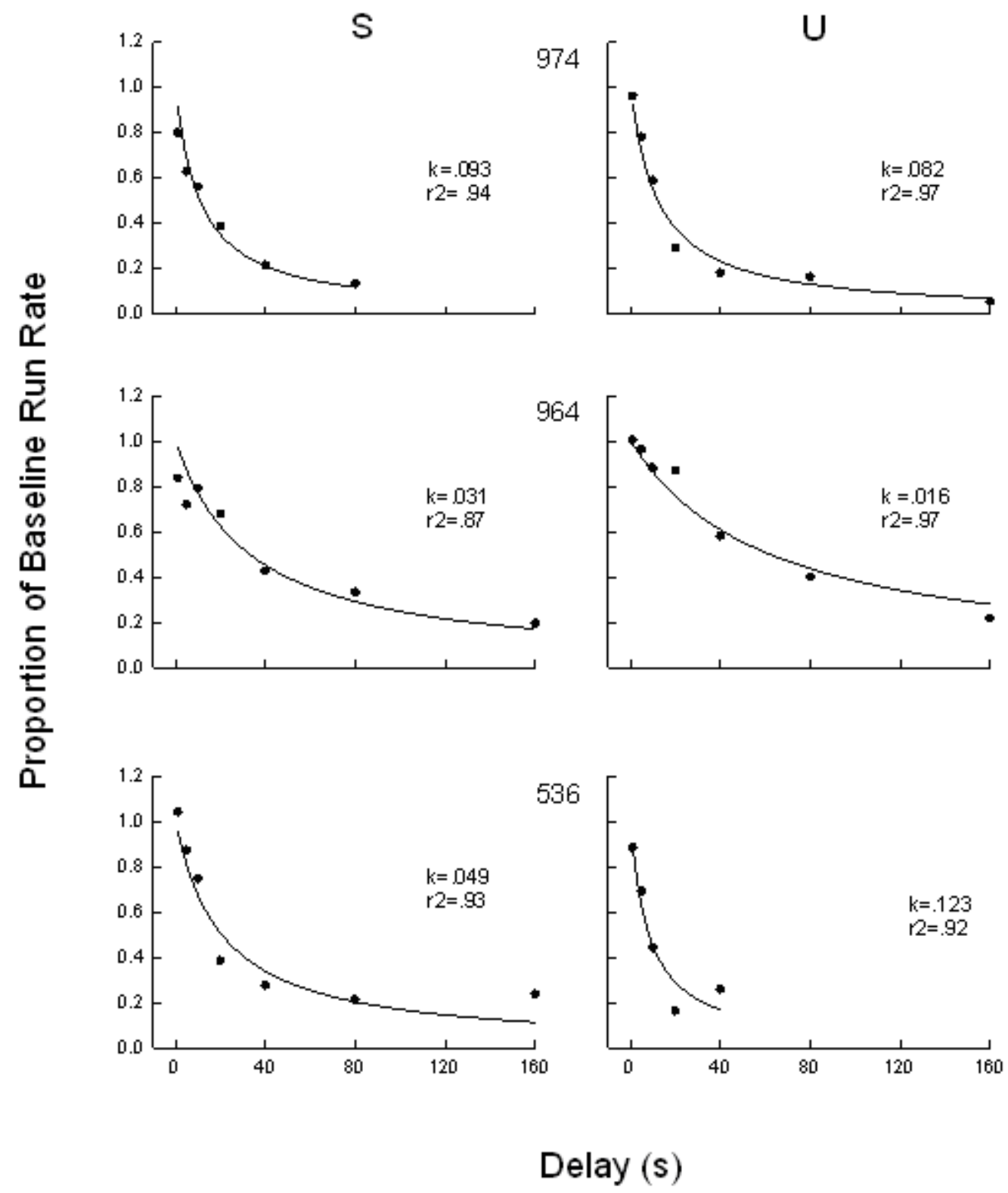

Figure 4. Hyperbolic-discounting data from Experiment 1. Proportion of baseline run rate during the signaled (left column) and unsignaled (right column) progressive-fixed-delay conditions for 974 (top row), 964 (middle row) and 536 (bottom row). The lines show the fit of Equation 2 to the data with the fitted parameter $k$ and the $\mathrm{r}^{2}$ value shown in each graph. 


\section{Discussion}

The results of Experiment 1 were notable in a number of respects. First, like previous studies of delayed reinforcement on FR schedules (e.g., Meunier \& Ryman, 1974; Morgan, 1972; Topping et al., 1973) PRPs increased as delay duration increased. Second, unlike previous studies examining effects of delay of reinforcement on FR schedules (e.g., Meunier \& Ryman; Morgan; Topping et al.) orderly relations between delay of reinforcement and both overall rate and run rate were obtained. This decrease in response rate as delay duration increased is consistent with findings from a number of studies using VI baselines (e.g., Reilly and Lattal; Richards, 1981; Shahan and Lattal, 2005; Sizemore and Lattal, 1978). Third, as can be seen from Figure 1, these effects were replicable across multiple repetitions of the progressively increasing delay sequences. Forth, the delay-of-reinforcement effects were described by Reilly and Lattal's modification of Mazur's (1987) hyperbolic discounting formula. Fifth, the large differences in delay of reinforcement gradients based on signaled and unsignaled delays found using VI schedules as baselines for maintaining responding (e.g., Reilly and Lattal; Richards) were not found using the present delay procedure in combination with FR schedules. And lastly, obtained delays increased with increasing programmed delay value for both signaled and unsignaled delays, and the unsignaled delays were shorter than the signaled delays.

\section{Experiment 2}

The results of Experiment 1, as well as the findings of previous investigations of delayof-reinforcement effects on FR schedules (e.g., Morgan, 1972), potentially are confounded by the simultaneous increases in delay duration and decreases in the rate of reinforcement. Because each increase in the duration of the delay of reinforcement resulted in a corresponding increase in the IRI, the relative contributions of delay of reinforcement (e.g., Shahan \& Lattal, 2005; 
Reilly \& Lattal, 2004) and decreases in rate of reinforcement (e.g., Baum, 1973; Herrnstein, 1970) to the delay-of-reinforcement effects seen on FR schedules is unknown. Experiment 2 was conducted to address this potential confound.

\section{Method}

Subjects

The three pigeons from Experiment 1 were used and maintained as described there.

\section{Apparatus}

The same apparatus used in Experiment 1 was used.

\section{Procedure}

Because of the pigeons' histories, each was exposed immediately to an FR-50 schedule. Sessions were conducted 6-7 days a week at approximately the same time each day and ended after either 60 (40 for Pigeon 536) reinforcers were delivered or when 300 s lapsed without a key peck. During the experiment, blocks of baseline sessions alternated with blocks of test (i.e., increasing delay) and control (i.e., increasing intertrial intervals [ITI]) sessions. Table 2 provides the order of conditions. During baseline sessions, completion of an FR-50 schedule resulted in the immediate delivery of 3-s (2.5-s for Pigeon 536) access to grain. Each baseline condition was in effect for at least 13 days and until both run rates and PRPs were stable (13-18 sessions, see Table 2). The stability criterion for changing conditions was as described in Experiment 1 . One signaled and one unsignaled-delay condition were conducted, each separated by a return to baseline, a control condition, and a second return to baseline. During these delay conditions the pigeons were exposed to an escalating sequence of either blackout-signaled (i.e., chained FR 50 FT x) or unsignaled (i.e., tandem FR 50 FT x) delays. This sequence consisted of 1-s, 5-s, 10-s, 20-s, 40-s, 80-s, 160-s, 320-s, \& 640-s delays presented across successive sessions. Delay 
Table 2

Order of conditions, number of sessions and reinforcement rate during Experiment 2

\begin{tabular}{|c|c|c|c|c|}
\hline Pigeon & Condition & Schedule & $\mathrm{N}$ & $\begin{array}{l}\text { Reinforcers per minute } \\
\text { (last } 6 \text { sessions) }\end{array}$ \\
\hline \multirow[t]{32}{*}{974} & Baseline & FR 50 & 14 & $3.36(3.68)$ \\
\hline & \multirow{7}{*}{$\begin{array}{l}\text { Unsignaled progressive- } \\
\text { fixed delay }\end{array}$} & Tandem FR 50 FT $1 \mathrm{~s}$ & 1 & 2.73 \\
\hline & & Tandem FR 50 FT $5 \mathrm{~s}$ & 1 & 1.64 \\
\hline & & Tandem FR 50 FT $10 \mathrm{~s}$ & 1 & 1.13 \\
\hline & & Tandem FR 50 FT $20 \mathrm{~s}$ & 1 & 0.87 \\
\hline & & Tandem FR 50 FT $40 \mathrm{~s}$ & 1 & 0.60 \\
\hline & & Tandem FR 50 FT $80 \mathrm{~s}$ & 1 & 0.36 \\
\hline & & Tandem FR 50 FT $160 \mathrm{~s}$ & 1 & 0.14 \\
\hline & Baseline & FR 50 & 16 & $3.62(3.74)$ \\
\hline & \multirow{7}{*}{$\begin{array}{l}\text { Unsignaled progressive } \\
\text { fixed intertrial interval }\end{array}$} & Tandem FT 1 s FR 50 & 1 & 4.07 \\
\hline & & Tandem FT 5 s FR 50 & 1 & 3.43 \\
\hline & & Tandem FT 10 s FR 50 & 1 & 2.92 \\
\hline & & Tandem FT 20 s FR 50 & 1 & 2.07 \\
\hline & & Tandem FT 40 s FR 50 & 1 & 1.00 \\
\hline & & Tandem FT 80 s FR 50 & 1 & 0.59 \\
\hline & & Tandem FT 160 s FR 50 & 1 & 0.29 \\
\hline & Baseline & FR 50 & 13 & $2.75(3.14)$ \\
\hline & \multirow{7}{*}{$\begin{array}{l}\text { Signaled progressive-fixed } \\
\text { delay }\end{array}$} & Chained FR 50 FT $1 \mathrm{~s}$ & 1 & 2.76 \\
\hline & & Chained FR 50 FT $5 \mathrm{~s}$ & 1 & 2.00 \\
\hline & & Chained FR 50 FT $10 \mathrm{~s}$ & 1 & 1.57 \\
\hline & & Chained FR 50 FT $20 \mathrm{~s}$ & 1 & 1.12 \\
\hline & & Chained FR $50 \mathrm{FT} 40 \mathrm{~s}$ & 1 & 0.69 \\
\hline & & Chained FR 50 FT $80 \mathrm{~s}$ & 1 & 0.43 \\
\hline & & Chained FR 50 FT $160 \mathrm{~s}$ & 1 & 0.25 \\
\hline & Baseline & FR 50 & 17 & $3.60(3.42)$ \\
\hline & \multirow{7}{*}{$\begin{array}{l}\text { Signaled progressive fixed } \\
\text { intertrial interval }\end{array}$} & Chained FT 1 s FR 50 & 1 & 3.79 \\
\hline & & Chained FT 5 s FR 50 & 1 & 3.51 \\
\hline & & Chained FT 10 s FR 50 & 1 & 2.96 \\
\hline & & Chained FT 20 s FR 50 & 1 & 1.91 \\
\hline & & Chained FT 40 s FR 50 & 1 & 1.14 \\
\hline & & Chained FT 80 s FR 50 & 1 & 0.63 \\
\hline & & Chained FT 160 s FR 50 & 1 & 0.34 \\
\hline \multirow[t]{9}{*}{964} & Baseline & FR 50 & 13 & $2.83(2.80)$ \\
\hline & \multirow{7}{*}{$\begin{array}{l}\text { Signaled progressive-fixed } \\
\text { delay }\end{array}$} & Chained FR 50 FT $1 \mathrm{~s}$ & 1 & 2.69 \\
\hline & & Chained FR 50 FT $5 \mathrm{~s}$ & 1 & 2.04 \\
\hline & & Chained FR 50 FT $10 \mathrm{~s}$ & 1 & 1.70 \\
\hline & & Chained FR 50 FT $20 \mathrm{~s}$ & 1 & 1.24 \\
\hline & & Chained FR 50 FT $40 \mathrm{~s}$ & 1 & 0.81 \\
\hline & & Chained FR 50 FT $80 \mathrm{~s}$ & 1 & 0.52 \\
\hline & & Chained FR 50 FT $160 \mathrm{~s}$ & 1 & 0.28 \\
\hline & Baseline & FR 50 & 13 & $2.52(2.19)$ \\
\hline
\end{tabular}


Signaled progressive fixed intertrial interval

Baseline
Unsignaled progressive-
fixed delay

Baseline

Unsignaled progressive fixed intertrial interval

Baseline

Signaled progressive fixed intertrial interval

Baseline

Unsignaled progressivefixed delay

Baseline

Unsignaled progressive fixed intertrial interval
Chained FT 1 s FR 50 $\quad 1 \quad 2.41$

Chained FT 5 s FR 50 $\quad 1 \quad 2.41$

Chained FT 10 s FR 50 $\quad 1 \quad 2.13$

Chained FT 20 s FR 50 111.58

Chained FT 40 s FR 50 111.03

Chained FT 80 s FR 50 110.60

Chained FT 160 s FR 50 110.32

$\begin{array}{lll}\text { FR50 } & 17 & 2.29(2.20)\end{array}$

Tandem FR 50 FT $1 \mathrm{~s} \quad 1 \quad 1.85$

Tandem FR 50 FT $5 \mathrm{~s} \quad 1 \quad 1.55$

Tandem FR 50 FT $10 \mathrm{~s} \quad 1 \quad 1.56$

Tandem FR 50 FT 20 s $\quad 1 \quad 1.09$

Tandem FR 50 FT 40 s $\quad 1 \quad 0.69$

Tandem FR 50 FT $80 \mathrm{~s} \quad 1 \quad 0.43$

Tandem FR 50 FT $160 \mathrm{~s} \quad 1 \quad 0.22$

Tandem FR 50 FT $320 \mathrm{~s} \quad 1 \quad 0.12$

$\begin{array}{lll}\text { FR50 } & 13 & 2.30(2.21)\end{array}$

Tandem FT 1 s FR $50 \quad 1 \quad 2.36$

Tandem FT 5 s FR $50 \quad 1 \quad 2.26$

Tandem FT 10 s FR $50 \quad 1 \quad 2.09$

Tandem FT 20 s FR 50 111.61

Tandem FT 40 s FR 50 111.06

Tandem FT 80 s FR $50 \quad 1 \quad 0.58$

Tandem FT 160 s FR $50 \quad 1 \quad 0.30$

Tandem FT 320 s FR $50 \quad 1 \quad 0.17$

$\begin{array}{lll}\text { FR50 } & 18.39 \text { (3.04) }\end{array}$

Chained FR 50 FT 1 s $\quad 1 \quad 2.14$

Chained FR 50 FT $5 \mathrm{~s} \quad 1 \quad 1.83$

Chained FR 50 FT $10 \mathrm{~s} \quad 1 \quad 1.13$

Chained FR 50 FT 20 s $\quad 1 \quad 0.47$

Chained FR 50 FT $40 \mathrm{~s} \quad 1 \quad 0.23$

$\begin{array}{lll}\text { FR50 } & 18 & 2.57(2.53)\end{array}$

Chained FT 1 s FR 50 $\quad 1 \quad 2.82$

Chained FT 5 s FR 50 $\quad 1 \quad 2.33$

Chained FT 10 s FR 50 111.82

Chained FT 20 s FR 50 11.80

Chained FT 40 s FR 50 111.05

$\begin{array}{lll}\text { FR50 } & 14 & 2.39(2.13)\end{array}$

Tandem FR 50 FT $1 \mathrm{~s} \quad 1 \quad 2.28$

Tandem FR 50 FT $5 \mathrm{~s} \quad 1 \quad 1.22$

Tandem FR 50 FT $10 \mathrm{~s} \quad 1 \quad 0.81$

Tandem FR 50 FT 20 s $\quad 1 \quad 0.33$

$\begin{array}{lll}\text { FR50 } & 17 & 2.33(2.33)\end{array}$

Tandem FT $1 \mathrm{~s}$ FR $50 \quad 1 \quad 2.22$

Tandem FT 5 s FR 50 $\quad 1 \quad 2.55$

Tandem FT 10 s FR $50 \quad 1 \quad 1.91$

Tandem FT 20 s FR 50 11.36 
Note. Last six sessions refers to the final six sessions of the baseline condition 
durations increased in this progression until a session was terminated due to a pause of $300 \mathrm{~s}$. At this point, the pigeon was returned to baseline during the following session. During the control conditions, the same pigeons were exposed to an escalating sequence of either blackout-signaled or unsignaled control conditions. During the signaled control condition an x second ITI, during which the key light was turned off, began immediately after the reinforcement period (i.e., chained FT x FR 50). The unsignaled control condition was like the signaled control condition except the key light was on during the ITI (i.e., tandem FT x FR 50). Similar to the delay conditions, a sequence of $1-\mathrm{s}, 5 \mathrm{~s}, 10-\mathrm{s}, 20-\mathrm{s}, 40-\mathrm{s}, 80-\mathrm{s}, 160-\mathrm{s}, 320-\mathrm{s}, \&$ 640-s ITIs was presented across subsequent sessions. The FT sequence used in the signaled control condition was yoked from the preceding signaled delay condition (i.e., the longest FT component presented during the control condition was the same as the longest FT component experienced during the delay condition), whereas the FT sequence in the unsignaled control condition was yoked from the preceding unsignaled delay condition. The pigeon was returned to the baseline condition after this yoked progression was completed.

\section{Results}

The left and right graphs of Figure 5 show the run rates (left) and PRPs (right) during the final session of each baseline and during the subsequent delay conditions. The highest run rates and lowest PRPs occurred during the immediate-reinforcement (baseline) sessions. During both signaled (labeled S) and unsignaled (labeled U) delay conditions, run rates systematically decreased and PRP systematically increased as delay durations increased. Similar relations were obtained for some of the subjects in the control conditions, but only at the longest ITIs.

Figure 6 show the proportion of baseline run rate, PRP, and overall response rate calculated as they were in Experiment 1. The left graphs of Figure 6 show the proportion of the 

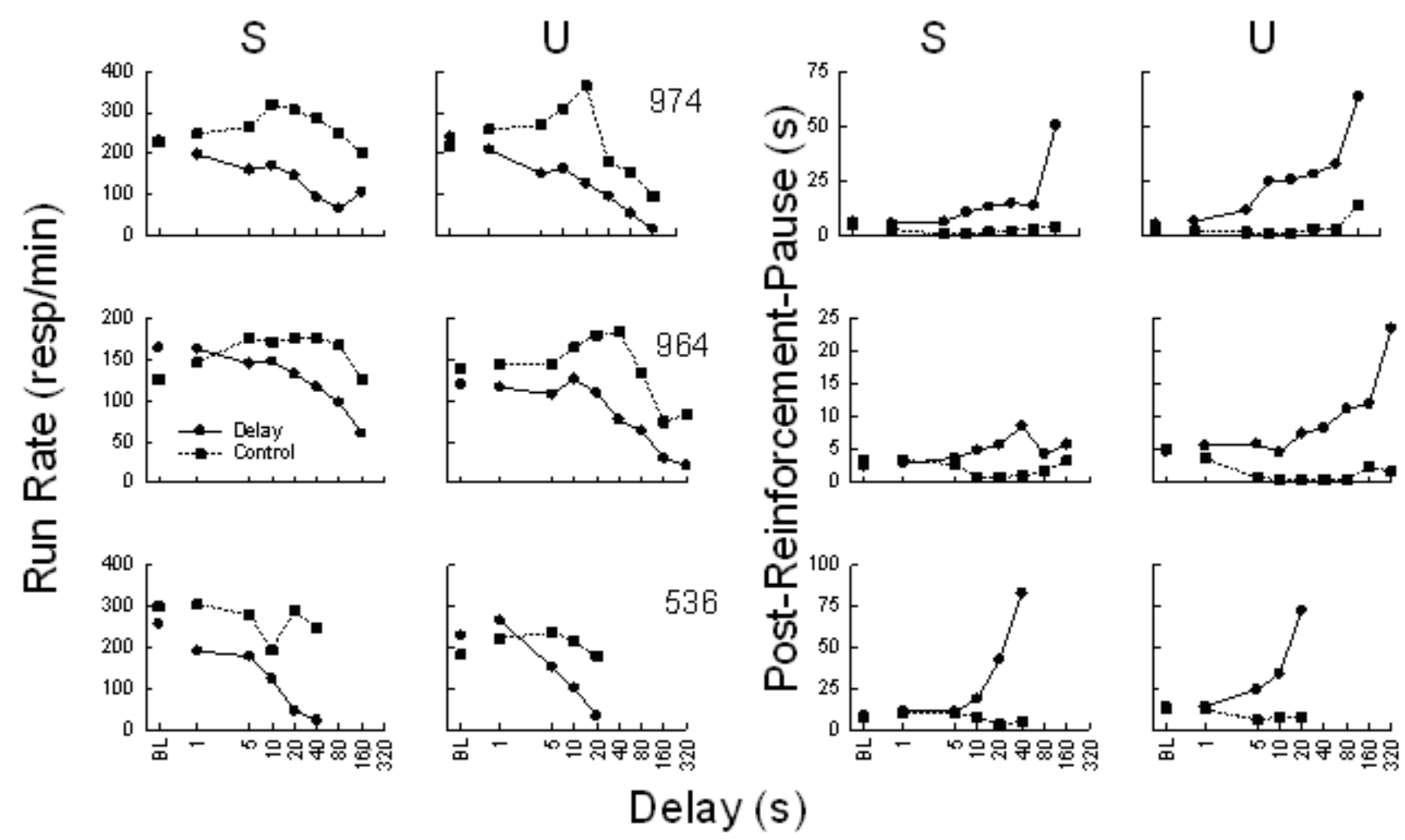

Figure 5. Session-by-session data from Experiment 2. Run rates (left two columns) and PRPs

(right two columns) at each delay duration (x-axis) during the final session of each baseline conditions and at each delay duration (x-axis) during the signaled (columns labeled $\mathrm{S}$ ) and unsignaled (columns labeled U) progressive-fixed-delay (circles) and control (squares) conditions for 974 (top row) 964 (middle row) and 536 (bottom row). 

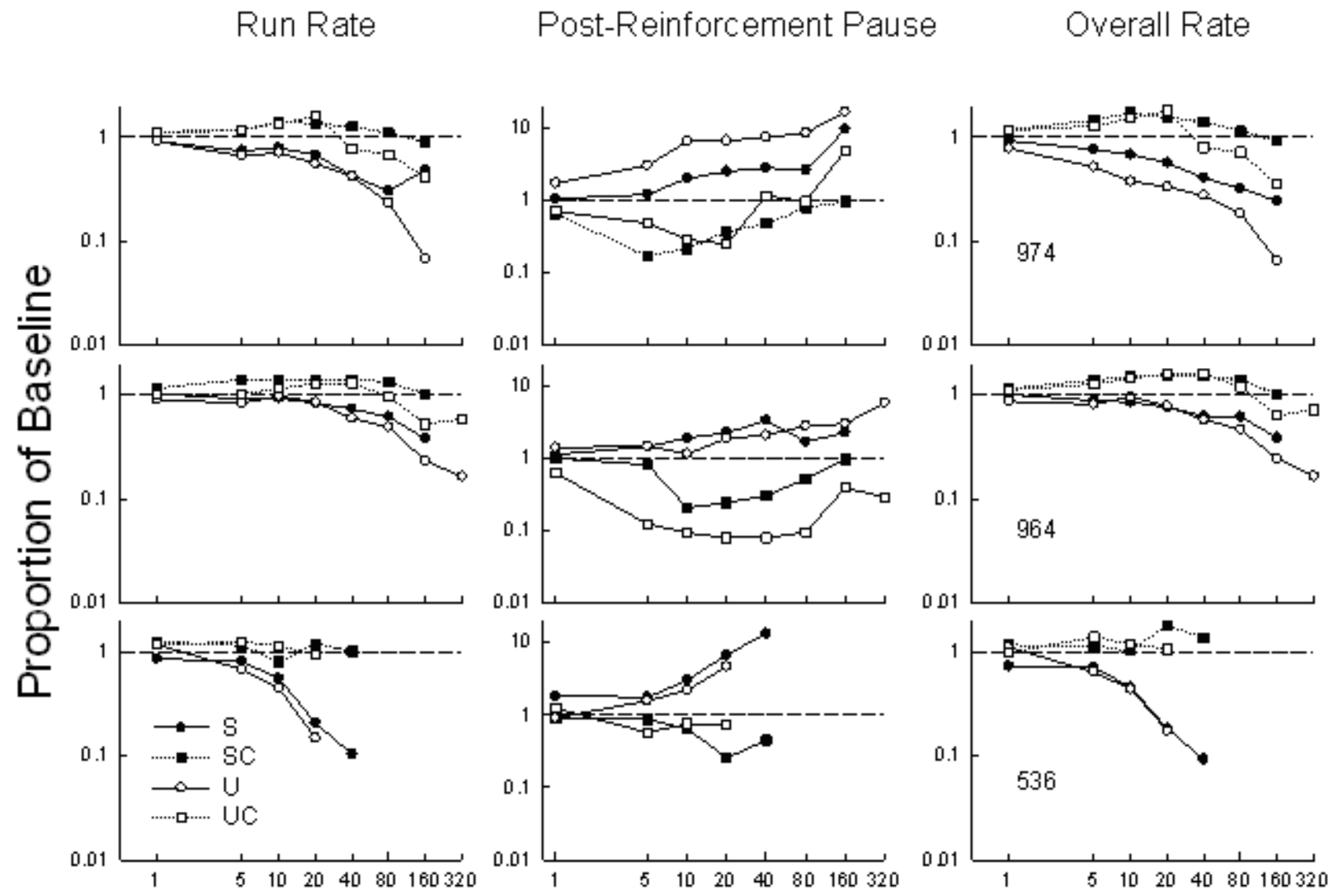

Delay (s)

Figure 6. Proportion of baseline data from Experiment 2. Proportion of baseline run rates (left column) PRPs (center column) and overall rates (right column) during the signaled (closed circles) and unsignaled (open circles) progressive-fixed-delay and increasing signaled (closed squares) and unsignaled (open squares) control conditions for 974 (top row), 964 (middle row) and 536 (bottom row). 
baseline mean run rate at each delay duration during the signaled- and unsignaled-delay conditions, as well as the control conditions. The proportion-of-baseline run rate decreased as the delay duration increased for each pigeon. A similar relation between ITI duration and proportionof-baseline run rate was obtained during the control conditions for 974 and 964, but not for 536. This effect, however, only occurred when ITIs were $40 \mathrm{~s}$ and longer, and the effect always was greater with the delays. As with Experiment 1, no consistent differences in run rates occurred during the signaled- and unsignaled-delay conditions.

The center graphs show the proportion of baseline PRPs at each delay duration for each pigeon. A positive relation between proportion-of-baseline PRP and delay duration was obtained in the signaled and unsignaled delay conditions. By contrast, a decrease in the proportion-ofbaseline PRP was obtained in the control conditions, particularly at brief to moderate delays. Additionally, the proportional increase from baseline PRP was greater in the unsignaled relative to the signaled delay conditions for 974 and 964 , but not for 536, particularly at the longer delay durations.

Figure 7 shows the proportion-of-baseline reinforcement rates at each FT-component duration during the signaled (left column) and unsignaled (right column) delay and control conditions. Proportion of baseline reinforcement rate was calculated in the same was as proportion of baseline run rate. As was programmed, a negative relation between proportion-ofbaseline reinforcement rate and FT-component duration occurred in both the delay and control conditions. Reinforcement rates were slightly but consistently higher in the control than in the delay conditions. 


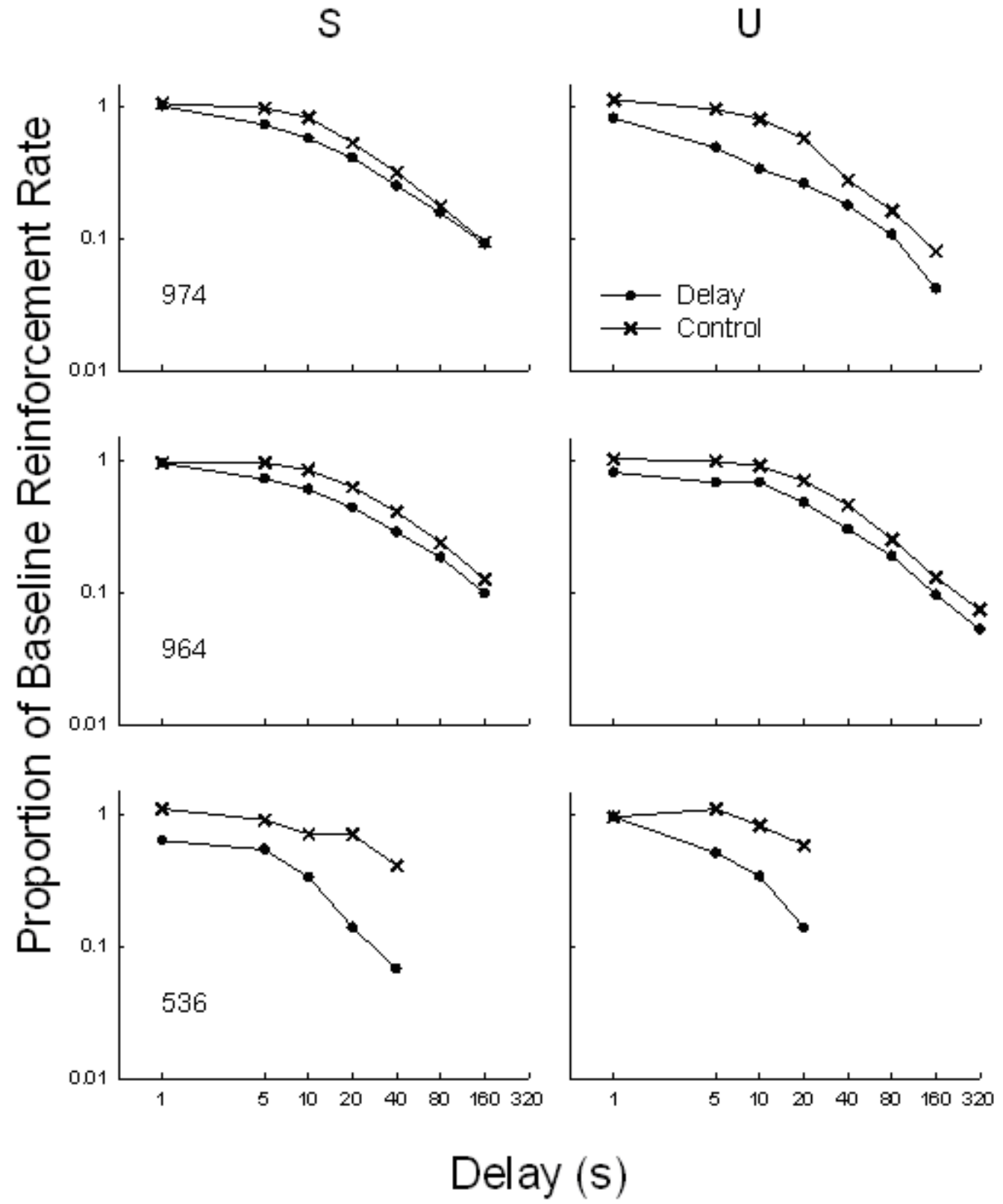

Figure 7. Reinforcement rate data from Experiment 2. Proportion of baseline reinforcement rates during the signaled (left column) and unsignaled (right column) progressive-fixed-delay (circles) and control (crosses) conditions for 974 (top row), 964 (middle row) and 536 (bottom row). 

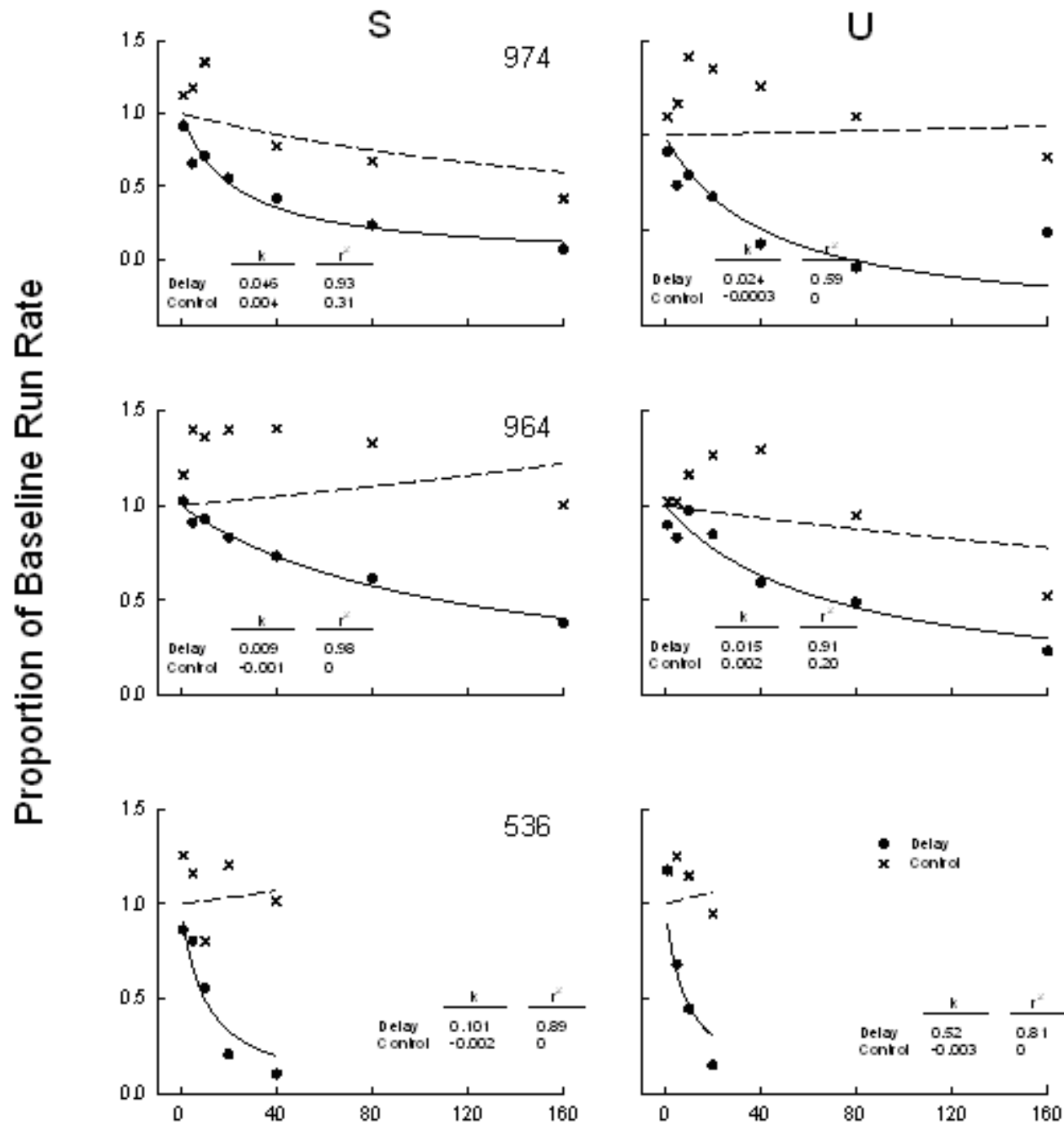

\section{Delay (s)}

Figure 8. Hyperbolic discounting data from Experiment 2. Proportion of baseline run rate during the signaled (left column) and unsignaled (right column) progressive-fixed-delay (circles) and control (crosses) conditions for 974 (top row), 964 (middle row) and 536 (bottom row). The solid lines show the fit of Equation 2 to the data from the delay condition and the dashed lines show the fit of Equation 2 to data from the control condition. 
Figure 8 shows the relation between proportion-of-baseline run rate and delay duration during the signaled (left column) and unsignaled (right column) delays. Like Experiment 1, hyperbolic functions were then fit to the data using Equation 2. Separate functions were fit to the data from the delay conditions (solid lines) and control conditions (broken lines). The hyperbolic equation described the data well $\left(\mathrm{r}^{2}=0.80\right.$ or higher $)$ for five of the six delay conditions, but not any of the control conditions. Furthermore, like Experiment $1, k$ did not systematically differ in the signaled versus unsignaled delay conditions. 


\section{Discussion}

The results of Experiment 2 replicated the results of Experiment 1: orderly relations between delay of reinforcement and overall rate, run rate, and PRP occurred using the PFD procedure. Also like Experiment 1, the differences in delay gradients during the signaled versus unsignaled delays were neither large nor consistent. Additionally, the hyperbolic equation that sufficiently described (i.e., $\mathrm{r}^{2}$ of 0.8 and higher) most of the delay data from Experiments 1 and 2 did not sufficiently describe any of the data from the control conditions.

The control conditions in Experiment 2 were designed to assess the relative contributions of delay and reinforcement rate to the delay of reinforcement gradients generated with FR schedules serving as the basis for the comparisons. As was programmed, reinforcement rates decreased in both the delay and control conditions. Response rates during the FR component, however, did not decrease as quickly in the control as they did in the delay condition. Hence, the decrease in rate of reinforcement was larger in the delay relative to control condition. It is therefore possible that decreased reinforcement rates influenced responding in the delay conditions. For example, although both overall and response rates decreased as delays increased in the signaled and unsignaled delay conditions, the decreases in rate were not as large or consistent in the corresponding control conditions. Because decreases in reinforcement rate alone did not decrease responding as much as did the corresponding delays, delays of reinforcement appear to have had a relatively larger impact on run rates than did decreased reinforcement rates.

\section{Experiment 3}

Because of the different contingencies arranged by interval and ratio schedules it was of interest to compare directly delay-of-reinforcement effects on ratio and interval schedules while holding constant the rate and distributions of reinforcers between them. Under these conditions, 
any differences between the two may be attributed to the different contingencies arranged by the two schedules.

\section{Method}

Subjects

The same three pigeons from Experiment 1 were used in Experiment 3. Details of their maintenance were as described in Experiment 1.

Apparatus

The same apparatus used in Experiment 1 was used in Experiment 3.

\section{Procedure}

Because the pigeons had histories of responding on FR schedules, the pigeons were exposed immediately to the multiple FR-50 YI schedule used during baseline. Sessions occurred 6-7 days a week at approximately the same time each day and ended after either 60 (40 for Pigeon 536) reinforcers were delivered or when 300 s lapsed without a key peck, whichever came first. During the experiment, blocks of baseline and test sessions alternated. The order of conditions for Experiment 3 is shown in Table 3. During baseline sessions, a multiple FR-50 yoked- interval (YI) schedule was in effect. The two components regularly alternated, with each session beginning with the FR component. Each component lasted for 10 reinforcers. In the FR50 component, the key was green and the completion of an FR-50 resulted in the immediate delivery of 3-s (2.5-s for Pigeon 536) access to grain. In the YI component, the key was white and the first peck after a reinforcer was made available resulted in the immediate delivery of 3-s (2.5-s for Pigeon 536) access to grain. The yoking procedure operated as follows. The IRIs during each FR-50 component were recorded. The intervals during the subsequent YI component consisted of these recorded IRIs. For example, if a reinforcer were delivered 35 s into the FR-50 
Table 3

Order of conditions, number of sessions and reinforcement rate during Experiment 3

\begin{tabular}{|c|c|c|c|c|c|c|}
\hline \multirow{2}{*}{ Pigeon } & \multirow[b]{2}{*}{ Condition } & \multicolumn{2}{|c|}{ Fixed-Ratio Component } & \multicolumn{2}{|c|}{ Yoked-Interval Component } & \multirow[b]{2}{*}{$\mathrm{n}$} \\
\hline & & Schedule & $\begin{array}{l}\begin{array}{l}\text { SR Rate } \\
\text { (last } 6 \\
\text { sessions) }\end{array} \\
\end{array}$ & Schedule & $\begin{array}{l}\begin{array}{l}\text { SR Rate } \\
\text { (last } 6 \\
\text { sessions) }\end{array} \\
\end{array}$ & \\
\hline \multirow[t]{36}{*}{974} & Baseline & FR50 & $\begin{array}{c}2.87 \\
(3.20)\end{array}$ & YI & $\begin{array}{c}2.83 \\
(3.16)\end{array}$ & 15 \\
\hline & Unsignaled & Tandem FR 50 FT $0.5 \mathrm{~s}$ & 3.22 & Tandem YI FT $0.5 \mathrm{~s}$ & 3.19 & 1 \\
\hline & progressive-fixed & Tandem FR 50 FT $1 \mathrm{~s}$ & 3.23 & Tandem YI FT $1 \mathrm{~s}$ & 3.23 & 1 \\
\hline & delay & Tandem FR 50 FT $5 \mathrm{~s}$ & 2.17 & Tandem YI FT $5 \mathrm{~s}$ & 2.12 & 1 \\
\hline & & Tandem FR 50 FT $10 \mathrm{~s}$ & 1.72 & Tandem YI FT $10 \mathrm{~s}$ & 1.70 & 1 \\
\hline & & Tandem FR 50 FT $20 \mathrm{~s}$ & 0.91 & Tandem YI FT $20 \mathrm{~s}$ & 0.90 & 1 \\
\hline & & Tandem FR 50 FT $40 \mathrm{~s}$ & 0.35 & Tandem YI FT $40 \mathrm{~s}$ & 0.35 & 1 \\
\hline & & Tandem FR 50 FT $80 \mathrm{~s}$ & 0.32 & Tandem YI FT $80 \mathrm{~s}$ & 0.31 & 1 \\
\hline & & Tandem FR 50 FT $160 \mathrm{~s}$ & 0.19 & Tandem YI FT $160 \mathrm{~s}$ & 0.18 & 1 \\
\hline & Baseline & FR50 & $\begin{array}{c}2.75 \\
(2.88)\end{array}$ & YI & $\begin{array}{c}2.70 \\
(2.82)\end{array}$ & 18 \\
\hline & Signaled & Chained FR 50 FT $0.5 \mathrm{~s}$ & 2.95 & Chained YI FT $0.5 \mathrm{~s}$ & 2.89 & 1 \\
\hline & progressive-fixed & Chained FR 50 FT $1 \mathrm{~s}$ & 2.16 & Chained YI FT $1 \mathrm{~s}$ & 2.09 & 1 \\
\hline & delay & Chained FR 50 FT $5 \mathrm{~s}$ & 1.95 & Chained YI FT $5 \mathrm{~s}$ & 1.90 & 1 \\
\hline & & Chained FR 50 FT $10 \mathrm{~s}$ & 1.05 & Chained YI FT $10 \mathrm{~s}$ & 1.02 & 1 \\
\hline & & Chained FR 50 FT $20 \mathrm{~s}$ & 0.92 & Chained YI FT $20 \mathrm{~s}$ & 0.90 & 1 \\
\hline & & Chained FR 50 FT $40 \mathrm{~s}$ & 0.41 & Chained YI FT $40 \mathrm{~s}$ & 0.37 & 1 \\
\hline & Baseline & FR50 & $\begin{array}{c}2.56 \\
(2.83)\end{array}$ & YI & $\begin{array}{c}2.49 \\
(2.77)\end{array}$ & 13 \\
\hline & Unsignaled & Tandem FR 50 FT $0.5 \mathrm{~s}$ & 2.74 & Tandem YI FT $0.5 \mathrm{~s}$ & 2.57 & 1 \\
\hline & progressive-fixed & Tandem FR 50 FT $1 \mathrm{~s}$ & 2.31 & Tandem YI FT $1 \mathrm{~s}$ & 2.28 & 1 \\
\hline & delay & Tandem FR 50 FT $5 \mathrm{~s}$ & 1.64 & Tandem YI FT $5 \mathrm{~s}$ & 1.60 & 1 \\
\hline & & Tandem FR 50 FT $10 \mathrm{~s}$ & 0.93 & Tandem YI FT $10 \mathrm{~s}$ & 0.89 & 1 \\
\hline & & Tandem FR 50 FT $20 \mathrm{~s}$ & 0.48 & Tandem YI FT $20 \mathrm{~s}$ & 0.46 & 1 \\
\hline & & Tandem FR 50 FT $40 \mathrm{~s}$ & 0.18 & Tandem YI FT $40 \mathrm{~s}$ & 0.25 & 1 \\
\hline & Baseline & FR50 & $\begin{array}{c}2.60 \\
(2.59)\end{array}$ & YI & $\begin{array}{c}2.49 \\
(2.51)\end{array}$ & 20 \\
\hline & Unsignaled & Tandem FR 50 FT $0.5 \mathrm{~s}$ & 2.75 & Tandem YI FT $0.5 \mathrm{~s}$ & 2.69 & 1 \\
\hline & progressive-fixed & Tandem FR 50 FT $1 \mathrm{~s}$ & 2.70 & Tandem YI FT $1 \mathrm{~s}$ & 2.63 & 1 \\
\hline & delay & Tandem FR 50 FT $5 \mathrm{~s}$ & 1.77 & Tandem YI FT $5 \mathrm{~s}$ & 1.73 & 1 \\
\hline & & Tandem FR 50 FT $10 \mathrm{~s}$ & 0.62 & Tandem YI FT $10 \mathrm{~s}$ & 0.56 & 1 \\
\hline & & Tandem FR 50 FT $20 \mathrm{~s}$ & 0.35 & Tandem YI FT $20 \mathrm{~s}$ & 0.40 & 1 \\
\hline & Baseline & FR50 & $\begin{array}{c}2.33 \\
(2.45)\end{array}$ & YI & $\begin{array}{c}2.27 \\
(2.39)\end{array}$ & 14 \\
\hline & Signaled & Chained FR 50 FT $0.5 \mathrm{~s}$ & 2.67 & Chained YI FT $0.5 \mathrm{~s}$ & 2.56 & 1 \\
\hline & progressive-fixed & Chained FR 50 FT $1 \mathrm{~s}$ & 2.27 & Chained YI FT $1 \mathrm{~s}$ & 2.23 & 1 \\
\hline & delay & Chained FR 50 FT $5 \mathrm{~s}$ & 1.97 & Chained YI FT $5 \mathrm{~s}$ & 1.92 & 1 \\
\hline & & Chained FR 50 FT $10 \mathrm{~s}$ & 1.22 & Chained YI FT $10 \mathrm{~s}$ & 1.20 & 1 \\
\hline & & Chained FR 50 FT $20 \mathrm{~s}$ & 0.71 & Chained YI FT $20 \mathrm{~s}$ & 0.69 & 1 \\
\hline & & Chained FR 50 FT $40 \mathrm{~s}$ & 0.43 & Chained YI FT $40 \mathrm{~s}$ & 0.40 & 1 \\
\hline
\end{tabular}




\begin{tabular}{|c|c|c|c|c|c|}
\hline \multirow{2}{*}{\multicolumn{2}{|c|}{964}} & Chained FR 50 FT $80 \mathrm{~s}$ & 0.26 & Chained YI FT $80 \mathrm{~s}$ & 0.25 \\
\hline & & FR50 & $\begin{array}{c}2.20 \\
(2.12)\end{array}$ & YI & $\begin{array}{c}2.17 \\
(2.09)\end{array}$ \\
\hline & $\begin{array}{l}\text { Unsignaled } \\
\text { progressive-fixed } \\
\text { delay }\end{array}$ & $\begin{array}{l}\text { Tandem FR 50 FT } 0.5 \mathrm{~s} \\
\text { Tandem FR 50 FT } 1 \mathrm{~s} \\
\text { Tandem FR 50 FT } 5 \mathrm{~s} \\
\text { Tandem FR 50 FT } 10 \mathrm{~s} \\
\text { Tandem FR 50 FT } 20 \mathrm{~s} \\
\text { Tandem FR 50 FT } 40 \mathrm{~s} \\
\text { Tandem FR 50 FT } 80 \mathrm{~s} \\
\text { Tandem FR 50 FT } 160 \mathrm{~s} \\
\text { Tandem FR 50 FT } 320 \mathrm{~s}\end{array}$ & $\begin{array}{l}1.92 \\
1.88 \\
1.69 \\
1.36 \\
1.06 \\
0.68 \\
0.46 \\
0.25 \\
0.14\end{array}$ & $\begin{array}{l}\text { Tandem YI FT } 0.5 \mathrm{~s} \\
\text { Tandem YI FT } 1 \mathrm{~s} \\
\text { Tandem YI FT } 5 \mathrm{~s} \\
\text { Tandem YI FT } 10 \mathrm{~s} \\
\text { Tandem YI FT } 20 \mathrm{~s} \\
\text { Tandem YI FT } 40 \mathrm{~s} \\
\text { Tandem YI FT } 80 \mathrm{~s} \\
\text { Tandem YI FT } 160 \mathrm{~s} \\
\text { Tandem YI FT } 320 \mathrm{~s}\end{array}$ & $\begin{array}{l}1.91 \\
1.84 \\
1.66 \\
1.34 \\
1.04 \\
0.67 \\
0.45 \\
0.25 \\
0.13\end{array}$ \\
\hline & Baseline & FR50 & $\begin{array}{c}2.55 \\
(2.62)\end{array}$ & YI & $\begin{array}{c}2.49 \\
(2.55)\end{array}$ \\
\hline & $\begin{array}{l}\text { Signaled } \\
\text { progressive-fixed } \\
\text { delay }\end{array}$ & $\begin{array}{l}\text { Chained FR } 50 \text { FT } 0.5 \mathrm{~s} \\
\text { Chained FR 50 FT } 1 \mathrm{~s} \\
\text { Chained FR 50 FT } 5 \mathrm{~s} \\
\text { Chained FR 50 FT } 10 \mathrm{~s} \\
\text { Chained FR 50 FT } 20 \mathrm{~s} \\
\text { Chained FR 50 FT } 40 \mathrm{~s} \\
\text { Chained FR 50 FT } 80 \mathrm{~s} \\
\text { Chained FR 50 FT160 s }\end{array}$ & $\begin{array}{l}2.45 \\
2.60 \\
1.86 \\
1.55 \\
1.00 \\
0.65 \\
0.35 \\
0.25\end{array}$ & $\begin{array}{l}\text { Chained YI FT } 0.5 \mathrm{~s} \\
\text { Chained YI FT } 1 \mathrm{~s} \\
\text { Chained YI FT } 5 \mathrm{~s} \\
\text { Chained YI FT } 10 \mathrm{~s} \\
\text { Chained YI FT } 20 \mathrm{~s} \\
\text { Chained YI FT } 40 \mathrm{~s} \\
\text { Chained YI FT } 80 \mathrm{~s} \\
\text { Chained YI FT } 160 \mathrm{~s}\end{array}$ & $\begin{array}{l}2.37 \\
2.55 \\
1.79 \\
1.51 \\
0.98 \\
0.64 \\
0.34 \\
0.22\end{array}$ \\
\hline & Baseline & FR50 & $\begin{array}{c}2.62 \\
(2.48)\end{array}$ & YI & $\begin{array}{c}2.55 \\
(2.41)\end{array}$ \\
\hline & $\begin{array}{l}\text { Unsignaled } \\
\text { progressive-fixed } \\
\text { delay }\end{array}$ & $\begin{array}{l}\text { Tandem FR 50 FT } 0.5 \mathrm{~s} \\
\text { Tandem FR 50 FT } 1 \mathrm{~s} \\
\text { Tandem FR 50 FT } 5 \mathrm{~s} \\
\text { Tandem FR 50 FT } 10 \mathrm{~s} \\
\text { Tandem FR 50 FT } 20 \mathrm{~s} \\
\text { Tandem FR 50 FT } 40 \mathrm{~s} \\
\text { Tandem FR 50 FT } 80 \mathrm{~s} \\
\text { Tandem FR 50 FT } 160 \mathrm{~s}\end{array}$ & $\begin{array}{l}2.52 \\
2.22 \\
1.97 \\
1.58 \\
1.11 \\
0.65 \\
0.36 \\
0.22\end{array}$ & $\begin{array}{l}\text { Tandem YI FT } 0.5 \mathrm{~s} \\
\text { Tandem YI FT } 1 \mathrm{~s} \\
\text { Tandem YI FT } 5 \mathrm{~s} \\
\text { Tandem YI FT } 10 \mathrm{~s} \\
\text { Tandem YI FT } 20 \mathrm{~s} \\
\text { Tandem YI FT } 40 \mathrm{~s} \\
\text { Tandem YI FT } 80 \mathrm{~s} \\
\text { Tandem YI FT } 160 \mathrm{~s}\end{array}$ & $\begin{array}{l}2.48 \\
2.16 \\
1.92 \\
1.51 \\
1.06 \\
0.63 \\
0.33 \\
0.20\end{array}$ \\
\hline & Baseline & FR50 & $\begin{array}{c}2.51 \\
(2.41)\end{array}$ & YI & $\begin{array}{c}2.42 \\
(2.27)\end{array}$ \\
\hline & $\begin{array}{l}\text { Unsignaled } \\
\text { progressive-fixed } \\
\text { delay }\end{array}$ & $\begin{array}{l}\text { Tandem FR 50 FT } 0.5 \mathrm{~s} \\
\text { Tandem FR 50 FT } 1 \mathrm{~s} \\
\text { Tandem FR 50 FT } 5 \mathrm{~s} \\
\text { Tandem FR 50 FT } 10 \mathrm{~s} \\
\text { Tandem FR 50 FT } 20 \mathrm{~s} \\
\text { Tandem FR 50 FT } 40 \mathrm{~s} \\
\text { Tandem FR 50 FT } 80 \mathrm{~s}\end{array}$ & $\begin{array}{l}2.11 \\
2.34 \\
2.06 \\
1.57 \\
0.85 \\
0.57 \\
0.30\end{array}$ & $\begin{array}{l}\text { Tandem YI FT } 0.5 \mathrm{~s} \\
\text { Tandem YI FT } 1 \mathrm{~s} \\
\text { Tandem YI FT } 5 \mathrm{~s} \\
\text { Tandem YI FT } 10 \mathrm{~s} \\
\text { Tandem YI FT } 20 \mathrm{~s} \\
\text { Tandem YI FT } 40 \mathrm{~s} \\
\text { Tandem YI FT } 80 \mathrm{~s}\end{array}$ & $\begin{array}{l}2.06 \\
2.26 \\
2.00 \\
1.53 \\
0.81 \\
0.51 \\
0.29\end{array}$ \\
\hline & Baseline & FR50 & $\begin{array}{c}2.67 \\
(2.53)\end{array}$ & YI & $\begin{array}{c}2.57 \\
(2.43)\end{array}$ \\
\hline & $\begin{array}{l}\text { Signaled } \\
\text { progressive-fixed } \\
\text { delay }\end{array}$ & $\begin{array}{l}\text { Chained FR 50 FT } 0.5 \mathrm{~s} \\
\text { Chained FR 50 FT } 1 \mathrm{~s} \\
\text { Chained FR 50 FT } 5 \mathrm{~s} \\
\text { Chained FR 50 FT } 10 \mathrm{~s} \\
\text { Chained FR 50 FT } 20 \mathrm{~s} \\
\text { Chained FR 50 FT } 40 \mathrm{~s}\end{array}$ & $\begin{array}{l}2.44 \\
2.41 \\
1.68 \\
1.60 \\
0.99 \\
0.65\end{array}$ & $\begin{array}{l}\text { Chained YI FT } 0.5 \mathrm{~s} \\
\text { Chained YI FT } 1 \mathrm{~s} \\
\text { Chained YI FT } 5 \mathrm{~s} \\
\text { Chained YI FT } 10 \mathrm{~s} \\
\text { Chained YI FT } 20 \mathrm{~s} \\
\text { Chained YI FT } 40 \mathrm{~s}\end{array}$ & $\begin{array}{l}2.40 \\
2.33 \\
1.59 \\
1.56 \\
0.95 \\
0.63\end{array}$ \\
\hline
\end{tabular}




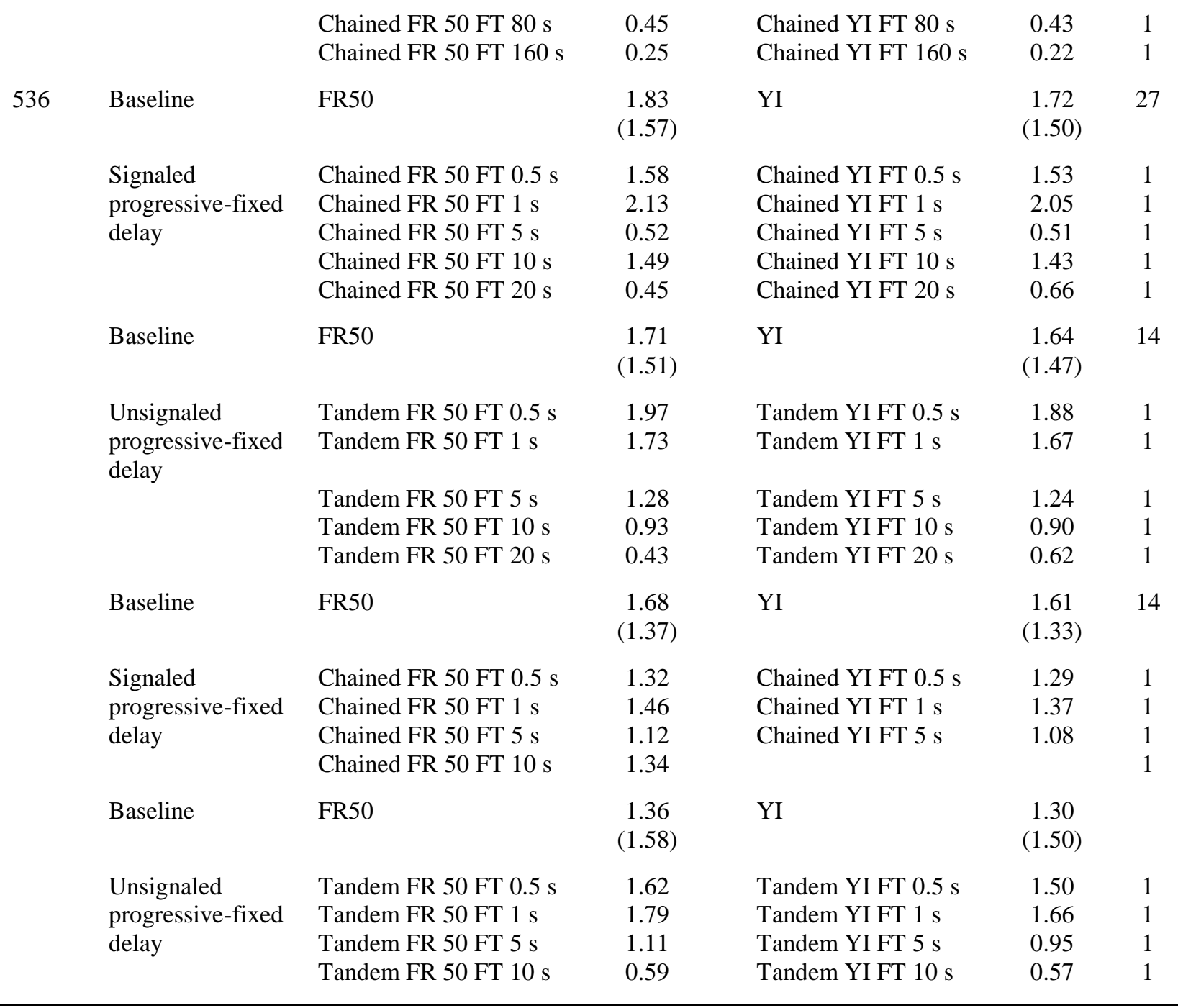

Note. Last six sessions refers to the final six sessions of the baseline condition 
component, a reinforcer would be made available $35 \mathrm{~s}$ into the following YI component. Each baseline condition was in effect for at least 13 days and until overall rates were stable in both components (13-27 sessions, see Table 3). The stability criterion was the same as was used in Experiment 1. During the testing conditions the pigeons were exposed to a progressive fixed delay procedure consisting of an escalating sequence of either blackout-signaled (i.e., multiple chained FR 50 FT x chained YI FT x) or unsignaled (i.e., multiple tandem FR 50 FT x tandem YI FT x) delays. This sequence consisted of 0.5-s, 1-s, 5-s, 10-s, 20-s, 40-s, 80-s, 160-s, 320-s, \& 640-s delays presented across successive sessions. Delay durations across successive sessions according to this progression until a test session was terminated due to a pause of $300 \mathrm{~s}$. At that point baseline was reinstated. The alternating delay testing and baseline immediate reinforcement sessions continued through two exposures to the signaled delay and three exposures to the unsignaled delay conditions.

\section{Results}

Because data from interval schedules typically are analyzed as overall response rates (e.g., Pierce et al., 1972; Sizemore \& Lattal, 1978; Richards, 1981; Williams, 1976), overall rates were analyzed here. Figure 9 shows the final session from each baseline condition and responding at each delay type and duration during the FR (left graphs) and YI (right graphs) components. The highest response rates occurred during the baseline conditions. During the delay conditions, response rates were higher in FR than in YI. During both signaled (labeled S) and unsignaled delay conditions (labeled $U$ ), overall rates systematically decreased in both components as the delays increased. 
FR

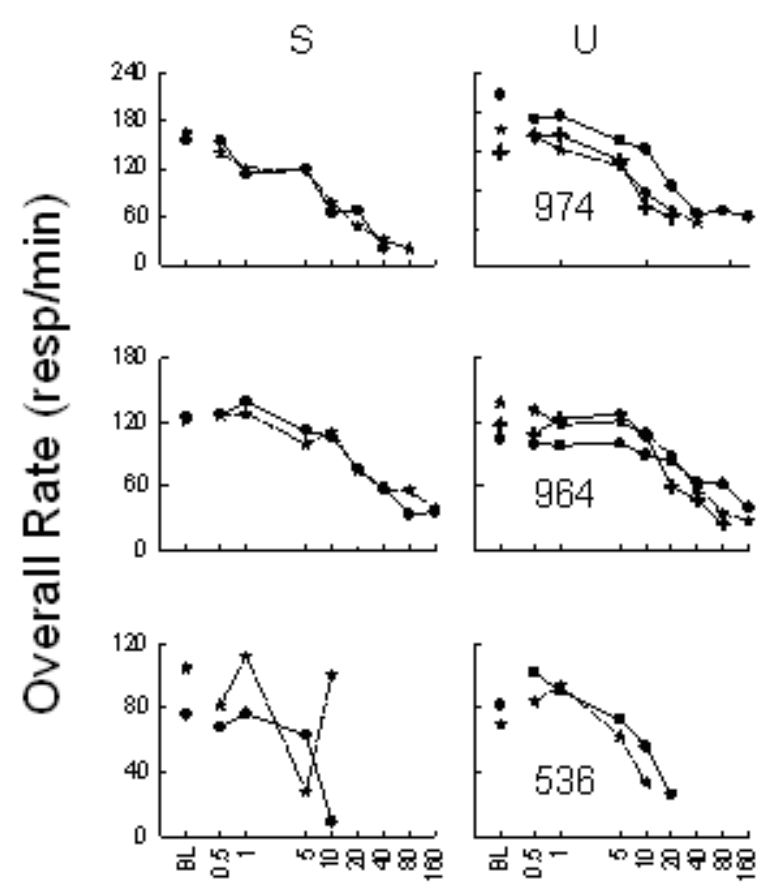

YI
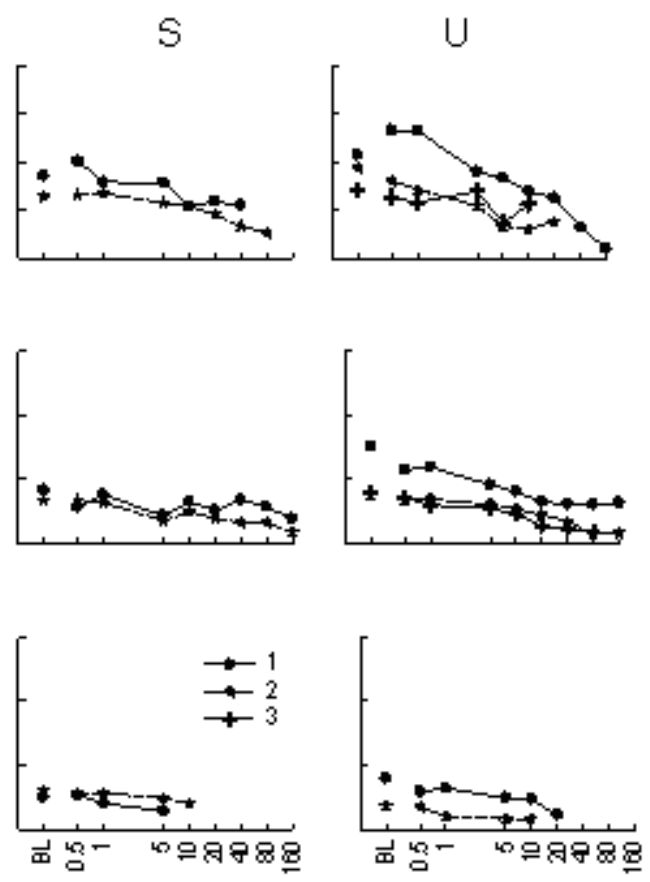

Delay (s)

Figure 9. Session-by-session data from Experiment 3. Overall rates during FR components (left two columns) and YI components (right two columns) during the final session of each baseline conditions and at each delay duration (x-axis) during the signaled (columns labeled $\mathrm{S}$ ) and unsignaled (columns labeled U) progressive-fixed-delay conditions for 974 (top row) 964 (middle row) and 536 (bottom row). Data from the first (circles) second (stars) and third (crosses) sets of delay are shown separately. 

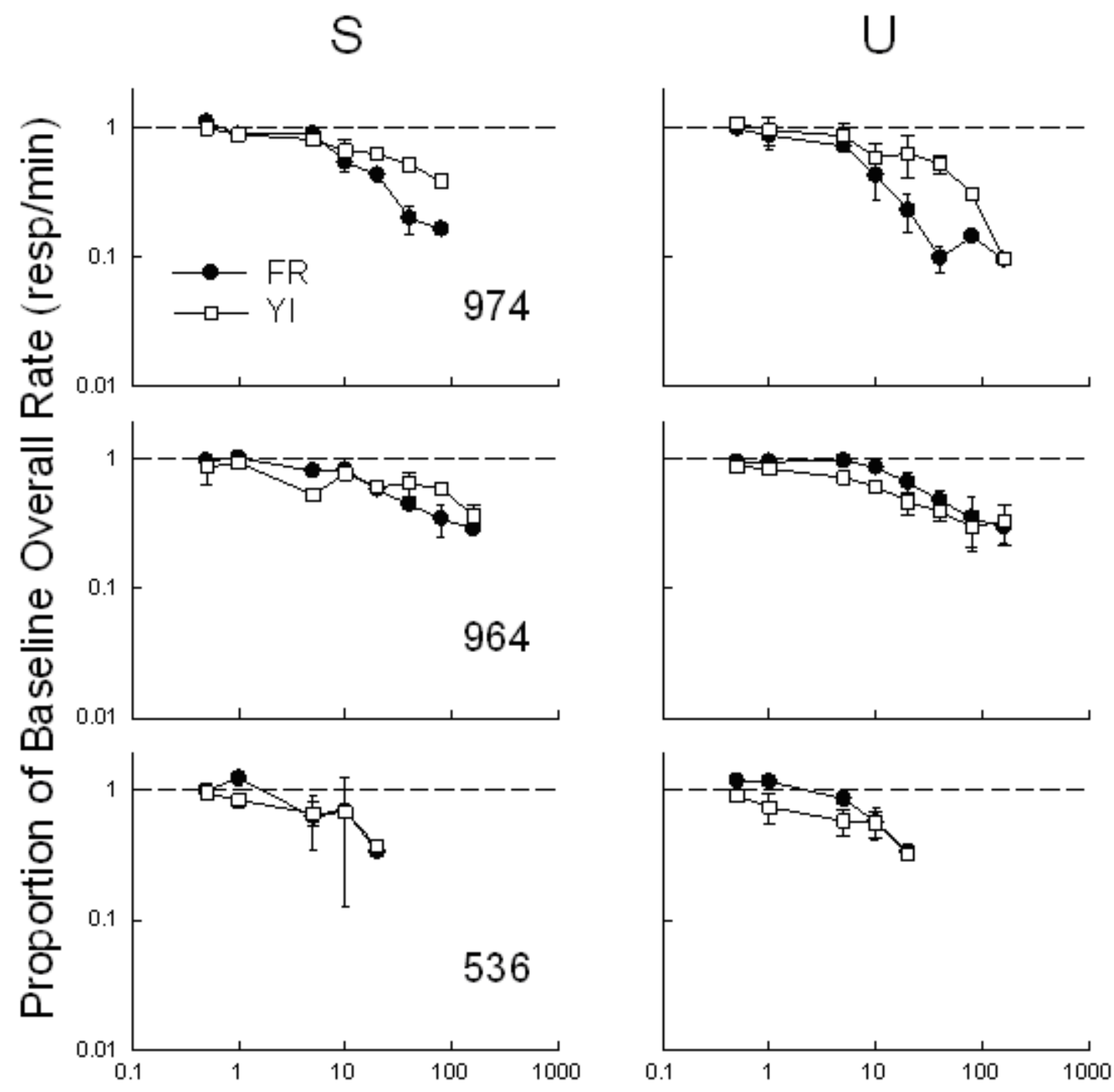

\section{Delay (s)}

Figure 10. Proportion-of-baseline data from Experiment 3. Proportion of baseline overall rates during the signaled (left column) and unsignaled (right column) progressive-fixed-delay conditions during the FR (closed circles) and YI (closed squares) components for 974 (top row), 964 (middle row) and 536 (bottom row). Error bars show one standard deviation. 
FR

S
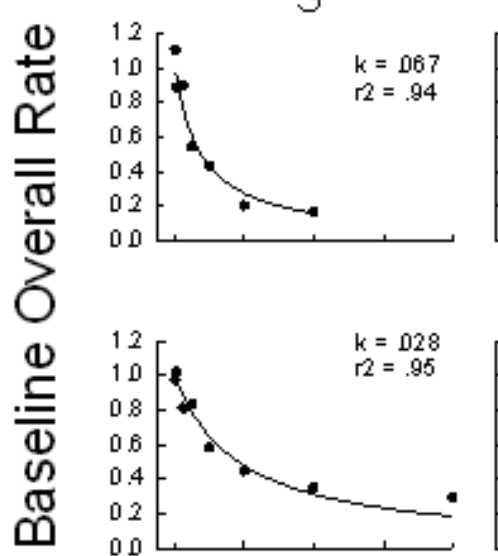

4

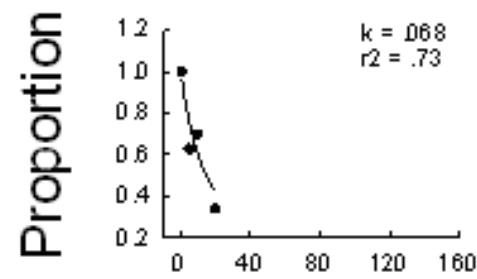

U
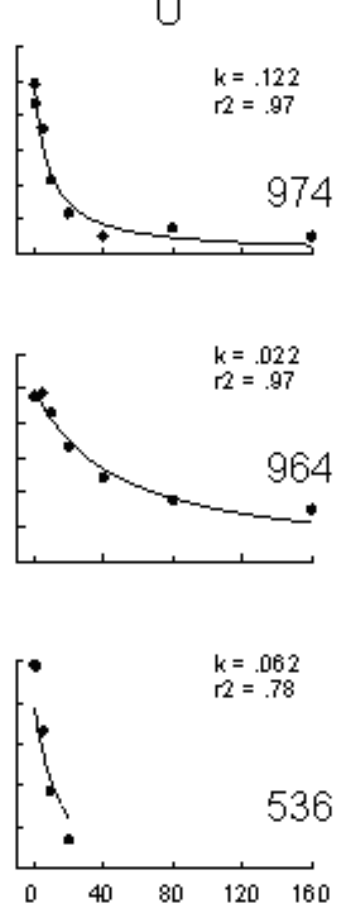

YI
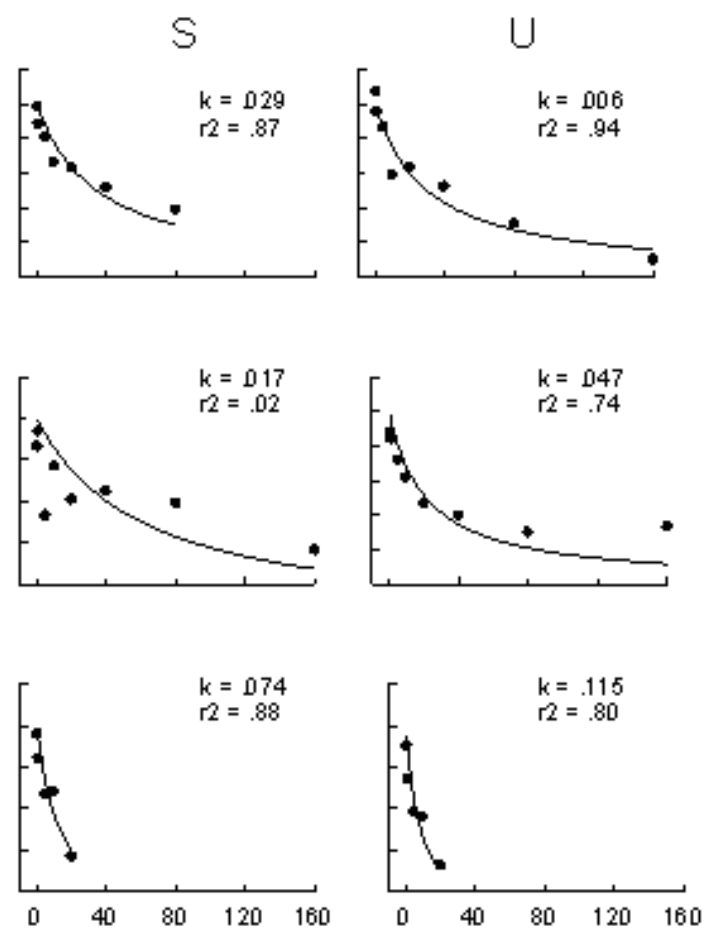

\section{Delay (s)}

Figure 11. Hyperbolic-discounting data from Experiment 3. Proportion of baseline overall rate during the FR (left columns) and YI (right column) components at each delay duration (x-axis) during the increasing signaled (columns labeled S) and unsignaled (columns labeled U) progressive-fixed-delay conditions for 974 (top row), 964 (middle row) and 536 (bottom row). The lines show the fit of Equation 2 to the data with the fitted parameter $k$ and the $\mathrm{r}^{2}$ value shown in each graph. 
The rates of reinforcement during the FR and YI components are shown in Table 3. The rates of reinforcement were nearly equal across these components. The rates of reinforcement, however, were slightly higher in the FR relative to the YI components.

Figure 10 compares the proportion-of-baseline overall rates from the signaled (left graphs) and unsignaled (right graphs) delays when responding was maintained by FR and YI schedules. These proportions were calculated as they were in Experiment 1. Although the proportion of baseline overall response rate consistently decreased as delay durations increased, delays did not differentially interact with interval and ratio schedules and no consistent effect of signaled versus unsignaled delay was obtained.

Figure 11 shows the relation between proportion-of-baseline overall response rate and delay duration during the FR (left graphs) and YI (right graphs) components. As in Figures 4 and 7, Equation 2 was fit to the data. It provided an adequate fit $\left(r^{2}=0.80\right.$ or higher) for eight of the 12 datasets and a moderate fit (i.e., $\left.\mathrm{r}^{2}=0.70-0.79\right)$ for an additional three datasets. The equation therefore provided at least a moderate fit for 11 of the 12 data sets. Like Experiments $1-2, k$ did not systematically differ in the signaled versus unsignaled delay conditions. Furthermore, $k$ values were similar when delays were imposed on FR or YI schedules. 


\section{Discussion}

The results of Experiment 3 were consistent with those of the first two experiments. A negative relation between delay duration and overall response rate was obtained, but there was no systematic difference in either overall response or discounting rate between signaled and unsignaled delays at any delay duration. Furthermore, the YI delay-of-reinforcement gradients were similar to the FR gradients, and the hyperbolic equation provided at least a moderate fit for most of the data. This finding has two implications. First, although the baseline rates of responding were consistent with those from previous comparisons of FR and YI schedules (e.g., Bauman, 1991), FR and YI responding was affected similarly by delays of reinforcement. Second, the utility of the PFD procedure used in the first two experiments is not restricted to FR schedules. This procedure therefore may be useful in comparing delay-of-reinforcement effects across other schedules of reinforcement.

The YIs used in the present experiment, however, limit the comparisons between the present findings and those of previous studies using VI schedules. Because FR schedules yield relatively consistent IRIs, the YI component may have been more similar to an FI than a VI schedule. Because the literature examining delay-of-reinforcement effects on FI schedules is limited (e.g., Dews, 1969; Elcoro \& Lattal., unpublished manuscript; Jarmolowicz \& Lattal, 2009), it is difficult to relate these findings to previous findings. The similarity of effects across the FR and YI components, however, suggest that delay-of-reinforcement effects may not be different on interval and ratio schedules.

\section{Experiment 4}

Experiments 1-3 have focused on effects of delays of reinforcement on behavior maintained by FR-50 schedules. It is, however, possible that delays may impact responding 
differently at different ratio requirements. This represents a parametric limitation of the current studies. The fourth experiment addresses this limitation by examining effects of three different delay durations on responding maintained across a range of FR requirements.

Method

Subjects

The three White Carneau pigeons used in Experiment 1 were used in Experiment 4. They were maintained as described in Experiment 1.

\section{Apparatus}

The apparatus was as described in Experiment 1.

\section{Procedure}

Because the pigeons had histories of responding on FR schedules, the pigeons were exposed immediately to several sessions of an FR-50 schedule. Sessions occurred 6-7 days a week at approximately the same time each day and ended after either 60 (40 for Pigeon 536) reinforcers were delivered or when 300 s lapsed without a key peck, whichever came first. During the experiment, blocks of baseline and test sessions alternated. The order of conditions and the reinforcement rate during each session is shown in Table 4. During baseline sessions, responding on a progressive-fixed-ratio (PFR; Jarmolowicz \& Lattal, 2010) schedule resulted in the immediate delivery of 3-s (2.5-s for Pigeon 536) access to grain. On this PFR schedule, the ratio requirement increased through a sequence of FR 10, FR 50, FR 100, FR 200, FR 400, and FR 800 across successive sessions. The ratio requirement increased according to this progression, across sessions, until a session ended due to a $300 \mathrm{~s}$ pause (This sequence of ratio requirements will hereafter be referred to as a set). After each PFR set, a single FR-50 session was conducted before the next set was initiated. These baseline PFR sets were repeated three 
Table 4 Order of sessions and reinforcement rate during Experiment 4

\begin{tabular}{|c|c|c|c|c|}
\hline Pigeon & Condition & $\begin{array}{l}\text { Progressive-Fixed-Ratio Set } 1 \\
\text { Schedule (reinforcement rate) }\end{array}$ & $\begin{array}{l}\text { Progressive-Fixed-Ratio Set } 2 \\
\text { Schedule (reinforcement rate) }\end{array}$ & $\begin{array}{l}\text { Progressive-Fixed-Ratio Set } 3 \\
\text { Schedule (reinforcement rate) } \\
\end{array}$ \\
\hline \multirow[t]{31}{*}{974} & Baseline & FR 10 (10.95) & FR 10 (14.77) & FR 10 (16.09) \\
\hline & & FR 50 (3.64) & FR 50 (3.44) & FR 50 (3.80) \\
\hline & & FR 100 (1.94) & FR $100(1.52)$ & FR 100 (1.62) \\
\hline & & FR $200(0.72)$ & FR $200(0.49)$ & FR $200(0.44)$ \\
\hline & & FR $400(0.24)$ & FR $400(0.18)$ & \\
\hline & 1-s Signaled & Chained FR 10 FT 1-s (10.95) & Chained FR 10 FT 1-s (11.60) & Chained FR 10 FT 1-s (10.82) \\
\hline & & Chained FR 50 FT 1-s (2.54) & Chained FR 50 FT 1-s (3.20) & Chained FR 50 FT 1-s (3.29) \\
\hline & & Chained FR 100 FT 1-s $(0.85)$ & Chained FR 100 FT 1 -s (1.59) & Chained FR 100 FT 1-s (1.46) \\
\hline & & Chained FR 200 FT 1 -s $(0.57)$ & Chained FR 200 FT 1 -s $(0.66)$ & Chained FR 200 FT 1 -s $(0.92)$ \\
\hline & & Chained FR 400 FT 1 -s $(0.22)$ & Chained FR 400 FT 1 -s $(0.19)$ & Chained FR 400 FT 1-s (0.27) \\
\hline & Baseline & FR 10 (16.72) & FR 10 (19.19) & FR 10 (18.59) \\
\hline & & FR $50(3.90)$ & FR 50 (4.04) & FR 50 (3.62) \\
\hline & & FR $100(1.85)$ & FR $100(2.00)$ & FR 100 (1.79) \\
\hline & & FR $200(0.83)$ & FR $200(0.84)$ & FR $200(1.00)$ \\
\hline & & FR $400(0.28)$ & FR $400(0.28)$ & FR $400(0.28)$ \\
\hline & 1-s Unsignaled & Tandem FR 10 FT 1-s (11.89) & Tandem FR 10 FT 1-s (14.66) & Tandem FR 10 FT 1-s (13.24) \\
\hline & & Tandem FR 50 FT 1 -s $(3.55)$ & Tandem FR 50 FT 1-s (3.89) & Tandem FR 50 FT 1-s (3.46) \\
\hline & & Tandem FR 100 FT 1-s (2.02) & Tandem FR 100 FT 1-s (2.03) & Tandem FR 100 FT 1-s (1.96) \\
\hline & & Tandem FR 200 FT 1 -s $(0.93)$ & Tandem FR 200 FT 1 -s (0.92) & Tandem FR 200 FT 1 -s (0.91) \\
\hline & & Tandem FR 400 FT 1-s (0.26) & Tandem FR 400 FT 1-s (0.24) & Tandem FR 400 FT 1-s (0.34) \\
\hline & & & Tandem FR 800 FT 1-s (0.17) & \\
\hline & Baseline & FR $10(21.81)$ & FR $10(20.58)$ & FR 10 (19.64) \\
\hline & & FR $50(3.77)$ & FR 50 (3.52) & FR 50 (3.51) \\
\hline & & FR $100(2.13)$ & FR $100(1.78)$ & FR $100(1.68)$ \\
\hline & & FR $200(0.90)$ & FR $200(1.01)$ & FR $200(1.10)$ \\
\hline & & FR $400(0.29)$ & FR $400(0.22)$ & FR $400(0.26)$ \\
\hline & 10-s Signaled & Chained FR 10 FT 10-s (2.56) & Chained FR 10 FT 10-s (2.90) & Chained FR 10 FT 10-s (2.92) \\
\hline & & Chained FR 50 FT 10-s (1.65) & Chained FR 50 FT 10-s (1.53) & Chained FR 50 FT 10-s (1.41) \\
\hline & & Chained FR 100 FT 10-s (1.17) & Chained FR 100 FT 10-s $(0.91)$ & Chained FR 100 FT $10-\mathrm{s}(0.89)$ \\
\hline & & Chained FR 200 FT 10 -s $(0.27)$ & Chained FR 200 FT $10-\mathrm{s}^{\mathrm{a}}$ & Chained FR 200 FT $10-\mathrm{s}(0.50)$ \\
\hline & & & Chained FR 400 FT 10-s (0.23) & Chained FR 400 FT 10-s (0.11) \\
\hline
\end{tabular}


Baseline

FR $10(18.39)$

FR $50(3.34)$

FR $100(1.97)$

FR $200(0.69)$

FR $400(0.23)$

10-s Unsignaled Tandem FR 10 FT 10-s (2.66) Tandem FR 50 FT 10-s (1.65)

Tandem FR 100 FT 10-s (0.96)

Tandem FR 200 FT 10-s (0.40)

Baseline

FR 10 (18.01)

FR $50(2.77)$

FR $100(1.40)$

FR $200(0.37)$

20-s Signaled

Chained FR 10 FT 20-s (1.61) Chained FR 50 FT 20-s (0.72)

Chained FR 100 FT 20-s (0.40)

Baseline

FR 10 (19.19)

FR 50 (3.24)

FR $100(1.48)$

FR $200(0.44)$

20-s Unsignaled Tandem FR 10 FT 20-s (1.18) Tandem FR 50 FT 20-s (0.42)

Baseline

FR $10(6.61)$

FR $50(2.73)$

FR $100(1.50)$

FR $200(0.53)$

FR $400(0.24)$

1-s Unsignaled Tandem FR 10 FT 1-s (7.13)

Tandem FR 50 FT 1-s (2.31)

Tandem FR 100 FT 1-s (1.14)

Tandem FR 200 FT 1-s (0.38)

Tandem FR 400 FT 1-s (0.18)

Baseline
FR $10(21.90)$

FR $50(3.74)$

FR 100 (2.02)

FR $200(0.93)$

FR $400(0.26)$

Tandem FR 10 FT 10-s (2.56)

Tandem FR 50 FT 10-s (1.58)

Tandem FR 100 FT 10-s (0.88)

Tandem FR 200 FT 10-s (0.37)

FR 10 (18.68)

FR 50 (3.06)

FR 100 (1.33)

FR $200(0.33)$

Chained FR 10 FT 20-s (1.29)

Chained FR 50 FT 20-s (0.74)

Chained FR 100 FT 20-s (0.32)

FR 10 (19.11)

FR 50 (2.85)

FR $100(1.20)$

FR $200(0.85)$

FR 400 (0.16)

Tandem FR 10 FT 20-s (1.46) Tandem FR 50 FT 20-s (0.59)

FR 10 (7.64)

FR 50 (2.42)

FR $100(1.16)$

FR $200(0.56)$

FR $400(0.20)$

Tandem FR 10 FT 1-s (8.29)

Tandem FR 50 FT 1-s (2.17)

Tandem FR 100 FT 1-s (1.01)

Tandem FR 200 FT 1-s (0.44)

Tandem FR 400 FT 1-s (0.21)

FR 10 (10.01)

FR 50 (2.51)
FR 10 (21.85)

FR 50 (3.36)

FR 100 (1.58)

FR 200 (0.89)

FR $400(0.23)$

Tandem FR 10 FT 10-s (2.73)

Tandem FR 50 FT 10-s (1.38)

Tandem FR 100 FT 10-s (0.43)

FR 10 (22.06)

FR 50 (2.74)

FR 100 (1.31)

FR 200 (0.42)

Chained FR 10 FT 20-s (1.45)

Chained FR 50 FT 20-s (0.88)

Chained FR 100 FT 20-s (0.29)

FR 10 (20.45)

FR 50 (3.08)

FR 100 (1.66)

FR 200 (0.46)

Tandem FR 10 FT 20-s (1.20)

Tandem FR 50 FT 20-s (0.36)

FR $10(9.44)$

FR 50 (2.24)

FR 100 (1.04)

FR 200 (0.48)

FR $400(0.23)$

Tandem FR 10 FT 1-s (8.10)

Tandem FR 50 FT 1-s (2.13)

Tandem FR 100 FT 1-s (1.09)

Tandem FR 200 FT 1-s (0.33)

Tandem FR 400 FT 1-s (0.19)

FR $10(9.61)$

FR 50 (2.63) 
FR $100(1.17)$

FR $200(0.39)$

1-s Signaled

Chained FR 10 FT 1-s (10.27)

Chained FR 50 FT 1-s (2.63)

Chained FR 100 FT 1-s (1.32)

Chained FR 200 FT 1-s (0.46)

Baseline

FR 10 (11.30)

FR $50(2.63)$

FR $100(1.35)$

FR $200(0.43)$

FR $400(0.10)$

10-s Unsignaled Tandem FR 10 FT 10-s (3.30) Tandem FR 50 FT 10-s (1.71)

Tandem FR 100 FT 10-s (0.73)

Tandem FR 200 FT 10-s (0.19)

Baseline

FR $10(10.52)$

FR $50(2.50)$

FR $100(1.20)$

FR $200(0.26)$

10-s Signaled Chained FR 10 FT 10-s (3.50)

Chained FR 50 FT 10-s (1.38)

Chained FR 100 FT 10-s (0.69)

Chained FR 200 FT 10-s (0.26)

Baseline

FR $10(11.25)$

FR $50(2.64)$

FR $100(0.91)$

FR $200(0.30)$

20-s Unsignaled Tandem FR 10 FT 20-s (1.87) Tandem FR 50 FT 20-s ( 0.89$)$

Tandem FR 100 FT 20-s (0.43)

Tandem FR 200 FT 20-s (0.13)

Baseline

FR $10(11.84)$
FR 100 (1.17)

FR $200(0.41)$

FR $400(0.16)$

Chained FR 10 FT 1-s (8.42)

Chained FR 50 FT 1-s (2.36)

Chained FR 100 FT 1-s (1.21)

Chained FR 200 FT 1-s (0.42)

Chained FR 400 FT 1-s (0.14)

FR 10 (11.89)

FR 50 (2.29)

FR 100 (1.11)

FR 200 (0.38)

Tandem FR 10 FT 10-s (3.19)

Tandem FR 50 FT 10-s (1.40)

Tandem FR 100 FT 10-s (0.73)

Tandem FR 200 FT 10-s (0.17)

FR $10(9.66)$

FR 50 (2.27)

FR 100 (1.05)

FR 200 (0.34)

Chained FR 10 FT 10-s (3.39)

Chained FR 50 FT 10-s (1.21)

Chained FR 100 FT 10-s (0.40)

FR 10 (11.92)

FR $50(2.40)$

FR 100 (1.33)

FR 200 (1.33)

Tandem FR 10 FT 20-s (1.90)

Tandem FR 50 FT 20-s (0.93)

Tandem FR 100 FT 20-s (0.47)

Tandem FR 200 FT 20-s (0.14)

FR 10 (10.90)
FR 100 (1.13)

FR $200(0.40)$

FR $400(0.15)$

Chained FR 10 FT 1-s (8.01)

Chained FR 50 FT 1-s (2.33)

Chained FR 100 FT 1-s (0.93)

Chained FR 200 FT 1-s (0.31)

FR 10 (10.30)

FR $50(2.60)$

FR 100 (1.29)

FR 200 (0.36)

Tandem FR 10 FT 10-s (3.02)

Tandem FR 50 FT 10-s (1.47)

Tandem FR 100 FT 10-s (0.68)

Tandem FR 200 FT 10-s (0.29)

FR 10 (11.32)

FR 50 (2.79)

FR 100 (1.44)

FR $200(0.45)$

FR 400 (0.17)

Chained FR 10 FT 10-s (3.22)

Chained FR 50 FT 10-s (0.88)

Chained FR 100 FT 10-s (0.42)

Chained FR 200 FT 10-s (0.18)

FR 10 (12.62)

FR 50 (2.67)

FR $100(1.22)$

FR 200 (0.29)

Tandem FR 10 FT 20-s (1.89)

Tandem FR 50 FT 20-s (0.66)

Tandem FR 100 FT 20-s (0.26)

Tandem FR 200 FT 20-s (0.21)

FR 10 (10.81) 
FR 50 (2.64)

FR $100(0.83)$

FR $200(0.30)$

20-s Signaled

Chained FR 10 FT 20-s (1.84) Chained FR 50 FT 20-s (1.05)

Chained FR 100 FT 20-s (0.57)

Chained FR 200 FT 20-s (0.21)

Baseline

FR $10(17.88)$

FR $50(5.15)$

FR $100(1.52)$

FR $200(0.43)$

1-s Unsignaled Tandem FR 10 FT 1-s (12.42) Tandem FR 50 FT 1-s (2.53)

Tandem FR 100 FT 1-s (1.24)

Tandem FR 200 FT 1-s (0.39)

Baseline

FR $10(19.60)$

FR 50 (4.70)

FR $100(1.40)$

FR $200(0.36)$

1-s Signaled Chained FR 10 FT 1-s (13.45) Chained FR 50 FT 1-s (2.74)

Chained FR 100 FT 1-s (1.12)

Chained FR 200 FT 1-s (0.47)

Baseline

FR 10 (13.71)

FR 50 (3.39)

FR 100 (1.49)

FR $200(0.32)$

10-s Unsignaled Tandem FR 10 FT 10-s (2.57) Tandem FR 50 FT 10-s (0.37)

Baseline

FR $10(15.45)$

FR 50 (3.55)

FR $100(1.40)$

FR $200(0.29)$

10-s Signaled
FR 50 (2.63)

FR 100 (1.38)

FR 200 (0.36)

Chained FR 10 FT 20-s (1.91)

Chained FR 50 FT 20-s (1.05)

Chained FR 100 FT 20-s (0.51)

FR 10 (23.06)

FR 50 (5.06)

FR 100 (2.06)

FR 200 (0.32)

Tandem FR 10 FT 1-s (12.86)

Tandem FR 50 FT 1-s (3.20)

Tandem FR 100 FT 1-s (1.19)

Tandem FR 200 FT 1-s (0.34)

FR 10 (19.55)

FR 50 (4.54)

FR 100 (1.38)

FR 200 (0.31)

Chained FR 10 FT 1-s (14.31)

Chained FR 50 FT 1-s (3.43)

Chained FR 100 FT 1-s (1.30)

Chained FR 200 FT 1-s (0.33)

\section{FR 10 (15.06)}

FR 50 (3.56)

FR 100 (1.31)

FR 200(0.34)

Tandem FR 10 FT 10-s (2.26)

Tandem FR 50 FT 10-s (0.27)

FR 10 (12.54)

FR 50 (3.16)

FR 100 (1.08)

FR $200(0.27)$

Chained FR 10 FT 10-s (2.77)
FR 50 (2.94)

FR 100 (1.67)

FR 200 (0.39)

Chained FR 10 FT 20-s (2.04)

Chained FR 50 FT 20-s (1.12)

Chained FR 100 FT 20-s (0.46)

FR 10 (19.22)

FR 50 (4.15)

FR 100 (0.87)

FR $200(0.21)$

Tandem FR 10 FT 1-s (13.20)

Tandem FR 50 FT 1-s (3.31)

Tandem FR 100 FT 1-s (0.87)

Tandem FR 200 FT 1-s (0.23)

FR 10 (22.08)

FR 50 (4.79)

FR 100 (0.49)

Chained FR 10 FT 1-s (11.94)

Chained FR 50 FT 1-s (3.30)

Chained FR 100 FT 1-s (1.25)

Chained FR 200 FT 1-s (0.04)

FR 10 (15.60)

FR 50 (2.81)

FR 100 (1.80)

FR 200(0.36)

Tandem FR 10 FT 10-s (2.17)

Tandem FR 50 FT 10-s (0.31)

FR 10 (12.86)

FR 50 (3.31)

FR 100 (1.27)

FR 200 (0.30)

Chained FR 10 FT 10-s (2.47) 
Chained FR 50 FT 10-s (1.29)

Chained FR 100 FT 10-s (0.85)

Chained FR 200 FT 10-s $(0.25)$

Baseline

FR $10(10.73)$

FR 50 (3.59)

FR $100(1.58)$

FR $200(0.42)$

20-s Unsignaled Tandem FR 10 FT 20-s (1.17)

Tandem FR 50 FT 20-s (0.28)

Baseline

FR 10 (9.05)

FR 50 (3.12)

FR $100(1.00)$

FR $200(0.29)$

10-s Signaled Chained FR 10 FT 10-s (1.77)

Chained FR 50 FT 10-s (1.04)

Chained FR 100 FT 10-s (0.31)
Chained FR 50 FT 10-s (1.55)

Chained FR 100 FT 10-s $(0.60)$

FR 10 (13.33)

FR 50 (3.53)

FR $100(1.22)$

FR 200 (0.32)

Tandem FR 10 FT 20-s (0.91)

Tandem FR 50 FT 20-s (0.25)

FR 10 (14.11)

FR 50 (3.57)

FR 100 (1.44)

FR $200(0.25)$

Chained FR 10 FT 10-s (1.61)

Chained FR 50 FT 10-s (0.52)
Chained FR 50 FT 10-s (0.70)

FR $10(10.47)$

FR 50 (2.29)

FR $100(0.48)$

Tandem FR 10 FT 20-s (0.25)

FR 10 (13.80)

FR 50 (3.48)

FR 100 (1.27)

FR $200(0.26)$

Chained FR 10 FT 10-s (1.33)

Chained FR 50 FT 10-s (0.71)

Chained FR 100 FT 10-s (0.23)

${ }^{\mathrm{a}}$ Data not available 
times, with a return to FR 50 following each set. The signaled and unsignaled delay conditions were like the baseline condition with the exception of the addition of either signaled FT X-S (blackout-signaled conditions; chained PFR FT) or unsignaled FT x-s (unsignaled conditions; tandem PFR FT) terminal links. As in the baseline condition, a single FR-50 (no delay) session was conducted after each PFR set. Delays were increased across conditions through a sequence of 1-s, 10-s and 20-s delays. Each delay condition was preceded by a baseline condition and both signaled and unsignaled delay conditions were conducted at one delay duration prior to increasing the delay duration. Pigeon 974 always experienced the signaled delays before the unsignaled delays, whereas pigeons 964 and 536 always experienced the unsignaled delays prior to the signaled delays (see Table 4 for details).

\section{Results}

Figures 12, 13, and 14 show the mean run rate, overall rate, and PRP (respectively) at all FR requirements and at all delay durations for immediate reinforcement and signaled and unsignaled delay conditions. Data points from the delay conditions show data at a particular ratio requirement averaged across all three sets of the PFR at that delay. Data points for the baseline conditions represent the mean at each ratio across all six PFR sets. If a particular ratio was not conducted during a PFR set (i.e., the pigeon did not complete the session at a lower ratio requirement) the data are only from the sessions that were conducted (i.e., an average of fewer than three delay sessions or fewer than six baseline sessions; see Table 4 for details). Data for these Figures (i.e., Figures 12-14) include all PFR data recorded. The appendices contain an analysis of the same data that only includes sessions that were completed.

Figure 12 shows the mean run rate at each ratio requirement and at each delay. Response rates decrease as delay durations increased. This relation was most clear for 536, but can also be 


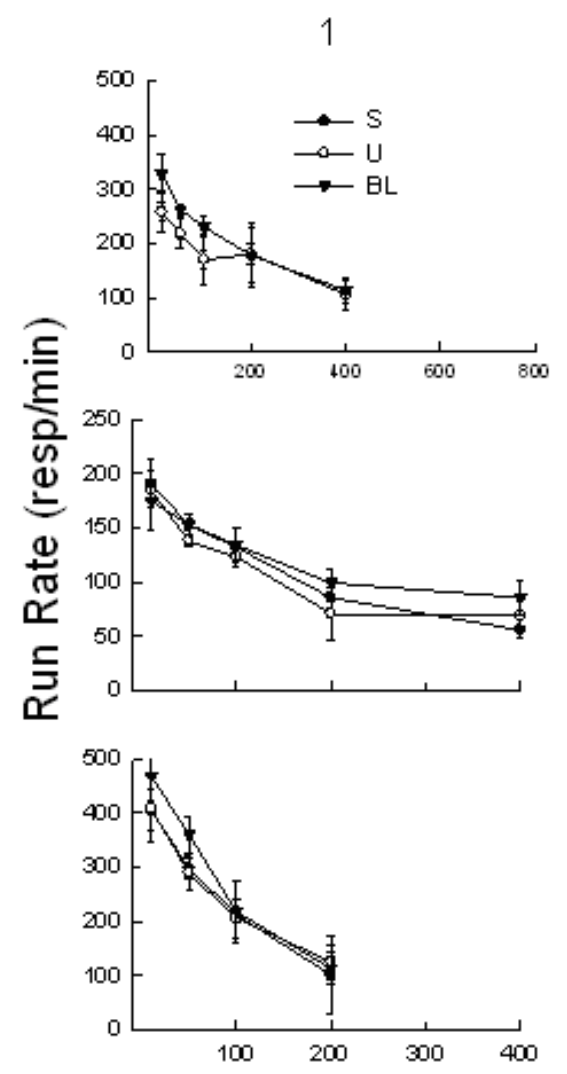

10
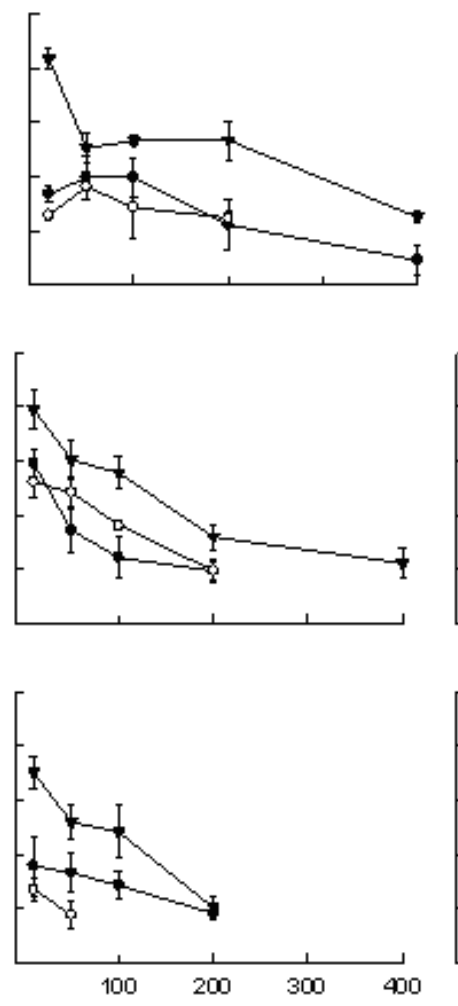

Ratio

20
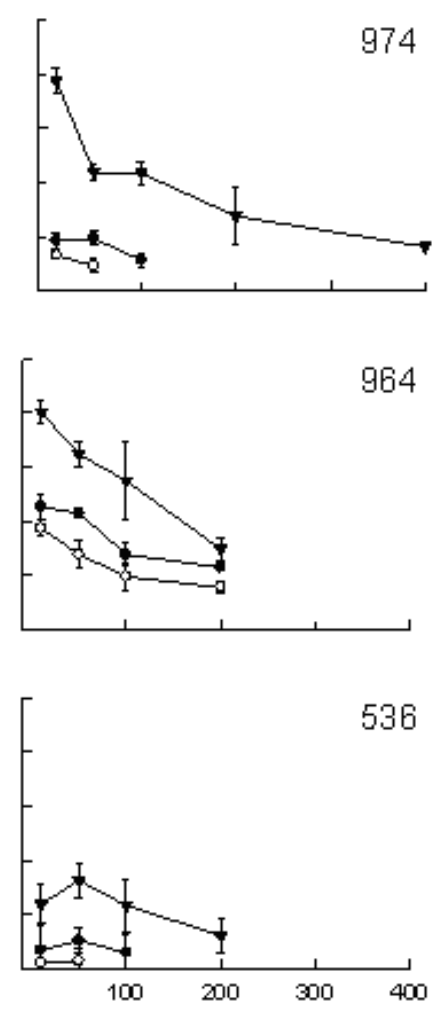

Figure 12. Run rates during Experiment 4. Run rate (y-axis) at each ratio requirement (x-axis) for 974 (top row), 964 (center row), and 536 (bottom row) at the 1-s (left column), 10-s (center column), and 20-s delays (right column). Separate data paths are provided for unsignaled delay (open circles), signaled delay (closed circles), and baseline conditions (closed triangles). Error bars show one standard deviation. 
1

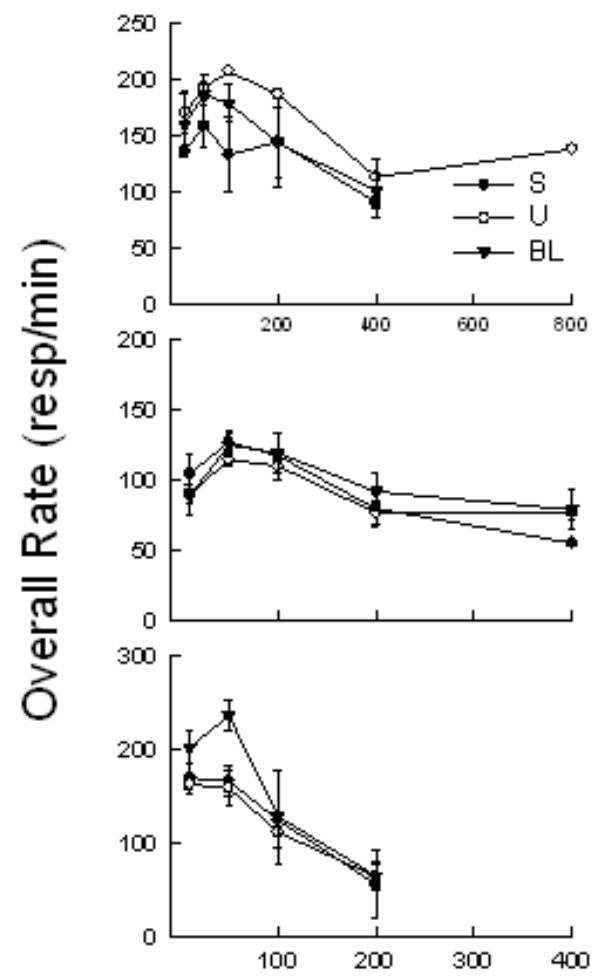

10
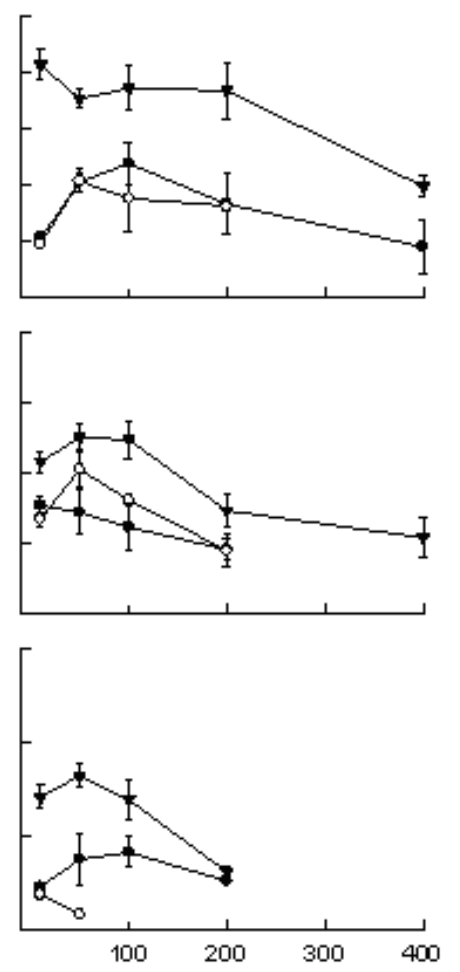

20
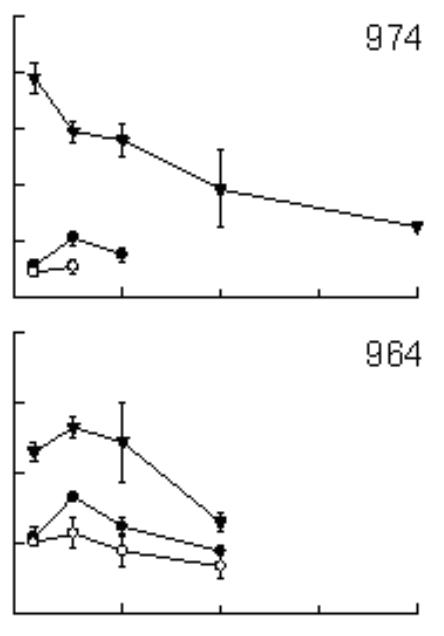

536

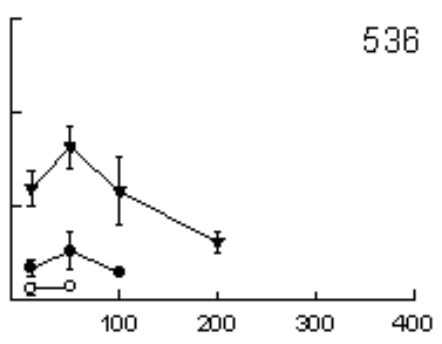

\section{Ratio}

Figure 13. Overall rates during Experiment 4. Overall rate of responding (y-axis) at each ratio requirement (x-axis) for 974 (top row), 964 (center row), and 536 (bottom row) at the 1-s (left column), 10-s (center column), and 20-s delays (right column). Separate data paths are provided for unsignaled delay (open circles), signaled delay (closed circles), and baseline conditions (closed triangles). Error bars show one standard deviation. 

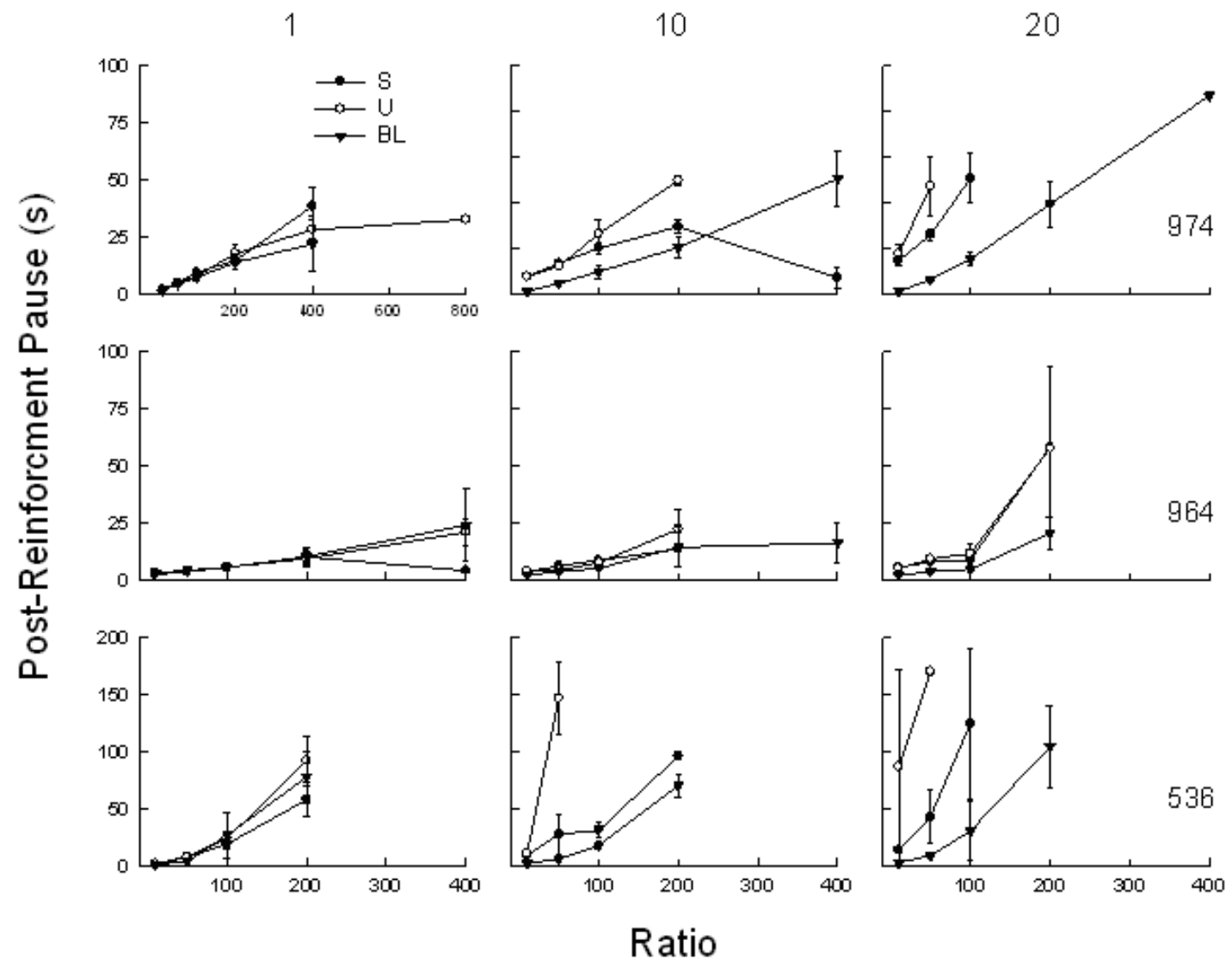

Figure 14. Post-reinforcement pauses during Experiment 4. Post-reinforcement pauses (y-axis) at each ratio requirement (x-axis) for 974 (top row), 964 (center row), and 536 (bottom row) at the 1-s (left column), 10-s (center column), and 20-s delays (right column). Separate data paths are provided for unsignaled delay (open circles), signaled delay (closed circles), and baseline conditions (closed triangles). Error bars show one standard deviation. 
seen with both signaled and unsignaled delays for 974 and with unsignaled delays for 964 . . Unlike the first experiment, run rates were higher in the signaled relative to the unsignaled delay conditions at the longer delay durations (i.e., $20 \mathrm{~s}$ ), but not at the shorter delay durations (i.e., $1 \mathrm{~s}$ $\& 10 \mathrm{~s})$.

Figure 13 shows the mean overall response rate at all FR requirements and delay durations. Overall response rates decreased as the ratio requirement increased and as the delay duration increased. In contrast to the first experiment, overall rates were higher in the signaled, relative to the unsignaled-delay condition at the longer-delay durations (e.g., $20 \mathrm{~s}$ ) for all three pigeons.

Figure 14 shows the mean PRP at all FR requirements at each delay duration. A positive relation between PRP and ratio requirement was obtained during all conditions. Also, there was a generally positive relation between PRP and delay duration. In contrast to the first experiment, PRPs in Experiment 4 were substantially higher in the unsignaled-delay condition, relative to the signaled-delay condition, particularly at the longer-delay durations (e.g., 20 s) for two of the three pigeons.

Table 4 shows mean reinforcement rates in each condition during the experimental sessions. The order of conditions for each pigeon (first column) is shown in the second column. The schedules of reinforcement in effect during each individual session of the three PFR sets are shown for the first (third column), second, (fourth column), and third (fifth column) PFR set of each condition. Reinforcement rates are indicated in parentheses. Reinforcement rates decreased as the ratio requirement increased, and this effect was consistent across each PFR set. Reinforcement rates were also lower during the delay, relative to baseline conditions. 
Table 5. Fitted parameters for delay discounting at each ratio requirement during Experiment 4

\begin{tabular}{|c|c|c|c|c|c|c|c|c|c|c|c|c|}
\hline \multirow[b]{3}{*}{ FR } & \multicolumn{4}{|c|}{974} & \multicolumn{4}{|c|}{964} & \multicolumn{4}{|c|}{536} \\
\hline & \multicolumn{2}{|c|}{$\begin{array}{l}\text { Signaled } \\
\text { Delay }\end{array}$} & \multicolumn{2}{|c|}{$\begin{array}{l}\text { Unsignaled } \\
\text { Delay }\end{array}$} & \multicolumn{2}{|c|}{$\begin{array}{l}\text { Signaled } \\
\text { Delay }\end{array}$} & \multicolumn{2}{|c|}{$\begin{array}{l}\text { Unsignaled } \\
\text { Delay }\end{array}$} & \multicolumn{2}{|c|}{$\begin{array}{c}\text { Signaled } \\
\text { Delay }\end{array}$} & \multicolumn{2}{|c|}{$\begin{array}{l}\text { Unsignaled } \\
\text { Delay }\end{array}$} \\
\hline & $\mathrm{k}$ & $r^{2}$ & $\mathrm{~K}$ & $r^{2}$ & $\mathrm{k}$ & $\mathrm{r}^{2}$ & $\mathrm{~K}$ & $r^{2}$ & $\mathrm{k}$ & $r^{2}$ & $\mathrm{k}$ & $\mathrm{r}^{2}$ \\
\hline 10 & 0.17 & 0.96 & 0.17 & 0.91 & 0.04 & 0.88 & 0.05 & 0.94 & 0.08 & 0.86 & 0.18 & 0.98 \\
\hline 50 & 0.05 & 0.66 & 0.07 & 0.79 & 0.04 & 0.67 & 0.05 & 0.80 & 0.07 & 0.84 & 0.18 & 0.96 \\
\hline 100 & 0.08 & 0.44 & 0.06 & 0.58 & 0.08 & 0.82 & 0.07 & 0.95 & 0.07 & 0.99 & & \\
\hline 200 & 0.12 & 0.91 & 0.07 & 0.40 & 0.03 & 0.00 & 0.06 & 0.00 & 0.07 & 0.99 & & \\
\hline 400 & 0.15 & 0.97 & & & & & & & & & & \\
\hline
\end{tabular}


As in Experiments 1-3, Equation 2 was fit to the proportion-of-baseline response rates at each delay duration for each of the FR requirements used in Experiment 4. The $\mathrm{r}^{2}$ and $k$ values obtained from this analysis are shown in Table 5. The model provided an adequate (i.e., $\mathrm{r}^{2}$ higher than 0.8) fit for 15 of the 23 datasets used in this analysis. Unlike run rates, however, consistent differences in $k$ value were not seen across the signaled versus unsignaled delays, nor was there any consistent relation between $k$ and FR requirement.

The proportional change in run rate from baseline during each of the delay conditions is shown in Figure 15 (note the double logarithmic axes). The data used for the delay conditions and the corresponding baselines to which they are compared are the same as in Figure 12. A generally negative relation between delay duration and proportion of baseline was obtained with a larger decrease in response rate with 20 -s unsignaled relative to signaled delays. No systematic relation (i.e., slope) between ratio requirement and proportion of baseline run rate was obtained. Furthermore, the proportion-of-baseline run rate was higher in the signaled, relative to the unsignaled-delay condition, particularly at the 20-s delay.

The proportion change in PRP from baseline during each of the delay conditions is shown in Figure 16. The data used for the delay conditions and the corresponding baselines to which they are compared are the same as in Figure 14. A generally positive relation between delay duration and proportion of baseline was obtained with a larger increase in PRP with 20-s unsignaled relative to signaled delays. The proportion of baseline was lower at high ratio requirements for 974, but not for 964 or 536. 

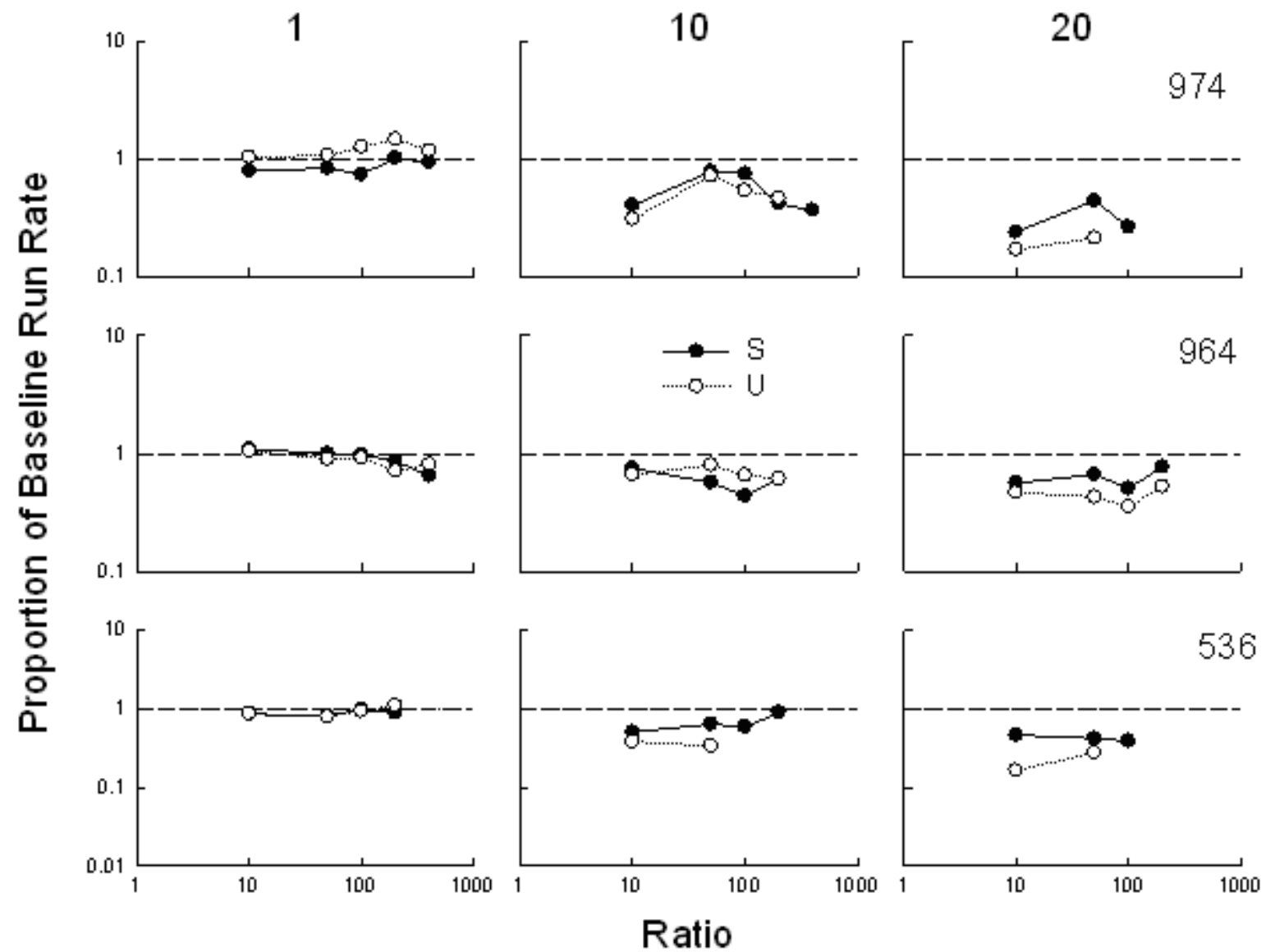

Figure 15. Proportion of baseline run rates from Experiment 4. Proportion of baseline run rate at each ratio requirement during signaled (closed circles) and unsignaled (open circles) delay sessions of Experiment 4 for (974 (top rows), 964 (middle rows) and 536 (bottom rows) during the 1-s (left columns), 10-s (center columns) and 20-s (right columns) delays. 


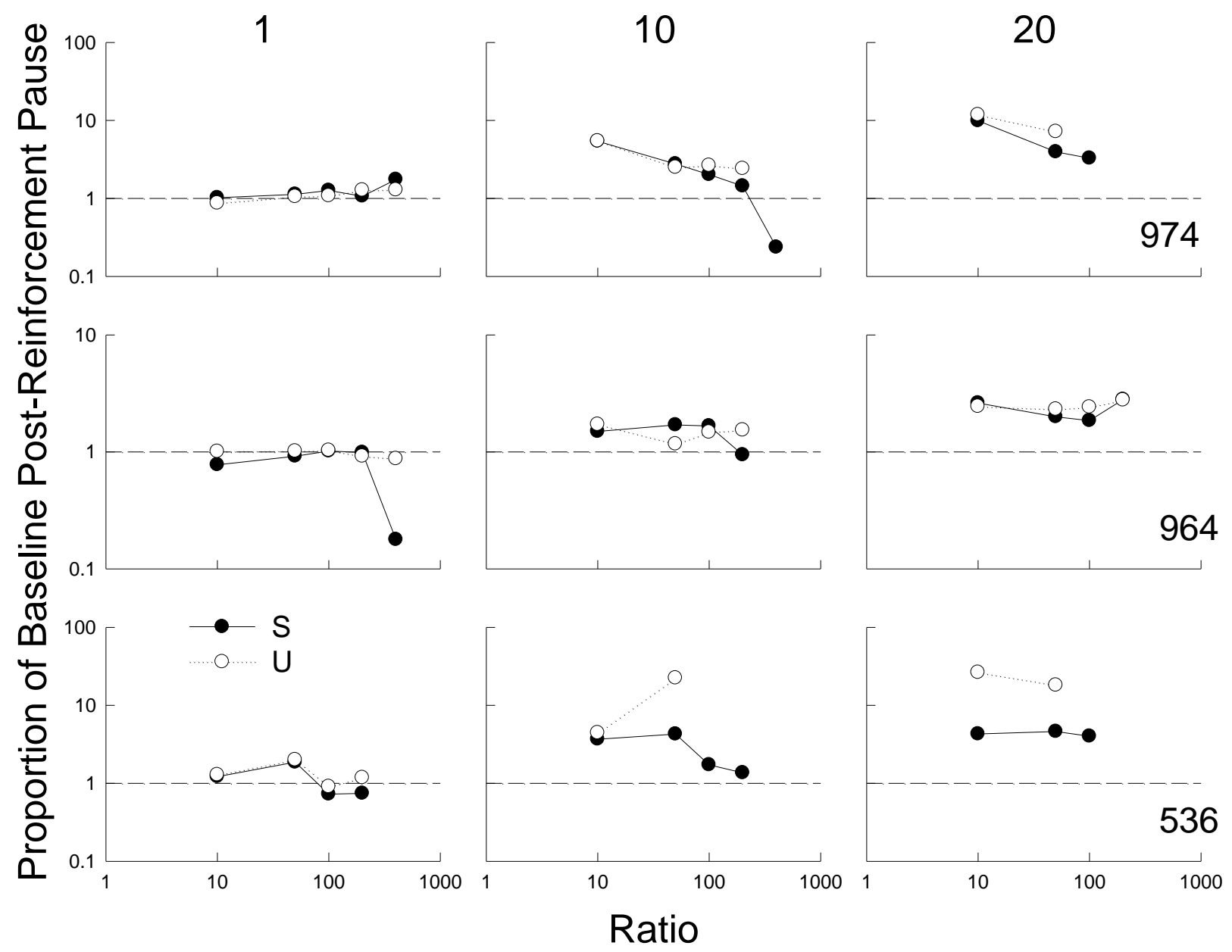

Figure 16. Proportion of baseline post-reinforcement pauses during Experiment 4. Proportion of baseline post-reinforcement pauses at each ratio requirement during signaled (closed circles) and unsignaled (open circles) delay sessions for (974 (top rows), 964 (middle rows) and 536 (bottom rows) during the 1-s (left columns), 10-s (center columns) and 20-s (right columns) delays. 


\section{Discussion}

Three aspects of the data from Experiment 4 are notable. First, like Experiments 1-3 response rates decreased as delays increased (Figures 1, 2, 4-6, 8-11). This is consistent with previous findings from VI schedules (e.g., Reilly and Lattal, 2004; Richards, 1981; Shahan and Lattal, 2005; Sizemore and Lattal, 1978), but not with findings from studies that employed FR baselines (i.e., Meunier \& Ryman, 1974; Morgan, 1972; Topping et al., 1973). Responding during Experiment 4, however, was in many ways consistent with previous experiments using FR schedules. First, PRPs increased as delays increased (Meunier \& Ryman; Morgan; Topping et al.). Second, response rates deceased as FR requirements increased (Bauman, 1991; Felton \& Lyon, 1966; Madden \& Hartman, 2006). And third, PRPs increased as FR requirements increased (Felton \& Lyon, 1966; Powell, 1968).

Like previous analyses of delayed reinforcement (e.g., Reilly and Lattal, 2004; Richards, 1981) response rates were higher with signaled relative to unsignaled delays of reinforcement. This finding, however, is inconsistent with the data from PFD procedure used in Experiments 1-3 (Figures 1, 2, 4-6, 8-11), wherein no consistent difference was observed. This discrepancy between the findings of Experiments 1-3 and Experiment 4 suggests that the failure to demonstrate this relation during Experiments 1-3 may have been due to details of the PFD procedure, rather than the use of an FR baseline. This possibility is discussed further below.

\section{General Discussion}

Because these four experiments both add to the general understanding of and assess novel procedures for the study of delay-of-reinforcement effects, the discussion that follows focuses on the relations between these findings and those of previous delay-of-reinforcement experiments 
with respect to the generality of delay-of-reinforcement effects and the methodological contributions of the present experiments.

\section{Delay-of-reinforcement effects}

Consistent delay-of-reinforcement effects were obtained across all four experiments. These findings generally were consistent those obtained using other schedules. The exception was that, unlike previous studies, response rates during Experiments 1-3 (Figures 1, 5, \& 9) were similar when delays were signaled or unsignaled.

Generality of delay-of-reinforcement effects

Both run and overall response rates decreased as delay duration increased in all four of the present experiments. This relation held for both response rates (Figures 1, 5, 9, 12, \& 13) and proportions of the previous baseline response rates (Figures 2, 4, 6, 8, 10, 11, \& 15). Although these findings seem inconsistent with other delay-of-reinforcement studies using FR baselines, the present findings are consistent with the delay-related decreases in response rates obtained when delays have been imposed on responding maintained by many other schedules.

Previous studies using FR baselines (i.e., Meunier \& Ryman, 1974; Morgan, 1972; Topping et al., 1973), and the present experiments (Figures 1, 5, 14) obtained positive relations between PRPs and delay duration. The three previous studies (i.e., Meunier \& Ryman; Morgan; Topping et al.), however, did not report the negative relation between response rate and delay duration observed in each of the four present experiments. Like previous studies examining other independent variables such as FR requirement (e.g., Felton \& Lyon, 1966; Powell, 1968) or reinforcer magnitude (e.g., Powell, 1969) the previous delay-of-reinforcement studies (i.e., Meunier \& Ryman; Morgan; Topping et al.) concluded that although experimental manipulations have large effects on PRPs, little if any effect on run rates is obtained. Topping et al., however, 
provided no data on response rates and Morgan provided no immediate-reinforcement baseline data to which rates during delay conditions could be compared. Meunier and Ryman provided response-rate data for both baseline and delay conditions, but, in light of the present results, prematurely concluded that delays did not impact run rates. In fact, run rates were lower with delays during five of their six comparisons of delay and control conditions (i.e., condition changes either to or from baseline conditions) yet Meunier and Ryman concluded that delays had no systematic effect on response rates.

Methodological limitations, however, limit the conclusions that can be drawn from the previous studies of delay-of-reinforcement on FR schedules. For example, of the three studies examining delay-of-reinforcement effects on FR schedule-maintained responding (i.e., Meunier \& Ryman, 1974; Morgan, 1972; Topping et al., 1973), only Topping et al. conducted withinsubject replications of the delay conditions. Neither Morgan, or Meunier and Ryman conducted within-subject replications of their delay conditions. Thus, unlike the present studies, which established the reliability of the delay-of-reinforcement effects through extensive within-subject replication, the reliability of Meunier and Ryman and Morgan's findings are untested.

Although most delay-of-reinforcement studies have imposed delays on responding maintained by VI baselines, the present findings provide further evidence of generality of delayof-reinforcement effects. For example, the negative relation between response rate and delay duration appears consistent across VI (e.g., Richards, 1981; Reilly \& Lattal, 2004; Shahan \& Lattal, 2005; Sizemore \& Lattal, 1978; Williams, 1976), FI (Dews, 1969; Elcoro \& Lattal, unpublished manuscript; Jarmolowicz \& Lattal, 2009), FR (Figures 1, 2, 4, 5, 6, 8-13, \& 15), differential-reinforcement-of-low-rate (Gonzalez \& Newlin, 1976; Richards), and PR schedules (Jarmolowicz \& Lattal, in press). Additionally, Experiment 3 isolated the role of interval versus 
ratio contingencies by yoking the rate and temporal distribution of reinforcers available on the interval schedule to the reinforcers delivered on the FR schedule, yet the delay-of-reinforcement gradients (Figure 10) were consistent across schedules. Thus, it appears that delay-related decreases in response rates are more similar than different across a range of baseline schedules.

Delays of reinforcement also have similar effects on responding across a range of reinforcement rates. For example, Shahan and Lattal (2005) examined delay-of-reinforcement effects across VI 15-s, 90-s, and 540-s schedules (0.36 - 2.93 reinforcers per minute) and found no interaction between reinforcement rate and the relative change in overall response rates from those maintained by immediate reinforcement. The present experiments also examined a wide range of reinforcement rates (0.12-22.06 reinforcers per minute; see Tables 1- 4 for details), and, like Shahan and Lattal, found similar effects of delay durations across these different reinforcement rates.

\section{Variables influencing response rate}

The generality of delay-of-reinforcement effects across schedules and rates of reinforcement suggests that the process whereby delays decrease response rates is the same across schedules. Previous accounts have either emphasized the role of decreases in reinforcement rate (Baum, 1973, 2002) or disruptions in temporal contiguity (Schneider, 1991; Sizemore \& Lattal, 1978). The degree to which these factors seem to influence the present findings is considered below.

Reinforcement rate. Reinforcement rate is often seen as a primary determinant of the effects of a reinforcer. Even though reinforcement rates changed with increasing delays, the results of the current experiments cannot be accounted for by these changes alone. Not only were delay-of-reinforcement gradients consistent across a wide range of baseline reinforcement rates 
(Figures $12 \& 13$ ), but reinforcement rates also decreased in both the delay and control conditions during Experiment 2 (Figure 7), yet response rate only decreased systematically in the PFD conditions (Figure 6). This decrease in reinforcement rate, however, was greater in the delay relative to control conditions. It is therefore possible that decreased reinforcement rates influenced run rates. The negative relation between response rate and delay duration, therefore, may contribute to, but is neither singularly nor primarily responsible for the decreases in reinforcement rate (see also Pierce et al., 1972; Reilly \& Lattal, 2004).

Temporal contiguity. Previous investigators have suggested that delay-of-reinforcement effects result from the disruption of the temporal contiguity between the response and reinforcer (e.g., Gleeson \& Lattal, 1987; Sizemore \& Lattal, 1977, 1978). For example, Sizemore and Lattal (1978) found a negative relation between response rate and obtained delays. Data from the present experiments suggest that disrupted temporal contiguity may have influenced response rates. Figure 3 shows that the obtained delays were higher than zero and increased as the programmed delay increased in both the signaled and unsignaled-delay conditions. This disruption in temporal contiguity was considerably greater in the signaled relative to unsignaled delay conditions. The presence of the signals during the delay, however, makes this difference in contiguity between the signaled and unsignaled delay conditions uninterpretable.

\section{Signaled delays}

Response rates generally are higher when signaled, as compared to unsignaled, delays are imposed during responding maintained by VI schedules (e.g., Lattal \& Ziegler, 1982; Reilly \& Lattal, 2004; Richards, 1981). Unlike previous studies, however, differences in response rates during signaled and unsignaled delays in the present experiments were neither large nor consistent at any delay duration during three of the four present experiments. During 
Experiments 1-3, neither overall nor run rates differed when the delays were signaled or unsignaled (Figures 1, 5,9), even when the data were reported as either proportion-of-baseline rates (Figures 2, 6, \& 10) or as the fitted parameter $k$ from Mazur's (1987) hyperbolicdiscounting equation (see Figures 4, 8, \& 11; Table 6).

The inconsistency between the present and previous findings may be the result of a difference between stable responding and behavior in transition. Large differences in response rate between signaled and unsignaled delays occur when stable responding is obtained during each experimental condition (e.g., Lattal \& Ziegler, 1982; Reilly \& Lattal, 2004; Richards, 1981). Response-rate differences in signaled versus unsignaled delay conditions take several sessions to develop (e.g., Hall et al., 1987). Because this stable responding is typically achieved by keeping the delay duration constant from session to session, response-rate differences between signaled and unsignaled-delay conditions have time to develop. Although the PFR procedure used in Experiment 4 involved rapidly cycling through ratio requirements, each delay was presented for three sets of the PFR schedule. Thus, the delays remained the same for several consecutive sessions. As a result, there may have been sufficient time for response rate differences between the signaled and unsignaled delay conditions to develop. Consistent with previous studies (e.g., Lattal \& Ziegler; Reilly \& Lattal; Richards) response rates during Experiment 4 were higher in the signaled, relative to the unsignaled, delay condition, particularly at the 20-s delay (Figures 12, $13 \& 15$ ).

Unlike the steady-state designs used in previous experiments, the delay durations used in Experiments 1-3 changed from one session to the next. This may have kept responding in transition from one delay duration to the next. Thus, unlike Experiment 4 and previous studies using steady state designs (e.g., Lattal \& Ziegler, 1982; Reilly \& Lattal, 2004; Richards, 1981), it 
is possible that differences in response rate in the signaled versus unsignaled PFD conditions did not have time to develop.

\section{Methodological Contributions}

Neither the PFD procedure used in Experiments 1-3 nor the PFR procedure used in Experiment 4 have been used previously in the analysis of delayed reinforcement. Unlike steadystate designs which typically allow responding to stabilize at each delay duration and return to a no-delay baseline between delay conditions (e.g., Arbuckle \& Lattal, 1988; Lattal \& Ziegler, 1982; Richards, 1981; Sizemore \& Lattal, 1988; Williams, 1976), the PFD procedure briefly exposed responding to each delay duration without intervening returns to an immediate reinforcement baseline. Although these procedures differ from those typically used to study delays, both the PFD and PFR procedures yielded systematic data. Advantages and disadvantages of using these procedures are considered below.

\section{Advantages}

Rapid. The PFD procedure used in Experiments 1-3 generated qualitatively similar gradients to those generated using steady-state designs (e.g., Sizemore \& Lattal, 1978) in relatively few sessions. For example, complete delay-of-reinforcement gradients were generated in 4-8 days in Experiment 2. By contrast, Sizemore and Lattal conducted immediatereinforcement baseline conditions prior to and after each delay condition, and each condition remained in effect until stable responding was established (i.e., between 6 and 42 days).

The PFR procedure used in Experiment 4 rapidly cycles through ratio requirements similar to the way the PFD procedure used in Experiments 1-3 cycles through delays. This rapid cycling allows the relation between ratio requirement and rate to be efficiently explored. Rather than spending many sessions at each FR requirement (e.g., Felton \& Lyon, 1966) prior to 
moving to the next, the ratio requirement increased before each session in Experiment 4, thereby surveying a wide range of FR requirements in relatively few sessions. In previous experiments, parametric explorations of ratio requirements took over 100 sessions to conduct when behavior was stabilized at each ratio requirement (Madden \& Hartman, 2006). By contrast, a similar parametric investigation would take, only 5-6 sessions using PFR schedules

Replicable. The findings of both the PFD and the PFR procedures were directly and systematically replicable. The delay-of-reinforcement gradients were similar each time the PFD procedure was used (Figures 1, $5 \& 9$ ) and the standard deviations for the proportion of baseline run rates, PRP or overall rates were relatively low at each delay duration (Figures $2 \& 10$ ). Similarly, the standard deviations for the run rates (Figure 12), PRPs (Figure 14), and overall rate (Figure 13) were low at each ratio requirement and during each delay condition of Experiment 4.

The PFD and PFR procedures also were systematically replicable. Parametric effects of delays and ratio requirements were consistently observed during the present experiments. Furthermore, each of the present experiments systematically replicated the other present experiments as well as previously published findings. For example, not only were the delay-ofreinforcement gradients generated during Experiment 3 (Figure 10) consistent with those obtained in Experiments 1 (Figure 2) and 2 (Figure 6), but they also were consistent with those generated across a range of other schedules (see the Generality of delay-of-reinforcement effects section above). Furthermore, the parametric functions generated in Experiment 4 (Figure 13) were similar to those previously generated using the PFR procedure (e.g., Hursh, Raslear, Shurtleff, Bauman, \& Simmons, 1988; Johnson \& Bickel, 2006) and to those generated when response rates at each ratio requirement were stabilized prior to increasing the ratio requirement (Madden \& Hartman, 2006). 
Extensive. The PFD procedure used in the current experiments allowed examination of delay-of-reinforcement effects across a range of delays. Because delays increased until responding ceased, response rates were determined at the longest such duration that would maintain responding. Using this procedure, each subject is exposed to delays that disrupt responding. Assuring that each subject is exposed to delays that disrupt responding has been one of the primary advantages of using parametric procedures to study delay-of-reinforcement (e.g., Richards, 1981; Sizemore \& Lattal, 1988; Williams, 1976). The PFD procedure, however, facilitated the examination of responding across a wider range of delay durations (i.e., 1 to 320-s) than have been examined in parametric analyses using steady state designs (e.g., 0.5 to 10 -s [Richards; Sizemore \& Lattal]). Like the PFD procedure, the PFR procedure increased ratio requirements until responding stopped, thereby determining response rates at the highest ratio requirement that maintained responding. Like the PFD procedure, the PFR procedure facilitated the study of delay-of-reinforcement effects across a wide range of FR requirements in each subject.

\section{Disadvantages}

Unknown effects of rapid progressions. Although the PFD procedure produced systematic and replicable data, it is unknown whether the delay-of-reinforcement gradients generated are comparable to those that would have been obtained had steady-state designs been used with the same subjects. Methodological limitations of previous studies examining delayed reinforcement on FR schedules make it difficult to usefully compare the present findings to those studies (i.e., Meunier \& Ryman, 1974; Morgan, 1972; Topping et al., 1973). The consistency between the delay gradients generated in Experiments 1-3 (Figures 2, 6, \& 10) and those generated with VI schedules when delays are increased across sessions (Richards, 1981; 
Sizemore \& Lattal, 1978), however, suggest that the PFD procedure produces findings that are systematically replicable. The present gradients also are similar to those reported by Reilly and Lattal (2004) using a within-session progressive-delay procedure. Thus, it appears that rapid delay progressions can yield delay-of-reinforcement gradients that are similar to those generated when delays are increased across conditions. Direct comparison of delay-of-reinforcement gradients using the PFD and across-condition delay progressions, of course, would strengthen the statements about the delay gradients generated using these differing delay progressions.

No return to baseline. Delay-of-reinforcement studies typically conduct baseline conditions before and after each delay condition (e.g., Arbuckle \& Lattal, 1988; Lattal \& Zeigler, 1982; Sizemore \& Lattal, 1978). This approach, which was used in Experiment 4 but not in Experiments 1-3, keeps the baseline condition to which each delay is compared consistent. These consistent baseline conditions help assure that delays are imposed on baselines with similar response rates.

Experiments 1-3, however, were not the first to forgo returns to baseline while obtaining findings that are consistent with studies that did return to baseline between each delay condition (e.g., Pierce et al., 1972; Reilly and Lattal, 2004). Although returns to baseline allow less ambiguous interpretation of experimental findings, their absence does not appear to influence the data obtained. Reilly and Lattal noted that cycling through delay durations without subsequent returns to baseline was an advantage because if one returns to baseline between delays and "such baseline response rates are not equal, questions arise about comparing absolute response rates across successive delay durations" (Reilly and Lattal, p.34).A direct comparison of findings with and without returns to baseline would be necessary to make definitive statements about the degree to which returns to baseline between delay conditions impact responding. In the absence 
of such definitive data, the present results in comparison with the extant delay gradients based on comparisons with stable immediate reinforcement baselines suggest the results of the two methods are more similar than different.

No differential effect of signals. Unlike previous studies (e.g., Reilly \& Lattal, 2004;

Richards, 1981), there were no differences between signaled and unsignaled delays in Experiments 1-3 (Figures 1, 2, 4-6, \& 8-11). This is likely due to the procedural differences that were discussed in the Signaled delays section. As with the effects of rapid delay progressions and returns to baseline between delay conditions, a direct comparison between the PFD procedure and steady-state designs would strengthen the statements that could be made about the cause for this discrepancy.

Analysis

On balance, the advantages of using the PFD and PFR procedures seem to outweigh the disadvantages. The procedures are rapid, replicable, and extensive, properties which may facilitate both further parametric analysis of delay-of-reinforcement effects and the study of interactions between delays and other independent variables such as reinforcer type or pharmacological agents. By contrast, the disadvantages of these procedures primarily focus on the unknown match between findings using the present procedures and steady-state designs; these are issues that could be resolved by a series of experiments comparing these procedural details.

\section{Conclusion}

A negative relation between response rate and delay duration was obtained in all of the present experiments. This finding is consistent with relations demonstrated on other schedules and when stable responding is obtained at each delay suggesting that delay-related decreases in 
response rate have considerable generality. This decrease in response rate appears to be primarily due to a decrease in temporal contiguity. By contrast, Experiments 1-3 failed to demonstrate the higher response rates with signaled, relative to unsignaled, delays seen elsewhere. This discrepancy suggests that higher response rates may be expected when stable responding is obtained at each delay duration, but not when behavior is in transition. The current experiments therefore are a step towards establishing the boundary conditions under which delay-ofreinforcement effects will and will not be obtained (Sidman, 1960).

The present experiments also tested novel procedures that quickly generated extensive delay-of-reinforcement gradients. The rapidity of these procedures may facilitate the study of interactions between delays and other independent variables such as reinforcer type or pharmacological variables. Future studies, however, will further determine the utility and generality of these procedures. 


\section{References}

Azrin, N. H. (1959). Punishment and recovery during fixed-ratio performance. Journal of the Experimental Analysis of Behavior, 2, 301-305.

Arbuckle, J. L. \& Lattal, K. A. (1988). Changes in functional response units with briefly delayed reinforcement. Journal of the Experimental Analysis of Behavior, 49, 249-263.

Baum, W. M. (1973). The correlation-based law of effect. Journal of the Experimental Analysis of Behavior, 20, 137-153.

Baum, W. M. (2002). From molecular to molar: A paradigm shift in behavior analysis. Journal of the Experimental Analysis of Behavior, 78, 95-116.

Bauman, R. (1991). An experimental analysis of the cost of food in a closed economy. Journal of the Experimental Analysis of Behavior, 56, 33-50.

Dews, P. B. (1969). Studies on responding under fixed-interval schedules of reinforcement: The effects on the pattern of responding of changes in requirements at reinforcement. Journal of the Experimental Analysis of Behavior, 12, 191-199

Felton, M. \& Lyon, D. O. (1966). The post-reinforcement pause. Journal of the Experimental Analysis of Behavior, 9, 131-134.

Ferster, C. B. (1953) Sustained behavior under delayed reinforcement. Journal of Experimental Psychology, 45, 218-224

Ferster, C. B., \& Skinner, B. F. (1957). Schedules of reinforcement. Englewood Cliffs, NJ: Prentice-Hall.

Gleeson, S.,\& Lattal, K. A. (1987). Response-reinforcer relations and the maintenance of behavior. Journal of the Experimental Analysis of Behavior, 48, 383-393. 
Hall, G., Channell, S., \& Schachtman, T. R. (1987) The instrumental overshadowing effect in pigeons: The role of response bursts. The Quarterly Journal of Experimental Psychology, Section B., 39, 173-188.

Herrnstein, R. J. (1970) On the law of effect. Journal of the Experimental Analysis of Behavior, $13,243-266$.

Hursh, S. R. Raslear, T. G. Shurtleff, D. Bauman, R. \& Simmons, L. (1988). A cost-benefit analysis of demand for food. Journal of the Experimental Analysis of Behavior, 50, 419440.

Jarmolowicz, D.P. \& Lattal, K. A. (October, 2009) Effects of Unsignaled Delays to Reinforcement on Response Rate and Temporal Control Poster presented at the $26^{\text {th }}$ Annual Meeting of the Southeastern Association for Behavior Analysis, Wilmington, NC

Jarmolowicz, D. P. \& Lattal, K. A. (2010). On distinguishing progressively increasing response requirements for reinforcement. The Behavior Analyst, 33, 119-125.

Jarmolowicz, D. P., \& Lattal, K. A. (in press). Reinforcer efficacy, response persistence, and delay of reinforcement. Psychological Research Reports

Johnson, M. W. \& Bickel, W. K. (2006) Replacing relative reinforcing efficacy with behavioral economic demand curves. Journal of the Experimental Analysis of Behavior, 85, 73- 93.

Lattal, K. A. (1984) Signal functions in delayed reinforcement. Journal of the Experimental Analysis of Behavior, 42, 239-253.

Lattal, K. A. (2010) Delayed reinforcement of operant behavior. Journal of the Experimental Analysis of Behavior, 93, 129-139.

Lattal, K. A. Reilly, M. P. \& Kohn, J. P. (1998). Response persistence under ratio and interval reinforcement schedules. Journal of the Experimental Analysis of Behavior, 70, 165-183. 
Lattal, K. A. \& Ziegler, D. R. (1982). Briefly delayed reinforcement: An interresponse time analysis. Journal of the Experimental Analysis of Behavior, 37, 407-416.

Madden, G. J. \& Hartman, E. C. (2006) A steady-state test of the demand curve analysis of relative reinforcer efficacy. Experimental Clinical Psychopharmacology, 14, 79-86.

MED Associates, Inc., \& Tatham, T. A. (1991). MED-PC Medstate notation. East Fairfield, NH: MED Associates, Inc.

Mazur, J. E. (1987). An adjusting procedure for studying delayed reinforcement. In M. L. Commons, J. E. Mazur, J. A. Nevin, \& H. Rachlin (Eds.) Quantitative analysis of behavior: Vol 5. Effects of delay and of intervening events on reinforcement value. Hillsdale, NJ: Erlbaum.

Meunier, G. F. \& Ryman, F. (1974) Delay of reinforcement in fixed-ratio behavior. Psychological Reports, 34, 350.

Morgan, M. J. (1972) Fixed-ratio performance under conditions of delayed reinforcement. Journal of the Experimental Analysis of Behavior, 17, 95-98.

Pearce, J. M., \& Hall, G. (1978). Overshadowing the instrumental conditioning of a lever-press response by a more valid predictor of the reinforcer. Journal of Experimental Psychology: Animal Behavior Processes, 4, 356-367.

Perone, M., \& Courtney, K. (1992). Fixed-ratio pausing: Joint effects of past reinforcer magnitude and stimuli correlated with upcoming magnitude. Journal of the Experimental Analysis of Behavior, 57, 33-46.

Pierce, C. H. Hanford, P. V. \& Zimmerman, J. (1972). Effects of different delay of reinforcement procedures on variable-interval responding. Journal of the Experimental Analysis of Behavior, 18, 141-146. 
Powell, R. W. (1968). The effect of small sequential changes in fixed-ratio size upon the postreinforcement pause. Journal of the Experimental Analysis of Behavior, 11, 589-593.

Powell, R. W. (1969). The effect of reinforcement magnitude upon responding under fixed-ratio schedules. Journal of the Experimental Analysis of Behavior, 12, 605-608

Reilly, M. P. \& Lattal, K. A. (2004). Within-session delay-of-reinforcement gradients. Journal of Experimental Analysis of Behavior, 82, 21-35.

Reed, P., \& Hall, G. (1988). The schedule dependency of the signaled reinforcement effect. Learning and Motivation, 19, 387-407.

Reed, P., Schachtman, T. R., \& Hall, G. (1988). Overshadowing and potentiation of instrumental responding in rats as a function of the schedule of reinforcement. Learning and Motivation, 19, 13-30.

Richards, R. W. (1981). A comparison of signaled and unsignaled delay of reinforcement. Journal of the Experimental Analysis of Behavior, 35, 145-152.

Schneider, S. M. (1990) The role of contiguity in free-operant unsignaled delay to reinforcement: A brief review. The Psychological Record, 40, 239-257.

Shahan, T. A. \& Lattal, K. A. (2005) Unsignaled delay of reinforcement, relative time, and resistance to change. Journal of the Experimental Analysis of Behavior, 83, 201- 219.

Sidman, M. (1960) Tactics of scientific research: Evaluating experimental data in psychology. Oxford, England: Basic Books.

Sizemore, O. J.,\& Lattal, K. A. (1977). Dependency, temporal contiguity, and responseindependent reinforcement. Journal of the Experimental Analysis of Behavior, 27, 119125. 
Sizemore, O. J. \& Lattal, K. A. (1978). Unsignalled delay of reinforcement in variable-interval schedules. Journal of the Experimental Analysis of Behavior, 30, 169-175.

Skinner, B. F. (1938). The behavior of organisms: An experimental analysis. New York: Appleton Century Crofts.

Thorndike, E. L. (1911) Animal intelligence. New York: MacMillan.

Topping, J. S., Johnson, D. L., \& Mc Glynn, F. D. (1973). Effects of delayed reinforcement and FR size on pre-ratio pausing. Psychological Reports, 32, 1295-1298.

Williams, B. A. (1976). The effects of unsignalled delayed reinforcement. Journal of the Experimental Analysis of Behavior, 26, 441-449.

Zeiler, M. D. (1999). Reversed schedule effects in closed and open economies. Journal of the Experimental Analysis of Behavior, 
Appendix A: Run rate data from Experiment 4 excluding incomplete sessions

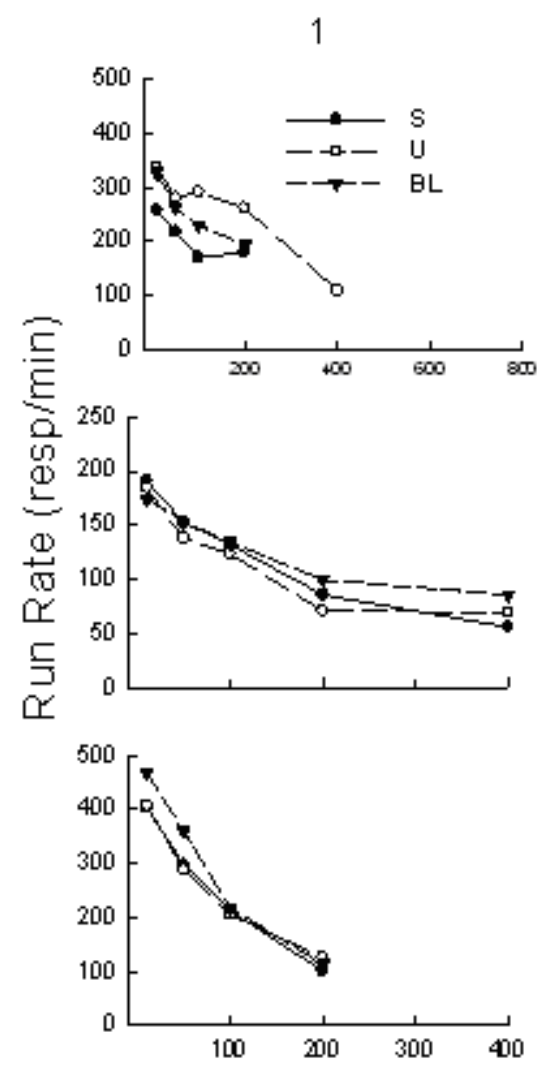

10
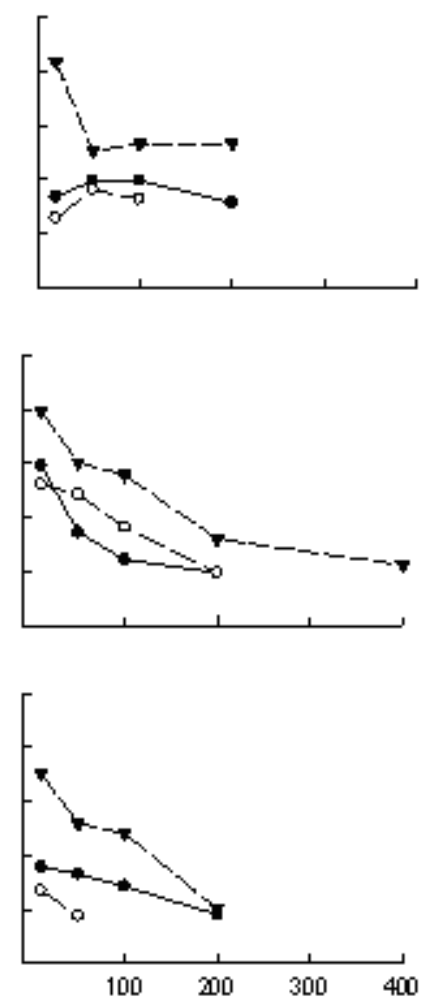

Ratio
20

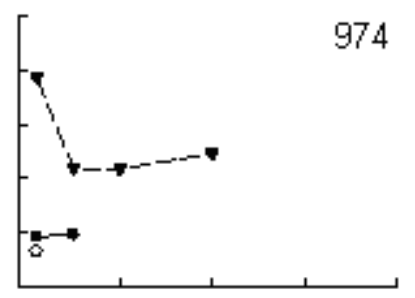

964
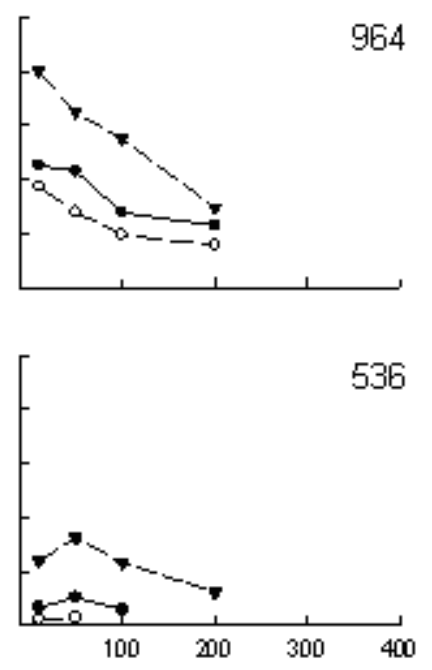

Run rate of responding (y-axis) at each ratio requirement (x-axis) for 974 (top row), 964 (center row), and 536 (bottom row) at the $1 \mathrm{~s}$ (left column), $10 \mathrm{~s}$ (center column), and $20 \mathrm{~s}$ delays (right column) during Experiment 4. Separate data paths are provided for unsignaled delay (open circles), signaled delay (closed circles), and baseline conditions (closed triangles). 
Appendix B: Overall rate data from Experiment 4 excluding incomplete sessions

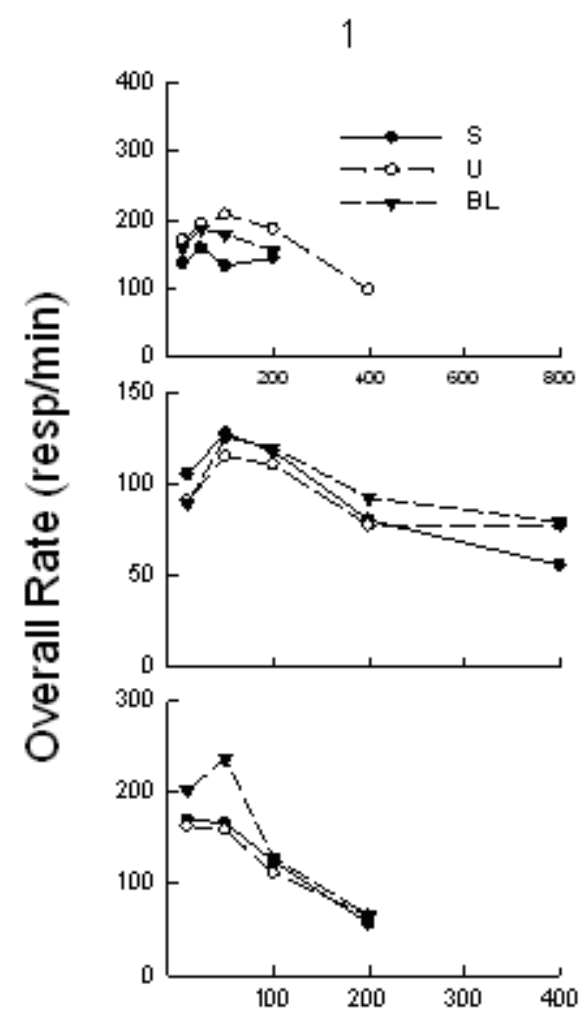

10
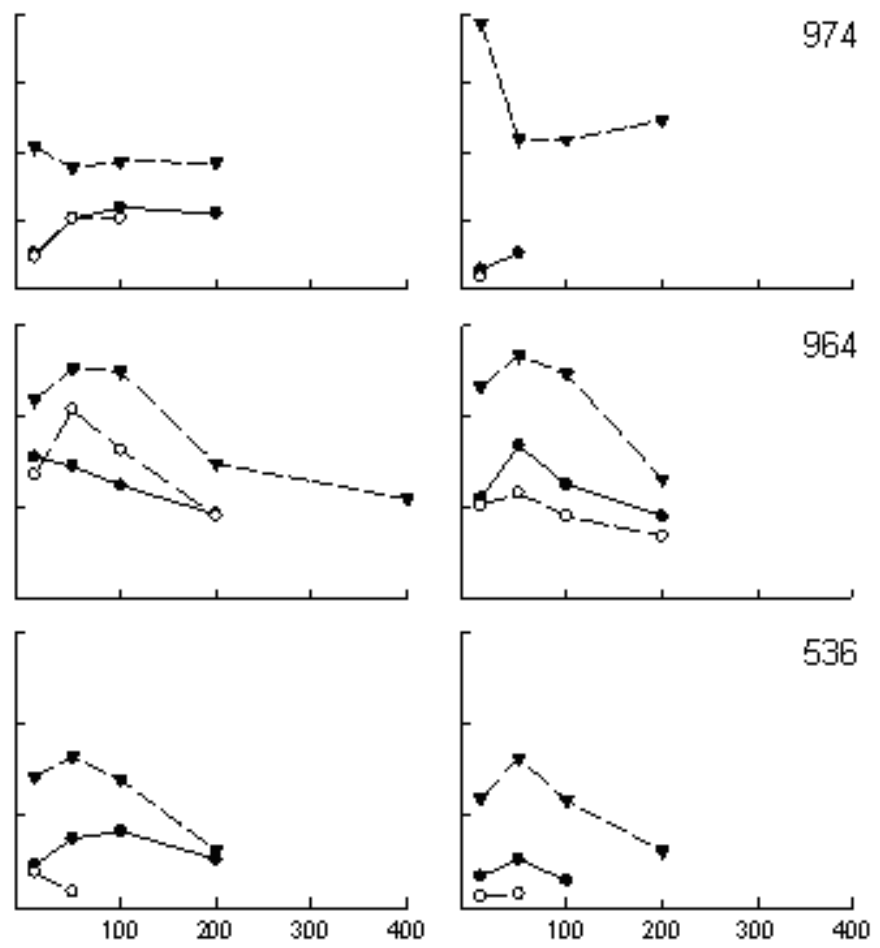

Ratio

Overall rate of responding (y-axis) at each ratio requirement (x-axis) for 974 (top row), 964 (center row), and 536 (bottom row) at the $1 \mathrm{~s}$ (left column), $10 \mathrm{~s}$ (center column), and $20 \mathrm{~s}$ delays (right column) during Experiment 4. Separate data paths are provided for unsignaled delay (open circles), signaled delay (closed circles), and baseline conditions (closed triangles). 
Appendix C: Post-reinforcement pause data from Experiment 4 excluding incomplete sessions
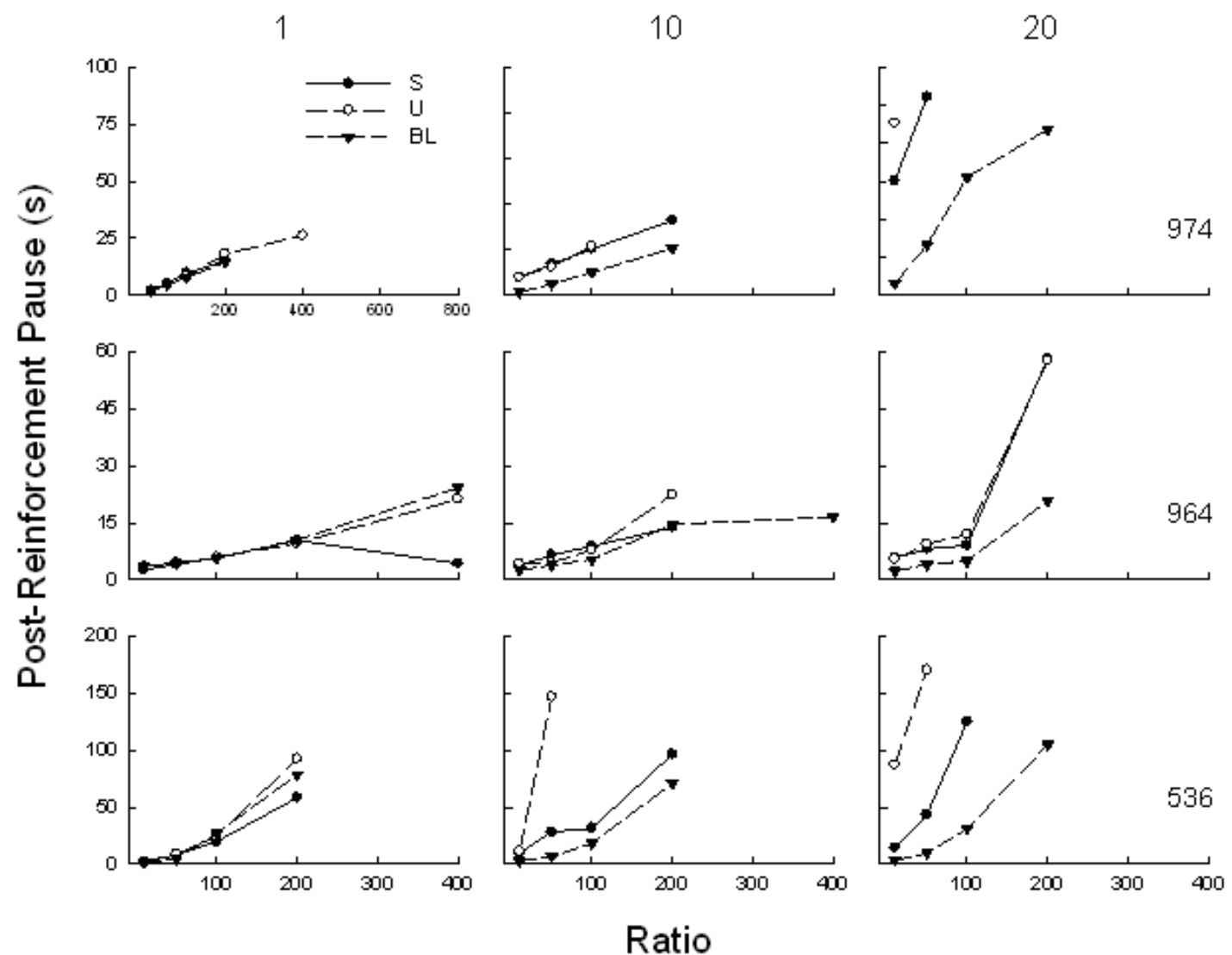

Post-reinforcement pauses (y-axis) at each ratio requirement (x-axis) for 974 (top row), 964 (center row), and 536 (bottom row) at the $1 \mathrm{~s}$ (left column), 10 s (center column), and 20 s delays (right column) during Experiment 4. Separate data paths are provided for unsignaled delay (open circles), signaled delay (closed circles), and baseline conditions (closed triangles). 
Appendix D: Meanings of abbreviations used in the text

\begin{tabular}{ll}
\hline Abbreviation & Meaning \\
\hline FI & Fixed interval \\
FR & Fixed ratio \\
IRI & Fixed time \\
ITI & Inter-reinforcer interval \\
PFD & Inter-trial interval \\
PFR & Progressive-fixed delay \\
PR & Progressive-fixed ratio \\
PRP & Progressive ratio \\
VI & Post-reinforcement pause \\
VR & Variable interval \\
YI & Variable ratio \\
\hline
\end{tabular}

